\title{
BASIC HYDRAULIC PRINCIPLES OF OPEN-CHANNEL FLOW
}

By Harvey E. Jobson and David C. Froehlich

U.S. GEOLOGICAL SURVEY Open-File Report $\mathbf{8 8 - 7 0 7}$

\author{
Reston, Virginia
}

1988 


\title{
DEPARTMENT OF THE INTERIOR DONALD PAUL HODEL, Secretary
}

\author{
U.S. GEOLOGICAL SURVEY \\ Dallas L. Peck, Director
}

For additional information write to:

Chief, Office of Surface Water U.S. Geological Survey 415 National Center 12201 Sunrise Valley Drive Reston, Virginia 22092
Copies of this report can be purchased from:

U.S. Geological Survey, Books and Open-File Reports Box 25425, Federal Center Denver, Colorado 80225 


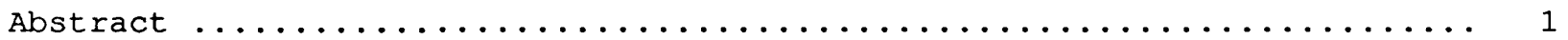

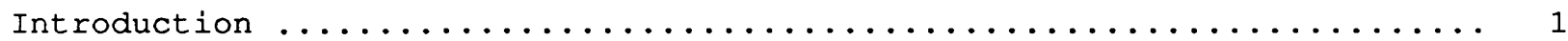

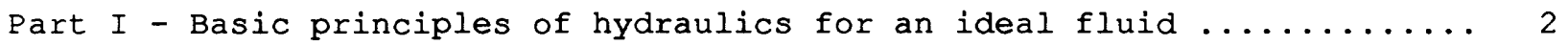

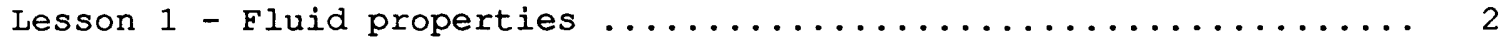

Lesson 2 - Forces on submerged objects ..................

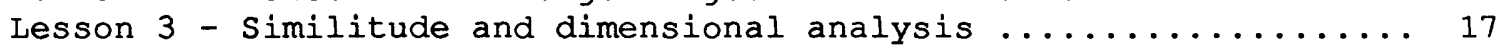

Lesson 4 - The energy equation for an ideal fluid ............ 27

Part II - Steady uniform flow of real fluids in open channels ....... 34

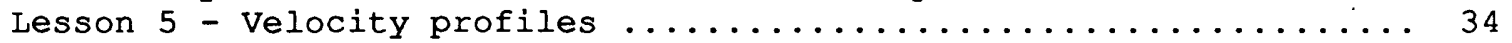

Lesson 6 - The energy equation applied to real fluids ......... 43

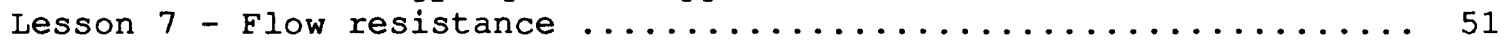

Lesson 8 - Computations for steady, uniform flow ........... 58

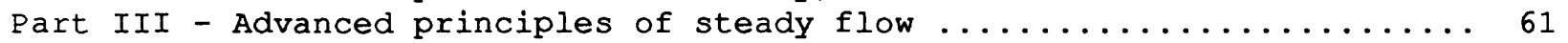

Lesson 9 - Flow in channel sections with variable roughness ..... 61

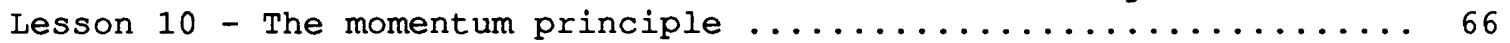

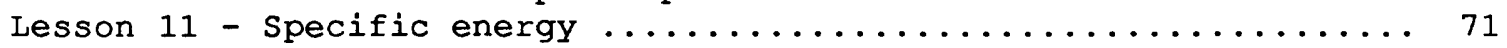

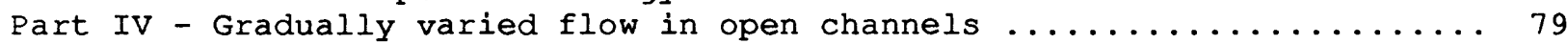

Lesson 12 - Determination of flow resistance in open channels ... 79

Lesson 13 - Classification of water-surface profiles ..........997

Lesson $14^{*}$ - Local energy losses in natural channels .......... . . . . . . . . . . .

Lesson 15 - Water-surface profile computations ............. 107

Part V - Discharge computations for rapidly varied flow .............116

Lesson 16 - Rapidly varied flow at constrictions ...........116

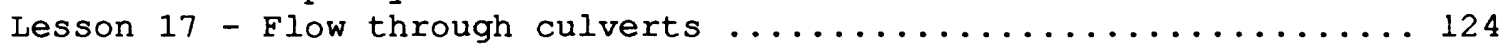

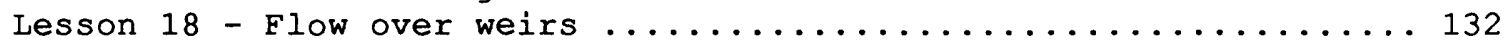

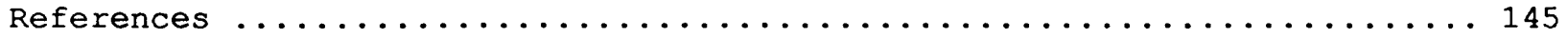

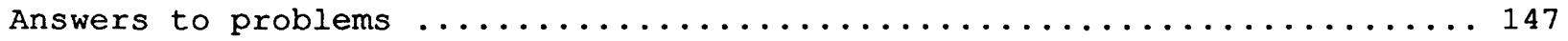

\section{ILLUSTRATIONS}

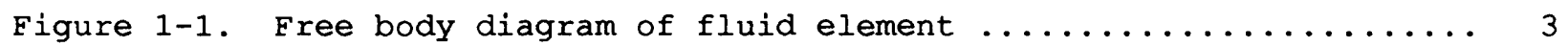

2-1. Definition sketch of the pressure prism for vertical

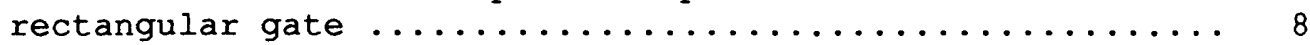

2-2. Definition sketch of the pressure prism for a submerged gate 4 feet wide .......................... 9

2-3. Definition sketch of the pressure prism to compute the total force of the water on a 4 -foot wide gate .........

3-1. Diagram illustrating flow through constriction, model, and

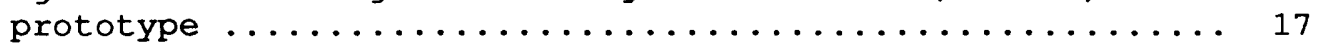

4-1. Definition sketch of steady flow through a streamtube ..... 28

4-2. Definition sketch for the flow of an ideal fluid in an open

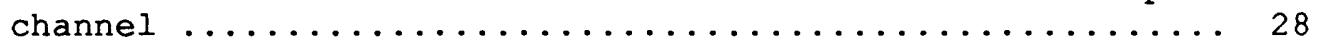

4-3. Definition sketch for the example problem of flow down a

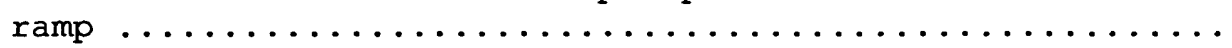

5-1. Definition sketch for sheet flow over a wide inclined plane

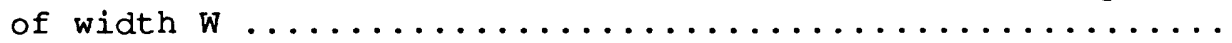

5-2. Diagram illustrating velocity distribution in a fully

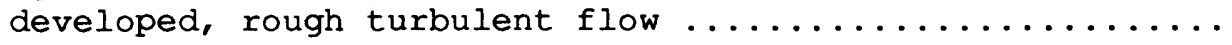


Figure 6-1. Definition sketch of the energy diagram for open-channel

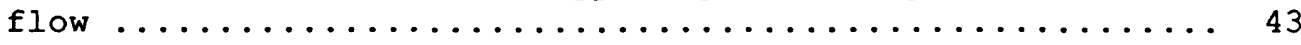

6-2. Diagram illustrating typical flow through a bridge

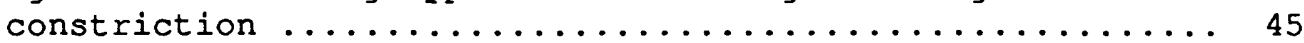

7-1. Diagram illustrating flow in a prismatic open channel ..... 51

9-1. Definition sketch for cross section with overbank flow ..... 61

10-1. Diagram illustrating the control volume for applying the conservation of momentum equation for the flow past a

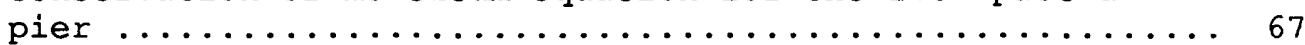

11-1. Definition sketch for the specific energy curve ..........

11-2. Diagram illustrating flow changes from subcritical to supercritical .........................

11-3. Diagram illustrating critical flow at the outlet of a box

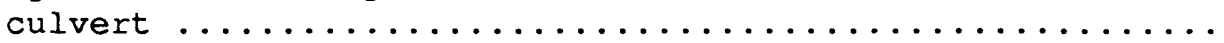

12-1. Diagram illustrating eight types of roughness found in

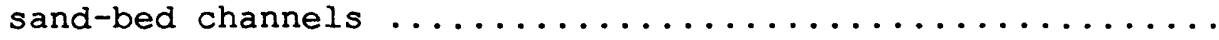

12-2. Diagram illustrating the effect of size of bed material and Froude number on the bed form and Manning's $n$ for a range of flow conditions with sands of 0.28 - and 0.45 -millimeter median diameter in an 8-foot wide

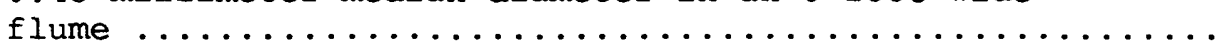

12-3. Graph showing the relation of stream power and median

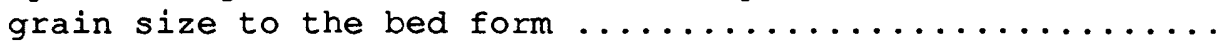

13-1. Sketch illustrating gradually varied flow in an open channel--longitudinal scale greatly reduced .......... 97

13-2. Definition sketch of surface profiles of varied flow ........

14-1. Sketch illustrating the energy grade lines at a local

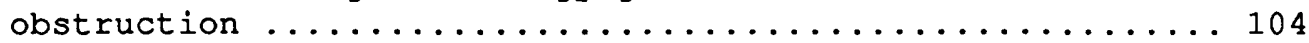

15-1. Definition sketch for water-surface profile computation ... 108

15-2. Graph showing the variation of friction slope with

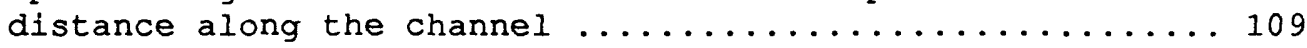

16-1. Sketch illustrating the theoretical water-surface and energy profiles through a contracted opening ......... 116

16-2. Sketch illustrating the streamlines for flow through a

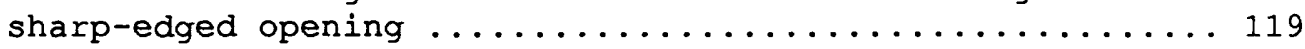

16-3. Graph showing the coefficients for type 1 opening, vertical embankments, and vertical abutments .......... 121

17-1. Definition sketch of culvert flow ................. 124

17-2. Diagram illustrating the classification of culvert flow ... 125

17-3. Graph showing the base coefficient of discharge for types 1,2 , and 3 flow in box culverts with square entrance mounted flush in vertical headwall .......... 127

18-1. Definition sketch for a contracted, sharp-crested weir .... 132

18-2. Definition sketch for a broad-crested weir ............. 132

18-3. Graph showing the coefficients of discharge for full width, broad-crested weirs with downstream slope $=1: 1$,

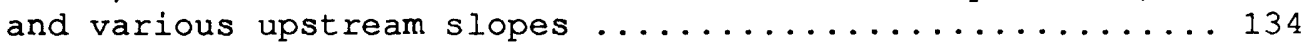

18-4. Definition sketch of a V-notch (triangular) sharp-crested

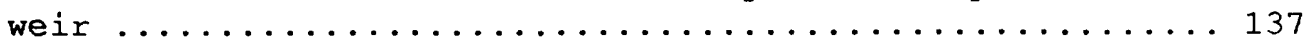

18-5. Definition sketch of a Cippoletti (trapezoidal)

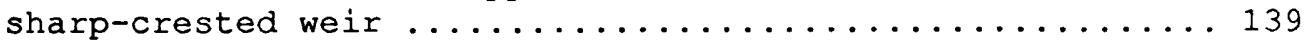

18-6. Diagram illustrating various other sharp-crested weir

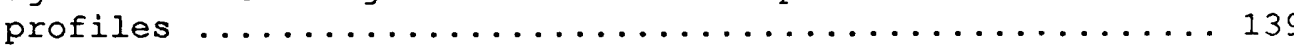


Table 1-1. Mechanical properties of some fluids ................4 6-1. Kinetic energy correction coefficients for natural

channels ................................ 44

12-1. Values of the Manning resistance coefficient ...........86

12-2. Equations for resistance based on bed-material size ....... 91

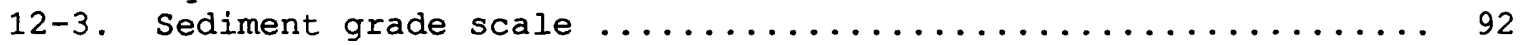

15-1. Criteria used to select friction slope equation ..........110

15-2. Computation sheet for backwater analysis ..............112

17-1. Discharge coefficients for box or pipe culverts set

flush in a vertical headwall; types 4 and 6 flow ....... 129 


\section{UNIT CONVERSION}

Data listed in this report are defined in the inch-pound system of units. A list of these units and the factors for their conversion to International System of units (SI) are provided below.

Abbreviations of units are defined in the conversion table below or where they first appear in the text. Symbols are defined where they first appear in the text.

\begin{tabular}{|c|c|c|}
\hline Multiply inch-pound unit & By & To obtain SI unit \\
\hline $\begin{array}{l}\text { foot (ft) } \\
\text { inch (in) } \\
\text { pound (lb) } \\
\text { slug }\end{array}$ & $\begin{array}{l}0.3048 \\
0.02540 \\
4.448 \\
14.59\end{array}$ & $\begin{array}{l}\text { meter }(\mathrm{m}) \\
\text { meter }(\mathrm{m}) \\
\text { newton }(\mathrm{N}) \\
\text { kilogram }(\mathrm{kg})\end{array}$ \\
\hline slug per cubic foot (slug/ft ${ }^{3}$ ) & 515.4 & $\begin{array}{l}\text { kilogram per cubic meter } \\
\left(\mathrm{kg} / \mathrm{m}^{3}\right)\end{array}$ \\
\hline $\begin{array}{l}\text { slug per foot second } \\
\text { (slug/s ft) }\end{array}$ & 47.88 & $\begin{array}{l}\text { newton per meter second } \\
\left(\mathrm{N} / \mathrm{m}^{2}\right)\end{array}$ \\
\hline $\begin{array}{l}\text { pound per cubic foot }\left(1 \mathrm{lb} / \mathrm{ft} \mathrm{t}^{3}\right) \\
\text { pound per square foot }\left(1 \mathrm{lb} / \mathrm{ft} \mathrm{t}^{2}\right)\end{array}$ & $\begin{array}{rl}157 & .1 \\
47.88\end{array}$ & $\begin{array}{l}\text { newton per cubic meter }\left(\mathrm{N} / \mathrm{m}^{3}\right) \\
\text { pascal }(\mathrm{Pa})\end{array}$ \\
\hline $\begin{array}{l}\text { square foot per second }\left(f t^{2} / \mathrm{s}\right) \\
\text { pound per square inch }\left(\mathrm{lb} / \mathrm{in}^{2}\right)\end{array}$ & $\begin{array}{l}0.09290 \\
6.895\end{array}$ & $\begin{array}{l}\text { square meter per second }\left(\mathrm{m}^{2} / \mathrm{s}\right) \\
\text { pascal ( } \mathrm{Pa})\end{array}$ \\
\hline $\begin{array}{l}\text { pound per cubic inch }\left(1 \mathrm{~b} / \mathrm{in}^{3}\right) \\
\text { pound per inch }(1 \mathrm{~b} / \mathrm{in})\end{array}$ & $\begin{aligned} & 271, 400 \\
& 175.1\end{aligned}$ & $\begin{array}{l}\text { newton per cubic meter }\left(\mathrm{N} / \mathrm{m}^{3}\right) \\
\text { newton per meter }(\mathrm{N} / \mathrm{m})\end{array}$ \\
\hline $\begin{array}{l}\text { pound second per square foot } \\
\left.\text { (1b s/ft }{ }^{2}\right)\end{array}$ & 47.88 & pascal second ( $\mathrm{Pa} \mathrm{s}$ ) \\
\hline $\begin{array}{l}\text { foot per square second }\left(\mathrm{ft} / \mathrm{s}^{2}\right) \\
\text { cubic foot per second }\left(\mathrm{ft}^{3} / \mathrm{s}\right) \\
\text { degree Fahrenheit }\left({ }^{\circ} \mathrm{F}\right)\end{array}$ & $\begin{array}{c}0.3048 \\
0.02832 \\
\left({ }^{\circ} \mathrm{F}-32\right) / 1.8\end{array}$ & $\begin{array}{l}\text { meter per square second }\left(\mathrm{m} / \mathrm{s}^{2}\right) \\
\text { cubic meter per second }\left(\mathrm{m}^{3} / \mathrm{s}\right) \\
\text { degree Celsius }\left({ }^{\circ} \mathrm{C}\right)\end{array}$ \\
\hline
\end{tabular}

SYMBOLS AND UNITS

Symbol

Explanation

Unit

A

$A_{i}$

$a_{i}$

B

b

C

D

$\mathrm{Db}$

$\mathrm{D}_{\mathrm{C}}$

Do

$\mathrm{DP}_{\mathrm{p}}$

d

$d_{p}$

E

F
Total area of a section

Total cross-section area at the cross-section number i

Area of a subsection $i$

Width of opening

Width of channel upstream of opening

Chezy resistance coefficient

Depth

Brink depth

Critical depth

Normal depth

Diameter or height of a culvert

Depth in overflow section

Particle size that is larger than $p$ percent of the bed material

Specific energy

Force

$$
\begin{gathered}
f t^{2} \\
f t^{2} \\
f t^{2} \\
f t \\
f t \\
f t / 2 / s \\
f t \\
f t \\
f t \\
f t \\
f t \\
f t \\
f t \\
f t \\
l b
\end{gathered}
$$


$\mathrm{F}_{\mathrm{H}}$

$\mathrm{F}_{\mathrm{R}}$

$\mathrm{F}_{\mathrm{d}}$

$\mathrm{F}_{\mathrm{p}}$

$E_{r}$

$\mathrm{F}_{\mathrm{V}}$

$\mathrm{F} \tau$

$\mathrm{f}$

$g$

$\mathrm{H}$

h

$h_{e}$

$h_{f}$

hl

$h_{t}$

$h_{v}$

I

$\mathrm{K}$

$\mathrm{K}_{\mathrm{i}}$

$\mathrm{k}$

$\mathrm{k}_{\mathrm{e}}$

$k_{i}$

$k_{\mathrm{v}}$

L

l

$l_{m}$

$l_{s}$

$\mathrm{M}$

m

$\mathrm{n}$

P

p

$P_{C}$

$Q$

q

R

$\mathrm{R}_{\mathrm{e}}$

$r$

$\mathrm{S}$

$\mathrm{S}_{\mathrm{e}}$

$\mathrm{S}_{\boldsymbol{f}}$

$\mathrm{S}_{\mathrm{g}}$

$\mathrm{S}_{\mathrm{O}}$

$T$

$t$

$u_{\text {* }}$

$\mathrm{V}$

$\mathrm{v}_{\mathrm{C}}$

$\mathrm{v}$

W

Horizontal force

Resultant force

lb

Drag force $1 \mathrm{lb}$

Water-pressure force lb

Froude number

Vertical force

$\sim$

Shear force

Darcy-Weisbach friction factor

Acceleration of gravity

Total head

Hydraulic (piezometric) head

Head loss due to local causes

Head loss due to boundary friction

$1 b$

lb

$\sim$

$f t / s^{2}$

$f t$

$f t$

ft

$f t$

Head loss due to any cause

$f t$

Tail-water elevation

ft

Velocity head

$f t$

Acceleration

$f t / s^{2}$

Conveyance

Total conveyance at cross-section number $i$

Efféctive roughness height of boundary

Expansion or contraction loss coefficient

$\mathrm{ft}^{3 / \mathrm{s}}$

$\mathrm{ft}^{3 / \mathrm{s}}$

ft

Conveyance at subsection $i$

Local loss coefficient

Distance along channel or length of structure

Length scale for Reynolds number or Prandtl's mixing length

The meander length of a channel reach

$\sim$

$\mathrm{ft} 3 / \mathrm{s}$

$\sim$

ft

ft

The straight length of a channel reach

ft

ft

Mass

slug

Channel contraction ratio

Manning's roughness factor

Wetted perimeter of channel or height of weir

$\sim$

$\sim$

Pressure

$1 b / f t^{2}$

Pressure at the center of pressure

$1 b / f t^{2}$

Discharge

Discharge per unit width

Hydraulic radius

$\mathrm{ft}^{3} / \mathrm{s}$

$\mathrm{ft}^{3} / \mathrm{s}$

Reynolds number

Radius of curvature

Slope

Slope of energy grade line

Friction slope

Specific gravity of fluid

slope of bed

Top width of the channel

Time

Shear velocity

$\mathrm{ft}$

$\sim$

ft

$\sim$

Average or mean velocity

Critical velocity

Local velocity

width

$\sim$
$\sim$
$\sim$
$\sim$
$\mathrm{ft}$
$\mathrm{s}$
$\mathrm{ft} / \mathrm{s}$
$\mathrm{ft} / \mathrm{s}$
$\mathrm{ft} / \mathrm{s}$
$\mathrm{ft} / \mathrm{s}$
$\mathrm{ft}$




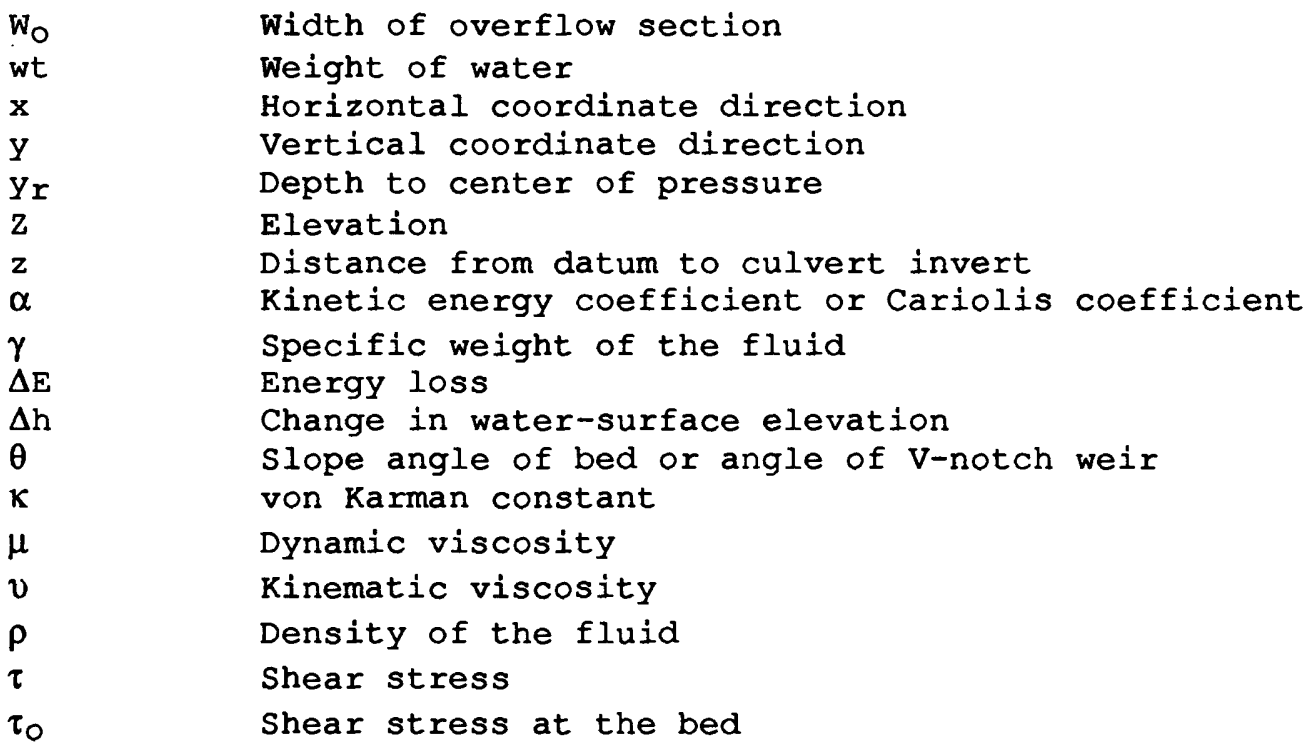

$\mathrm{ft}$
$\mathrm{lb}$
$\mathrm{ft}$
$\mathrm{ft}$
$\mathrm{ft}$
$\mathrm{ft}$
$\mathrm{ft}$
$\sim$
$\mathrm{lb} / \mathrm{ft}^{3}$
$\mathrm{ft}$
$\mathrm{ft}$
$\sim$
$\sim$
$\mathrm{lb} \mathrm{s} / \mathrm{ft}{ }^{2}, \mathrm{slug} / \mathrm{s} \quad \mathrm{ft}$
$\mathrm{ft} \mathrm{t}^{2} / \mathrm{s}$
$\mathrm{slugs} / \mathrm{ft}^{3}$
$1 \mathrm{~b} / \mathrm{ft}^{2}$
$\mathrm{lb} / \mathrm{ft}^{2}$




\section{BASIC HYDRAULIC PRINCIPLES OF OPEN-CHANNEL FLOW}

by Harvey E. Jobson and David C. Froehlich

\section{ABSTRACT}

The three basic principles of open-channel-flow analysis--the conservation of mass, energy, and momentum--are derived, explained, and applied to solve problems of open-channel flow. These principles are introduced at a level that can be comprehended by a person with an understanding of the principles of physics and mechanics equivalent to that presented in the first college level course of the subject. The reader is assumed to have a working knowledge of algebra and plane geometry as well as some knowledge of calculus.

Once the principles have been derived, a number of example applications are presented that illustrate the computation of flow through culverts and bridges, and over structures, such as dams and weirs.

Because resistance to flow is a major obstacle to the successful application of the energy principle to open-channel flow, procedures are outlined for the rational selection of flow-resistance coefficients. The principle of specific energy is shown to be useful in the prediction of water-surface profiles both in the qualitative and quantitative sense.

\section{INTRODUCTION}

Most of the principles and concepts presented in a beginning level college course in fluid mechanics are presented herein, but their application is focused on open-channel hydraulics. Some concepts that are unique to open channels--for example, specific energy and channel roughness--are developed in somewhat more detail here than would be expected in an introductory college course.

It is assumed that the reader is familiar with the physical principles of mechanics, at least to the level covered by a beginning college physics book. The reader also is assumed to have a working knowledge of algebra and trigonometry and to comprehend simple derivatives and integrations.

The emphasis of this text is on teaching the application of the theory of hydraulics to solving practical problems and not on the standard techniques used in problem solutions. The final equations developed in this text are frequently used as the starting point in other chapters of Book 3 of the Techniques of Water-Resources Investigations of the U.S. Geological Survey. 
All quantities used in this report can be defined in terms of three basic units (length (foot), time (second), and mass (slug)). Another quantity that is commonly used is force (pound), but the units of this quantity are defined in terms of mass and acceleration.

The weight on earth (force) of a mass of one slug is defined to be 32.2 pounds (1b). Therefore, the units of pounds force are equivalent to the units of slug feet per second squared (slug $\mathrm{ft} / \mathrm{s}^{2}$ ) or

$$
\text { Force }=F=32.2 \mathrm{lb}=\mathrm{Mg}=(1 \mathrm{slug}) 32.2 \mathrm{ft} / \mathrm{s}^{2} \text {, }
$$

where the mass of the body is $M$, and $g$ is the acceleration of gravity (32.2 $\left.\mathrm{ft} / \mathrm{s}^{2}\right)$.

Because fluid does not have a definite form and specific particles of fluid are difficult to identify, it is customary to work with the weight or mass of fluid per unit volume. The mass of a fluid per unit volume is defined as its density $(\rho)$ :

$$
\text { Density }=\rho=\frac{\text { Mass of fluid (slugs) }}{\text { Volume of fluid }\left(\mathrm{ft}^{3}\right)}
$$

The specific (unit) weight of a fluid $\gamma$ is defined as:

$$
\text { Specific weight }=\gamma=\frac{\text { Weight of fluid (lb) }}{\text { Volume of fluid }\left(\mathrm{ft}^{3}\right)} \text {. }
$$

The specific gravity of a fluid is defined as the ratio of the density of the fluid to the density of water at standard conditions (1.94 slugs/ft ${ }^{3}$ )-that is,

$$
\text { Specific Gravity }=s_{g}=\frac{\text { density of fluid }\left(\mathrm{slugs} / \mathrm{ft}^{3}\right)}{\text { density of water (slugs/ft } \left.{ }^{3}\right)}
$$

Because it is a ratio, specific gravity is unitless. By multiplying both the numerator and the denominator of the expression for the specific gravity by $g$, it is seen that the specific gravity also is equal to the ratio of specific weights,

$$
s_{g}=\frac{\rho_{f}}{\rho_{w}}=\frac{\rho_{f}\left(\frac{s l u g}{f t^{3}}\right) g\left(f t / s^{2}\right)}{\rho_{w}\left(\frac{s l u g}{f t^{3}}\right) g\left(f t / s^{2}\right)}=\frac{\gamma_{f}\left(\frac{1}{f t^{3}} \frac{s l u g f t}{s^{2}}\right)}{\gamma_{w}\left(\frac{1}{f t^{3}} \frac{s l u g f t}{s^{2}}\right)}=\frac{\gamma_{f}\left(l b / f t^{3}\right)}{\gamma_{w}\left(l b / f t^{3}\right)},
$$

in which the subscripts $f$ and $w$ refer to the fluid and water, respectively. $A$ fluid is a substance that can flow. Specifically, this means that it continually deforms as long as a shearing stress is applied and that the internal shear stress is a function of the rate of deformation rather than the amount of deformation as in a solid. A Newtonian fluid is a substance in which the internal shear stress is determined as 


$$
\tau=\mu \frac{\partial \mathrm{v}}{\partial y}
$$

in which $\tau$ is the shear stress ( $\left.1 \mathrm{~b} / \mathrm{ft}^{2}\right), \partial \mathrm{v}$ is the change in velocity (ft/s) that occurs over a small distance $\partial y(f t)$, and the dynamic viscosity $\mu \frac{s l b}{f t^{2}}$ or $\frac{\text { slug }}{\mathrm{s} f t}$ is a specific fluid property, which is a measure of its resistance to deformation (shear or flow). Table 1-1 contains some tabulated viscosities of fluids and gases. The kinematic viscosity $v$ is defined as

$$
v=\frac{\mu \mathrm{slug} / \mathrm{s} f t}{\rho \mathrm{slug} / \mathrm{ft} t^{3}}=\frac{\mathrm{ft} \mathrm{t}^{2}}{\mathrm{~s}}
$$

Figure 1-1 shows a free body diagram of an isolated block of fluid of height $y$, width $d x$, and thickness of 1 foot. Figure 1-1 is called a free-body diagram. A free-body diagram is a cutaway view of the fluid or object in which the effect of any surface that is cut is replaced by the forces exerted on that surface. For example, the bottom surface could exert a shear force $(\tau d x(1))$ on the fluid and a pressure force $(p d x(1))$. These are the only forces the water beneath could exert on the block of fluid. The fluid is at rest, therefore, all shear stresses $(\tau)$ are zero (see equation 1-1).

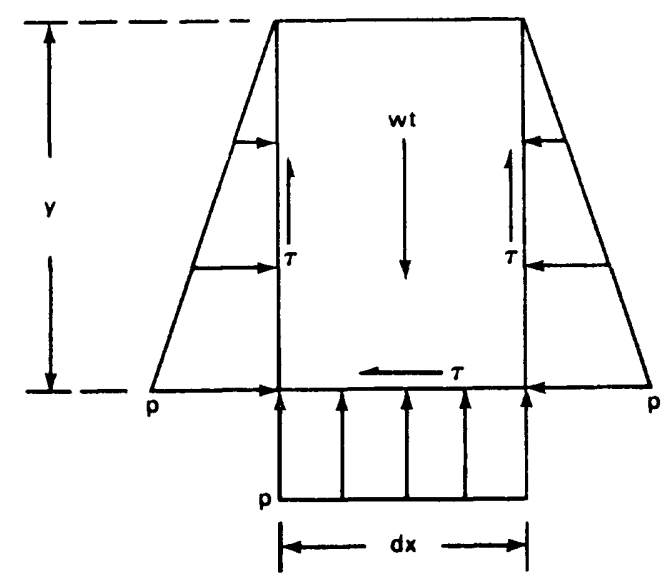

Figure 1-1.--Eree-body diagram of fluid element.

The pressure (p) at the bottom of the block in figure 1-1 can be computed as follows. Because the sides are vertical and the shear stress is zero, the weight (wt) is balanced by the pressure at the bottom times the area of the bottom of the block or

but the weight is

$$
\text { wt }=p d x(1) \text {, }
$$

or

$$
\text { wt }=\gamma \text { volume }=\gamma \mathrm{ydx}(1)
$$

therefore

$$
\gamma_{y d x}(1)=\operatorname{pdx}(1) ;
$$

$$
\mathrm{p}=\boldsymbol{\gamma} \mathrm{y}
$$

which shows that in a fluid at rest, the pressure increases linearly with depth below the surface. 
Table 1-1.--Mechanical properties of some fluids

$\left[\mathrm{ft}^{3}\right.$, cubic foot; $1 \mathrm{~b} / \mathrm{ft}^{3}$, pounds per cubic foot; $s$ lb, second times pound; ${ }^{\circ} \mathrm{F}$, degrees Fahrenheit]

(A) Some properties of air at atmospheric pressure

\begin{tabular}{cccc}
\hline $\begin{array}{c}\text { Temperature } \\
{ }^{\circ} \mathrm{F}\end{array}$ & $\begin{array}{c}\text { Density } \\
\text { slug/ft } \\
\rho\end{array}$ & $\begin{array}{c}\text { Specific weight } \\
\text { lb/ft } \\
\gamma\end{array}$ & $\begin{array}{c}\text { Kinematic viscosity } \\
\mathrm{ft}^{2} / \mathrm{s} \\
v\end{array}$ \\
\hline 0 & 0.00268 & 0.0862 & $12.6 \times 10^{-5}$ \\
40 & .00247 & .0794 & $14.6 \times 10^{-5}$ \\
80 & .00228 & .0735 & $16.9 \times 10^{-5}$ \\
120 & .00215 & .0684 & $18.9 \times 10^{-5}$ \\
\hline
\end{tabular}

(B) Mechanical properties of water at atmospheric pressure

\begin{tabular}{cccc}
\hline $\begin{array}{c}\text { Temperature } \\
{ }^{\circ} \mathrm{F}\end{array}$ & $\begin{array}{c}\text { Density } \\
\text { slug/ft } \\
\rho\end{array}$ & $\begin{array}{c}\text { Specific weight } \\
\mathrm{lb} / \mathrm{ft}^{3} \\
\boldsymbol{\gamma}\end{array}$ & $\begin{array}{c}\text { Dynamic viscosity } \\
\mathrm{s} / \mathrm{ft}^{2} \\
\mu\end{array}$ \\
\hline 32 & 1.94 & 62.4 & $3.75 \times 10^{-5}$ \\
40 & 1.94 & 62.4 & $3.24 \times 10^{-5}$ \\
50 & 1.94 & 62.4 & $2.74 \times 10^{-5}$ \\
60 & 1.94 & 62.4 & $2.36 \times 10^{-5}$ \\
70 & 1.94 & 62.3 & $2.04 \times 10^{-5}$ \\
80 & 1.93 & 62.2 & $1.80 \times 10^{-5}$ \\
90 & 1.93 & 62.1 & $1.59 \times 10^{-5}$ \\
100 & 1.93 & 62.0 & $1.42 \times 10^{-5}$ \\
120 & 1.92 & 61.7 & $1.17 \times 10^{-5}$ \\
\hline
\end{tabular}


Table 1-1.--Mechanical properties of some fluids--continued

(C) Specific gravity and kinematic viscosity of certain liquids (Kinematic viscosity = tabular value $\times 10^{-5}$ )

\begin{tabular}{|c|c|c|c|c|}
\hline \multirow[b]{2}{*}{$\begin{array}{l}\text { Temperature } \\
{ }^{\circ} \mathrm{F}\end{array}$} & \multicolumn{2}{|c|}{ Carbon tetrachloride } & \multicolumn{2}{|c|}{$\begin{array}{c}\text { Medium } \\
\text { lubricating oil }\end{array}$} \\
\hline & $\begin{array}{c}\text { Specific } \\
\text { gravity } \\
\mathrm{s}_{g}\end{array}$ & $\begin{array}{c}\text { Kinematic } \\
\text { viscosity } \\
\mathrm{ft}^{2} / \mathrm{s} \\
v\end{array}$ & $\begin{array}{c}\text { Specific } \\
\text { gravity } \\
\mathrm{s}_{\mathrm{g}}\end{array}$ & $\begin{array}{c}\text { Kinematic } \\
\text { viscosity } \\
f t^{2} / \mathrm{s} \\
v\end{array}$ \\
\hline $\begin{array}{r}40 \\
60 \\
80 \\
100\end{array}$ & $\begin{array}{l}1.621 \\
1.595 \\
1.569 \\
1.542\end{array}$ & $\begin{array}{r}0.810 \\
.700 \\
.607 \\
.530\end{array}$ & $\begin{array}{l}0.905 \\
.896 \\
.888 \\
.882\end{array}$ & $\begin{array}{l}477 \\
188 \\
94 \\
49.2\end{array}$ \\
\hline $\begin{array}{c}\text { Temperature } \\
{ }^{\circ} \mathrm{F}\end{array}$ & $\begin{array}{l}\text { Mediur } \\
\text { Specific } \\
\text { gravity } \\
s_{g}\end{array}$ & $\begin{array}{c}\text { fuel oil } \\
\text { Kinematic } \\
\text { viscosity } \\
\mathrm{ft} \mathrm{t}^{2} / \mathrm{s} \\
\mathrm{v}\end{array}$ & $\begin{array}{c}\text { Specific } \\
\text { gravity } \\
\mathrm{s}_{\mathrm{g}}\end{array}$ & $\begin{array}{c}\text { asoline } \\
\text { Kinematic } \\
\text { viscosity } \\
f t^{2} / \mathrm{s} \\
v\end{array}$ \\
\hline $\begin{array}{r}40 \\
60 \\
80 \\
100\end{array}$ & $\begin{array}{l}0.865 \\
.858 \\
.851 \\
.843\end{array}$ & $\begin{array}{l}6.55 \\
4.75 \\
3.65 \\
2.78\end{array}$ & $\begin{array}{r}0.738 \\
.728 \\
.719 \\
.710\end{array}$ & $\begin{array}{l}0.810 \\
.730 \\
.660 \\
.600\end{array}$ \\
\hline
\end{tabular}

(D) Specific gravity and kinematic viscosity of some other liquids

\begin{tabular}{lcc}
\hline Liquid and temperature & $\begin{array}{c}\text { Specific } \\
\text { gravity } \\
\mathrm{Sg}_{\mathrm{g}}\end{array}$ & $\begin{array}{c}\text { Kinematic } \\
\text { viscosity } \\
\mathrm{ft}{ }^{2} / \mathrm{s} \\
\mathrm{v}\end{array}$ \\
\hline Turpentine at $68{ }^{\circ} \mathrm{F}$ & 0.862 & 1.86 \\
Linseed oil at $86^{\circ} \mathrm{F}$ & .925 & 38.6 \\
Ethyl alcohol at $68^{\circ} \mathrm{F}$ & .789 & 1.65 \\
Benzene at $68{ }^{\circ} \mathrm{F}$ & .879 & 0.802 \\
Glycerin at $68{ }^{\circ} \mathrm{F}$ & 1.262 & 711 \\
Castor oil at $68{ }^{\circ} \mathrm{F}$ & .960 & 1.110 \\
Light machinery oil at $62{ }^{\circ} \mathrm{F}$ & .907 & 147 \\
\hline
\end{tabular}


PROBLEMS

1. Compute your mass in slugs.

2. The density of alcohol is 1.53 slugs $/ \mathrm{ft}^{3}$. Calculate its specific weight and specific gravity. 
3. A stream gager falls in the river and gets his boots full of water. He manages to get to shore but his boots are still full of water. What is the maximum pressure inside his boots when he stands up? His boots are 3 feet high.

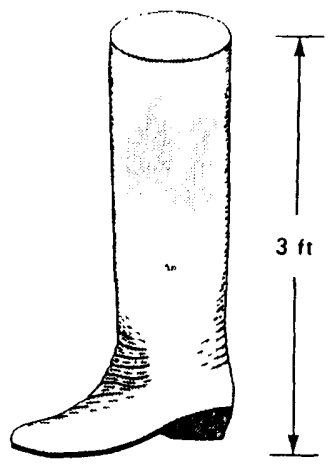

4. The inside of a pipe, which has an inside diameter of 6 inches, is coated with heavy oil. A 2-1b cylinder 6 inches long and 5.98 inches in diameter falls through the vertical pipe at a rate of $0.15 \mathrm{ft} / \mathrm{s}$. Calculate the dynamic viscosity of the oil.

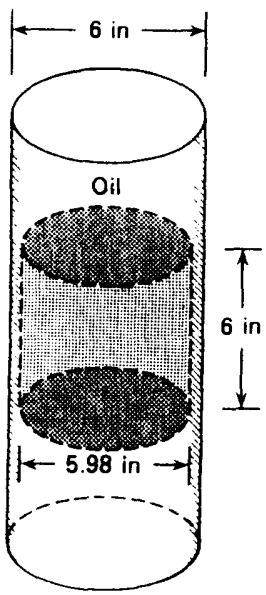




\section{Lesson 2 - Forces on Submerged Objects}

Only fluids at rest will be dealt with in this lesson so no tangential (shear) forces are exerted, and hence all forces are normal to the free body surfaces in question. Consider the force on a vertical rectangular gate as illustrated in figure 2-1. As seen from equation 1-2, the pressure increases with increasing distance below the water surface; hence, the force (dF) on a narrow strip of the gate of height dy and width $w$ is computed as

$$
d F=p d A=\gamma y \text { W } d y .
$$

Figure 2-1.--Pressure prism for vertical rectangular gate.

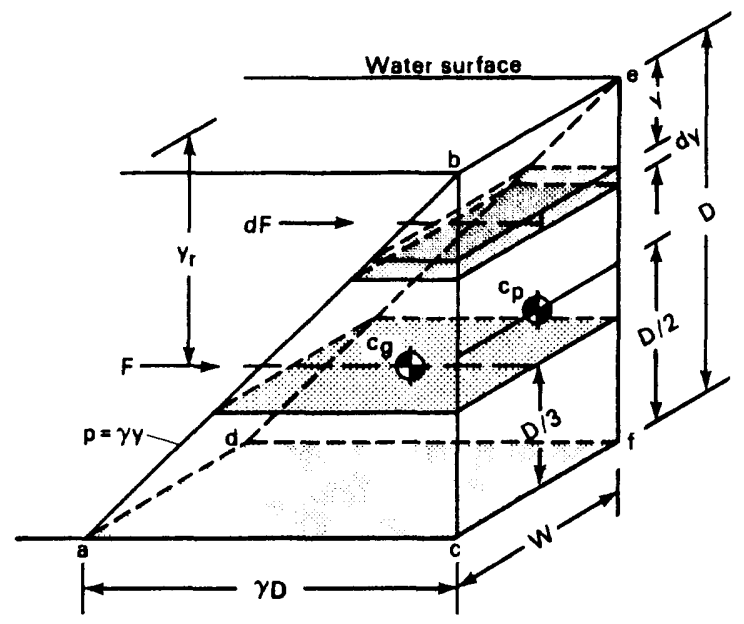

The total force on the vertical surface may be computed as the sum of all of the differential force values (dF on fig. 2-1). Hence, the total horizontal force on the surface is

$$
F=\int_{A} d F=\gamma w \int_{O}^{D} y d y=\gamma \mathrm{wD}^{2} / 2 .
$$

Another technique to compute the force is based on the fact that the force is equal to the volume of the pressure prism defined by the solid abcdef in figure 2-1. The force on any submerged surface is equal to the volume of the pressure prism. The pressure prism is the solid with a base equal to the area of the surface in contact between the gate and the water and with a height equal to the pressure on the surface. It is often easier to visualize the pressure prism and compute its volume than to integrate an expression such as the equation for $\mathrm{dF}$. For example, the pressure prism in figure 2-1 is a solid of triangular shape and width W. The area of the base is the area of the triangle with one side equal to $D$ and the other side equal to ${ }^{D}$. For complex shapes it is usually possible to break up the pressure prism into simpler geometric shapes and compute the volume of each simple shape. The total force is then the sum of the volumes.

A third way to visualize the force on a surface is that it is equal to pressure at the centroid of the wetted area (called the center of pressure, $C_{p}$, see fig. 2-1) times that area. The total force on an object can always be correctly computed using this approach also. On figure 2-1 the wetted area is 
a rectangle (bcfe), which has its centroid at $D / 2$ feet below the surface. The force is therefore

$$
F=p_{C} A=(\gamma D / 2) \quad(D W) .
$$

\section{Example:}

As an example, the horizontal and vertical components of the force of the water on the 4-foot wide gate shown in figure 2-2 will be computed. The pressure prism for the horizontal force is shown on the figure with a height defined by $a$ b $c d$ a and a base of 4 feet by 8 feet.

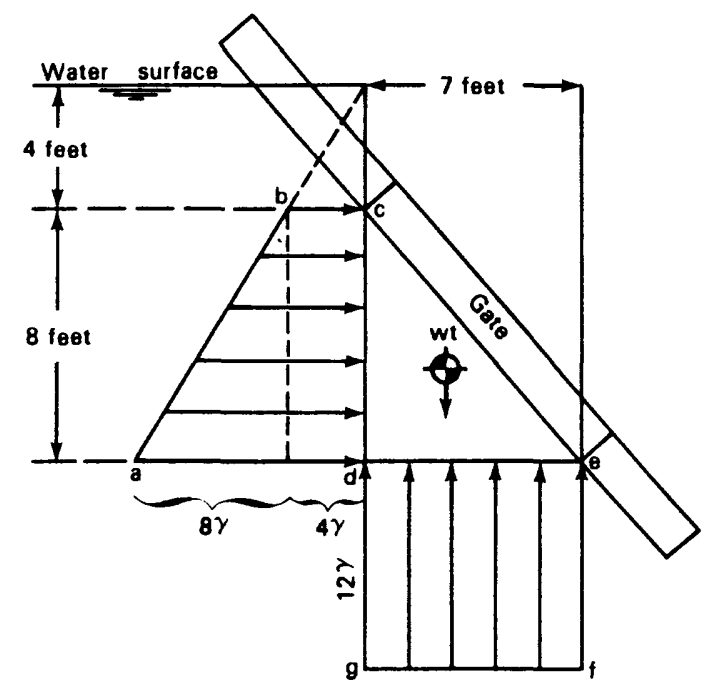

Figure 2-2.--Pressure prism for a submerged gate 4 feet wide.

\section{Solution:}

The volume of the pressure prism may be obtained by breaking it into a triangle with sides of $8 \gamma \mathrm{lb} / \mathrm{ft}^{2}$ and 8 feet and a rectangle with sides of $4 \gamma \mathrm{lb} / \mathrm{ft}^{2}$ and 8 feet. The total horizontal force, $F_{H}$, of the water on the vertical plane $c d \times 4$ feet is then computed as the sum of these two volumes.

$$
\mathrm{F}_{\mathrm{H}}=\frac{8 \gamma}{2}(8)(4)+4 \gamma(8)(4)=256 \gamma=15,974 \mathrm{lb} \text {. }
$$

The fluid force on this plane is the same as the horizontal component of the force of the water on the gate because there are no shear stresses when the fluid is at rest.

The vertical force of the water, Fv, on the plane $d e x 4$ feet is computed from the volume of the pressure prism defined by the points $d$ e $f \mathrm{~g} d$ and the 4-foot width.

$$
F_{\mathrm{V}}=12 \gamma(7)(4)=336 \gamma=20,966 \mathrm{lb} .
$$

This force supports the weight of the water in the volume $\mathrm{c} \mathrm{de} \mathrm{c} \mathrm{x} 4 \mathrm{feet}$; the balance being the force exerted on the gate. The vertical force of the water on the gate is therefore

$$
F_{V}=[12 \gamma(7)(4)]-[(8 / 2) \gamma(7)(4)]=13,9781 \mathrm{~b} .
$$


The vertical component of force on any area is equal to the weight of that volume of fluid that would extend vertically from the area to the free surface. As a result of this, the buoyant force on any object is equal to the weight of the water displaced.

The total resultant force is

$$
F R=\sqrt{F_{v}^{2}+F_{H}^{2}}=340.2 \gamma=21,2261 \mathrm{lb} .
$$

Another way to compute the resultant force is to draw the pressure prism as shown in figure 2-3. This time the force on the surface b $c$ will be computed directly and it should be the resultant force on the gate. As before, it is natural to break the pressure prism into a triangle with sides $8 \gamma \mathrm{lb} / \mathrm{ft}^{2}$ and 10.63 feet and a rectangle with sides of $4 \gamma \mathrm{lb} / \mathrm{ft}^{2}$ and 10.63 feet. Notice one side is 10.63 feet long in this case rather than 8 feet long when looking at only the horizontal component. The volume of the pressure prism is

$$
F_{R}=\frac{8 \gamma}{2}(10.63) 4+4 \gamma(10.63) 4=340.2 \gamma=21,2261 \mathrm{~b},
$$

which is the same result as obtained above.

Figure 2-3.--Pressure prism to compute the total force of the water on a 4-foot wide gate.

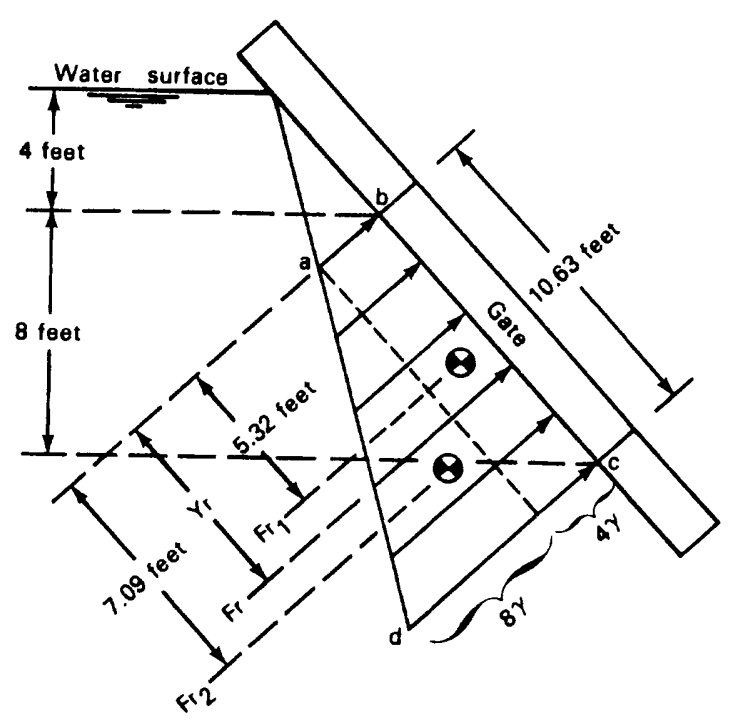

Forces not only have a magnitude and direction but a line of action as well. The line of action is the location where a single resultant force must be applied to have the same effect on a body as the distributed forces it replaces. For example, the center of gravity of a solid body is the point where a single force must be applied to the body to counter its weight without causing a torque (or moment) on the body.

Consider the line of action of the resultant pressure force on the surface in figure 2-1. The resultant force $F$ must act at a point such that its moment (or torque) about any point is equal to the sum of the moments of each small force $\mathrm{dF}$. Sum the moments about the line b-e and set them equal to F times $y_{r}$ to determine the distance of the line of action of the resultant force below the water surface $\left(y_{r}\right)$. 


$$
F y_{r}=\left(\gamma w D^{2} / 2\right)\left(y_{r}\right)=\int_{0}^{D} y d F=\gamma w \int_{0}^{D} y^{2} d y=\gamma w D^{3} / 3
$$

from which

$$
\mathrm{Yr}_{\mathrm{r}}=2 / 3 \mathrm{D} .
$$

Notice the line of action is through the center of gravity of the pressure prism abcdef. This will always be the case. Complex pressure prisms can usually be subdivided into simpler shapes for which the center of gravity can be easily determined. The resultant line of action is then obtained by summing the moments of each subvolume about a convenient reference point.

\section{Example:}

Compute the location of the resultant force of the water on the gate shown in figure $2-3$.

\section{Solution:}

The location of the force due the rectangular part of the pressure prism $\left(F_{R_{1}}\right)$ in figure 2-3 is located 5.32 feet from the top of the gate. The resultant force, $F_{R_{2}}$, due to the triangular part of the pressure prism is located 7.09 feet from the top of the gate. The total resultant force is located by summing moments.

$$
F_{R}(y)=F_{R_{1}}(5.32)+F_{R_{2}}(7.09)
$$

or

$$
y=\frac{170.1 \gamma(5.32)+170.1 \gamma(7.09)}{340.2 \gamma}=6.20 \text { feet, }
$$

so the resultant force is located 6.20 feet from the top of the gate, which is between $F_{R_{1}}$ and $F_{R_{2}}$ as would be expected. 


\section{PROBLEMS}

1. Determine the total horizontal water-pressure force on a 1-foot wide section of the dam shown below. If this distributed pressure were replaced by a single resultant hydrostatic force, at what distance below the water surface $y$ would it be considered to act?

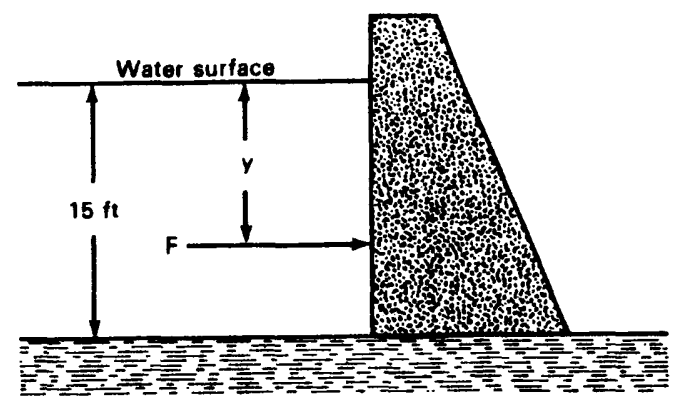


2. Determine the magnitude and location of the resultant water-pressure force acting on a 1-foot wide section of the gate shown below.

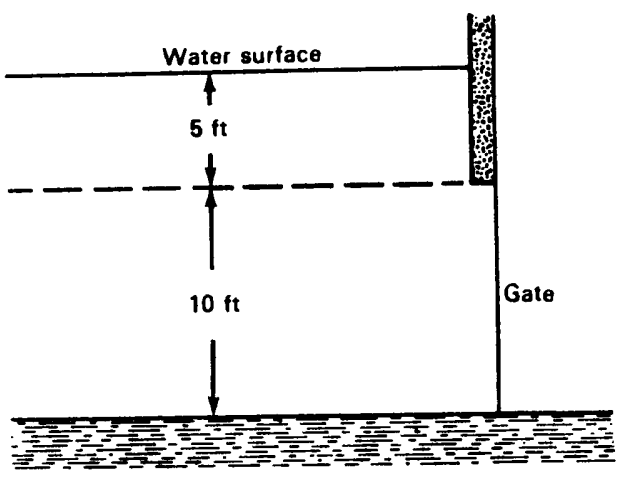


3. Compute both the horizontal and vertical hydrostatic forces acting on a 1 -foot wide section of the sloping rectangular gate shown below.

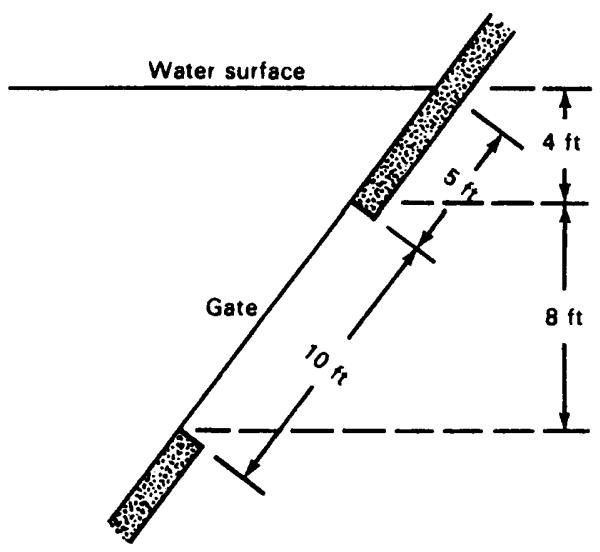


4. Compute the net horizontal force acting on a 1-foot wide section of the gate separating two tanks as shown below. The specific gravity of the oil in the right-hand tank is 0.750 .

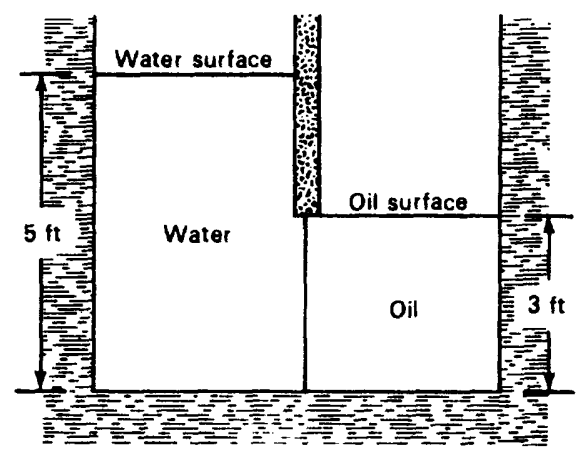


5. The quarter cylinder is 10 feet long. Calculate the horizontal and vertical components of the forces acting on the cylinder.

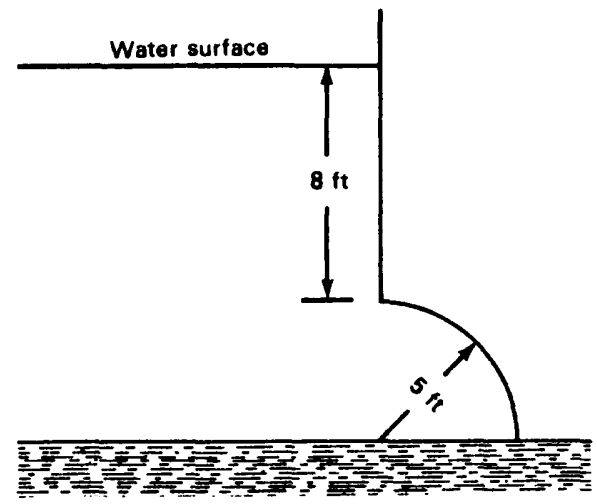




\section{Similitude}

Many approximations are made in analyzing any but the simplest of flow problems. And for complex situations it is usually desirable to test the validity of the computations before large investments in hydraulic structures are made. In many cases this validity is first checked by use of physical models of proposed structures. It costs very little to build and test a model of a structure in comparison to the cost of building a prototype, which may not function as desired. On the other hand, analytical computations are cheap in comparison to building and testing a scale model, so models are only built where the validity of the computations are in doubt.

Although the basic theory for interpretation of model results is quite simple, it is seldom possible to design and operate a flow model from theory alone. In general, only by use of experience, judgement, and patience can correct prototype behavior be predicted from model results. Similarity of flows between the model and prototype requires that certain laws of similitude be satisfied.

There are many types of similarity, all of which must be obtained if complete similarity is to exist between fluid phenomena. The first of these is geometric similarity, which states that model and prototype must have the same shape and, therefore, that the ratios between corresponding lengths in the model and prototype are the same. In the model and prototype of figure 3-1, for example, geometric similarity exists if

$$
\frac{B_{m}}{B_{p}}=\frac{b_{m}}{b_{p}}=\frac{L_{m}}{L_{p}} .
$$

It follows that the requirements for geometric similarity are met if the ratio of all linear dimensions in the model are the same as in the prototype.

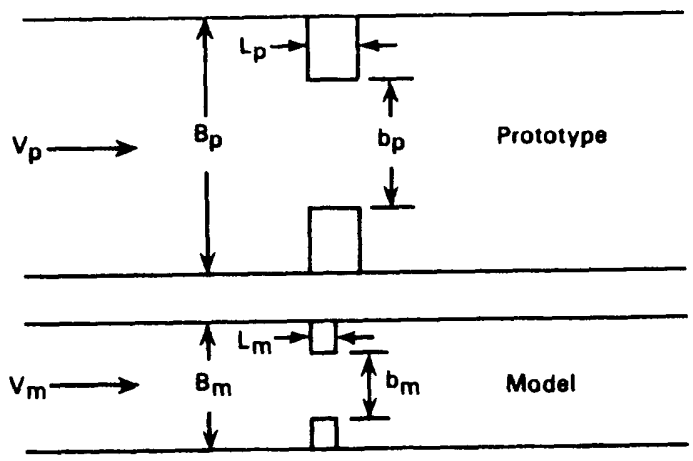

Figure 3-1.--Flow through constriction, model, and prototype.

Corollaries of geometric similarity are that corresponding areas vary with the squares of their linear dimensions,

$$
\frac{A_{m}}{A_{p}}=\left(\frac{l_{m}}{l_{p}}\right)^{2}
$$

and that volumes vary with the cubes of their linear dimensions. 
Consider now the flows through the model and prototype, figure 3-1. If the ratio of corresponding velocities and accelerations are the same throughout the flow, the two flows are said to possess kinematic similarity. For kinematically similar flows, the streamline patterns will be similar in shape.

In order to maintain geometric and kinematic similarity between the flow pictures, the forces acting on the corresponding fluid masses must be related by ratios similar to those above this similarity is known as dynamic similarity. The forces that may exist in a fluid flow are those of pressure, $F_{P}$, gravity, $F_{g}$, viscosity, $F_{V}$, elasticity, $F_{E}$, and surface tension, $F_{T}$. The vector sum of all forces acting on a fluid mass must equal its mass times its acceleration, which is the inertial force, FI. Written in mathematical terms for the prototype

$$
\left(F_{P}+F_{g}+F_{V}+F_{E}+F_{T}=F_{I}=M I\right)_{P},
$$

in which $M=$ mass of the fluid parcel and $I$ = acceleration of the fluid parcel. Of course an identical equation can be written for a mass of fluid in the model. For the ratio of accelerations (and therefore velocities) to be similar between the model and prototype requires that the ratio of inertial forces be similar, or

$$
\frac{\left(\vec{F}_{I}\right)_{m}}{\left(\vec{F}_{I}\right)_{p}}=\frac{M_{m} \vec{I}_{m}}{M_{p} \vec{I}_{p}}=\frac{\left(\vec{F}_{p}+\vec{F}_{q}+\vec{F}_{V}+\vec{F}_{E}+\vec{F}_{T}\right)_{m}}{\left(\vec{F}_{p}+\vec{F}_{g}+\vec{F}_{V}+\vec{F}_{E}+\vec{F}_{T}\right)_{p}}
$$

The ratio of the inertial forces will be constant if the ratio of the inertial force to each component force is constant, so dividing the inertial force by each component force one sees that dynamic and kinematic similarity can only be achieved provided that

$$
\left(\frac{F_{I}}{F_{P}}\right)_{m}=\left(\frac{F_{I}}{F_{P}}\right)_{P}
$$

which states that the accelerations $\left(F_{I}\right)$ due to pressure forces (FP) must be similar in both the model and prototype and that

$$
\left(\frac{F_{I}}{F_{v}}\right)_{m}=\left(\frac{F_{I}}{F_{v}}\right)_{p}
$$

which states that the accelerations due to viscous forces must be similar, etc.

Each of the forces is governed by relations between the dynamic and kinematic properties of the flow and by physical properties of the fluid. For example, the viscous force is given by the definition of viscosity (equation $1-1)$

$$
F_{V}=\tau A=\mu \frac{\Delta v}{\Delta y} A
$$

or

$$
F_{\mathrm{v}}=\mu \frac{\mathrm{v}}{\mathrm{l}} \mathrm{l}^{2}=\mu \mathrm{vl}
$$


where $\mathrm{v}=$ characteristic velocity and $\mathrm{l}=\mathrm{a}$ characteristic length. Because the ratios of all velocities and lengths in model and prototype are equal, it theoretically makes no difference which length or velocity is used in the equation. The generalized expressions for the forces are as follows

$$
\begin{aligned}
& \text { Pressure force, } \mathrm{F}_{\mathrm{P}}=\mathrm{Pl}^{2} \\
& \text { Inertial force, } \mathrm{F}_{\mathrm{I}}=\mathrm{MI}=\rho \mathrm{l}^{3} \frac{\mathrm{v}^{2}}{\mathrm{l}}=\rho \mathrm{v}^{2} \mathrm{l}^{2} \\
& \text { Gravity force, } \mathrm{F}_{\mathrm{g}}=\mathrm{M}_{\mathrm{g}}=\rho \mathrm{l}^{3} \mathrm{~g} \\
& \text { Viscous force, } \mathrm{F}_{\mathrm{v}}=\mu \frac{\Delta \mathrm{v}}{\Delta \mathrm{Y}} \mathrm{A}=\mu \frac{\mathrm{vl}^{2}}{l}=\mu \mathrm{vl} \\
& \text { Elastic force, } \mathrm{F}_{\mathrm{E}}=\mathrm{EA}=\mathrm{El} l^{2} \\
& \text { Surface tension force, } \mathrm{F}_{\mathrm{T}}=\sigma l
\end{aligned}
$$

in which $\mathrm{p}=$ pressure, $\mathrm{M}=$ mass, $\mathrm{E}=$ elasticity, and $\sigma$ = surface tension force per unit length.

Each of the five force ratios, which are dimensionless numbers, have names. These are as follows:

$$
\begin{aligned}
& \frac{F_{I}}{F_{p}}=\frac{\rho v^{2}}{\Delta P}=\text { square of the Euler number } \\
& \frac{F_{I}}{F_{v}}=\frac{v \rho l}{\mu}=\text { Reynolds number } \\
& \frac{F_{I}}{F_{g}}=\frac{v^{2}}{l g}=\text { Square of Froude number } \\
& \frac{F_{I}}{F_{E}}=\frac{\rho v^{2}}{E}=\text { Square of the Mach number } \\
& \frac{F_{I}}{F_{T}}=\frac{\rho l v^{2}}{\sigma}=\text { Weber number }
\end{aligned}
$$

Fortunately in most engineering problems for open-channel flow, the compressibility and surface tension effects can be ignored so only the Froude, Reynolds, and Euler numbers are important. The Euler number can be ignored because if four of the five ratios are satisfied, the fifth is automatically satisfied because the inertial force is the sum of the other forces.

In these ratios, $v$ and $l$ may be any velocity and length provided the same quantities are used in both the model and prototype. In open-channel flow, the depth of flow is commonly used for the length term and the mean velocity for the velocity term. 
Complete similarity is usually impossible to attain even when only the Froude number and the Reynolds number are significant. For example, if in figure 3-1 the prototype velocity and depth are $8 \mathrm{ft} / \mathrm{s}$ and $10 \mathrm{feet}$, respectively, can both the Reynolds number and Froude number be the same in the model and the prototype? The Reynolds number for the prototype at $70^{\circ} \mathrm{F}$ is

$$
R_{e}^{P}=\frac{8 \times 10 \times 1.94}{2.04 \times 10^{-5}}=7.6 \times 10^{6}
$$

and the Froude number for the prototype is

$$
\mathrm{F}_{\mathrm{r}}^{\mathrm{P}}=\frac{8}{\sqrt{32.2 \times 10}}=0.45
$$

If water is used as the fluid in model and prototype, then density and viscosity are the same for both cases. If a depth of 0.5 was selected for the model, the corresponding velocity for the Froude numbers to be the same would be $1.8 \mathrm{ft} / \mathrm{s}$. With a model depth of 0.5 foot, the velocity in the model would have to be $158 \mathrm{ft} / \mathrm{s}$ to have the Reynolds number in both the model and prototype to be equal.

From a practical viewpoint, equality of Reynolds numbers cannot be achieved for model and prototype in open-channel flow so model studies are limited to those cases for which the effect of viscosity can be neglected. This is generally true for highly turbulent flows that occur when the model Reynolds number is above $10^{6}$.

Froude number similarity can be easily achieved so the model approach is ideal for rapidly varied flow problems where the gravity force dominates the flow. The discharge coefficients for dams, culverts, and contracted openings have all been defined by model studies and are assumed to apply to full scale situations with an equal Froude number and geometric similarity.

\section{Example:}

Laboratory tests were conducted on a box culvert. It is known that dynamic similarity will be achieved if the Froude number in both the laboratory and field are equal. A $1 / 10$ scale model is built and tested. Under test conditions, the laboratory flow rate is measured as $1.0 \mathrm{ft}^{3} / \mathrm{s}$, the velocity at the wingwall was $1.3 \mathrm{ft} / \mathrm{s}$ and it required 1.6 seconds for a water parcel to move through the culvert. For the prototype culvert operating under similar conditions, calculate the flow rate, the velocity at the wingwall, and the time required for a water parcel to move through the culvert.

\section{Solution:}

Because the Froude number in the model and prototype must be equal

$$
F_{r}^{m}=F_{r}^{p}=\frac{V_{m}}{\sqrt{g l m}}=\frac{V_{p}}{\sqrt{g l p}}
$$

or

$$
v_{p}=v_{m} \sqrt{\frac{g l_{p}}{g l_{m}}}=v_{m} \sqrt{\frac{l_{p}}{l_{m}}}=v_{m} \sqrt{\frac{10}{1}}=3.16 v_{m} .
$$


So any velocity in the prototype will be 3.16 times the corresponding velocity in the model, and the velocity at the wingwall will be $3.16(1.3)=4.11 \mathrm{ft} / \mathrm{s}$ in the prototype.

As will be shown later in the course, the discharge (Q) can always be computed as the product of the velocity (V) times the flow area (A) and the area is proportional to the product of two lengths so

$$
\frac{Q_{p}}{Q_{m}}=\frac{V_{p} A_{p}}{V_{m} A_{m}}=\frac{V_{p}}{V_{m}} \frac{l_{p}^{2}}{l_{m}^{2}}
$$

or

$$
Q_{p}=Q_{m}(3.16) \quad\left(\frac{10}{1}\right)^{2}=316 Q_{m}
$$

The discharge in the prototype under test conditions will be $316 \mathrm{ft}^{3} / \mathrm{s}$.

The time for a parcel of water to move between two points is the distance between the points 1 divided by the average velocity of the water as it traverses the path between the points so

$$
\frac{T_{p}}{T_{m}}=\frac{l_{p} / V_{p}}{l_{m} / V_{m}}=\frac{l_{p}}{l_{m}} \frac{V_{m}}{V_{p}}=\left(\frac{10}{1}\right)\left(\frac{1}{3.16}\right)=3.16
$$

The time for a parcel to pass through the prototype structure will be 3.16 $(1.6)=5.06$ seconds.

\section{Dimensional Analysis}

Most variables used in engineering are expressed in terms of three dimensions. These basic dimensions are force (F), time (T), and length (L). In this section the "brackets" mean "the dimensions of"

Example: the dimensions of pressure can be designated as

$$
[\mathrm{p}]=\frac{F}{\mathrm{~L}^{2}} \text {. }
$$

All rational equations (those developed by basic laws of physics) must balance in magnitude and must also be dimensionally homogeneous. That is, the dimensions of the left side of a rational equation must be the same as the dimensions on the right side and each term in the equation must have the same dimension.

In 1915 Buckingham showed that the number of independent dimensionless groups of variables (dimensionless parameters) needed to correlate the variables in a given process is equal to the number of variables involved minus the number of basic dimensions included in the variables.

Example: If it is known from experience or from experimental results that the drag force $E$ of a fluid moving past a sphere is a function of the velocity $\underline{V}$, mass density $R$, viscosity $\mu$, and the diameter $D$, then five variables ( $F, V, \rho, \mu, D)$ are involved and by inspecting the dimensions of each of these variables it is seen that three basic dimensions ( $L, F, T)$ are involved. 
Thus, by the Buckingham theorem one should be able to organize the five variables into two basic groupings for correlating experimental results.

The key to successful application of dimensional analysis is to select all necessary variables. Sometimes this can be done by looking at the appropriate physical laws that govern the process. If the appropriate physical laws are not available, a preliminary test can be run to gather all possible significant data, combine the variables using dimensional analysis, and discard those that do not have much impact. This may be done in advance by examining physical evidence of other experiments.

Repeating - the key to practical use of dimensional analysis is to select only those variables that are significant to the problem.

Once the variables are selected, there are numerous methods for combining the variables such that each remaining parameter is dimensionless. A process that is easy and reveals the process is outlined and applied below.

Keep in mind what the goal is to reduce the number of separate variables involved in the problem to the smallest number of independent dimensionless groups of variables (dimensionless parameters).

Rules of the game:

1. Identify all significant variables associated with the problem and write the functional equation.

$$
\mathrm{Z}=\mathrm{f}(\mathrm{V}, \mathrm{D}, \mathrm{X}, \mathrm{Y})
$$

2. Select a dimension (F, I, T) you wish to eliminate and a variable that contains this dimension. Then by inspection combine the variable with all other variables that contain the dimension in such a way that the new terms do not contain that dimension.

Then select another dimension and variable and repeat process above.

If all three dimensions (F, I, T) are involved, the manipulation is performed three times.

HINTS :

a. Get rid of $F$ dimension first. If $\rho$ is one of the variables, get rid of the $F$ first by combining $\rho$ in an appropriate manner with each variable that has the $F$ dimension. (Remember Newton's law that says force equals mass times acceleration so $[F]=M \mathrm{~L} / \mathrm{T}^{2}$ in which $M$ is mass so $[M]=\frac{F T^{2}}{I}$.) Use a power of $\rho$ necessary to cancel the force dimension. Combine $\rho$ only with the variables that contain $F$. The power of $\rho$ may vary from term to term.

b. If velocity is one of the variables present, get rid of the $T$ dimension (as in a above).

NOTE: If only one variable in the entire group of variables has the $T$ (time) dimension, it is usually advisable to add the acceleration of gravity $(g)$ to the list of significant variables. (It is usually part of the driving mechanism for the flow.) 
c. If depth is one of the variables, combine it with all terms that have the I dimension, and eliminate all L dimensions.

d. After all terms are dimensionless, it is perfectly legal to take terms to any power if it is convenient to do so. Remember each term is dimensionless so it does not matter if it is raised to a power and/or inverted.

Example:

Consider all fluid variables that might be significant in a general flow situation in which pressure difference between two points in the flow field is expected to be a function of $V, D, \rho, \mu, E, \sigma$, and $\gamma$.

$$
E=\text { bulk modulus of elasticity, } F / L^{2}, \sigma=\text { surface tension } F / L \text {. }
$$

Solution:

Because the difference in pressure $(\Delta \mathrm{P})$ is the main variable of interest, place it on the left side of the equation

$$
\Delta \mathrm{P}=\mathrm{f}_{1}(\mathrm{~V}, \mathrm{D}, \rho, \mu, \mathrm{E}, \sigma, \gamma)
$$

in which $f_{1}$ means $\Delta \mathrm{P}$ is a function of the variables in the parentheses. Display each variable and its dimension.
$[\Delta \mathrm{P}]=\frac{E}{\mathrm{~L}^{2}}$
$[V]=\frac{L}{T}$
$[D]=\mathrm{L}$
$[\rho]=\frac{E T^{2}}{L^{4}}$
$[\mu]=\frac{\mathrm{FT}}{\mathrm{L}^{2}}$
$[E]=\frac{E}{L^{2}}$
$[\sigma]=\frac{E}{L}$
$[\gamma]=\frac{F}{L^{3}}$

1. Eliminate $F$ dimension by dividing appropriate terms by some power of $\rho$ $\left(\rho=M / L^{3}=\mathrm{FT}^{2} / \mathrm{L}^{4}\right)$

$$
\begin{aligned}
& {\left[\frac{\Delta \mathrm{P}}{\rho}\right]=\mathrm{f}_{2} \quad\left(\mathrm{~V}, \mathrm{D}, \frac{\mu}{\rho^{\prime}} \frac{\mathrm{E}}{\rho^{\prime}}, \frac{\sigma}{\rho^{\prime}} \frac{\gamma}{\rho}\right)} \\
& {\left[\frac{\Delta \mathrm{P}}{\rho}\right]=\frac{F \mathrm{~L}^{4}}{\mathrm{~L}^{2} \mathrm{ET}}=\frac{\mathrm{L}^{2}}{\mathrm{~T}^{2}}} \\
& {\left[\frac{\mu}{\rho}\right]=\frac{E T L^{4}}{L^{2} F T^{2}}=\frac{L^{2}}{T^{2}}} \\
& {\left[\frac{E}{\rho}\right]=\frac{E L^{4}}{L^{2} E T^{2}}=\frac{L^{2}}{T^{2}}} \\
& {\left[\frac{\sigma}{\rho}\right]=\frac{E L^{4}}{L F T^{2}}=\frac{L^{3}}{T^{2}}} \\
& {\left[\begin{array}{l}
\gamma \\
\rho
\end{array}\right]=\frac{E L^{4}}{L^{3} E T^{2}}=\frac{L}{T^{2}}}
\end{aligned}
$$


2. Eliminate $\mathrm{T}$ using some power of $\mathrm{V}$

$$
\begin{aligned}
& {\left[\frac{\Delta \mathrm{P}}{\rho \mathrm{V}^{2}}\right]=\mathrm{f}_{3}\left(\mathrm{D}, \frac{\mu}{\rho \mathrm{V}^{\prime}} \frac{\mathrm{E}}{\rho \mathrm{V}^{2}}, \frac{\sigma}{\rho \mathrm{V}^{2}}, \frac{\gamma}{\rho \mathrm{V}^{2}}\right)} \\
& {\left[\frac{\Delta \mathrm{P}}{\rho \mathrm{V}^{2}}\right]=\frac{\mathrm{L}^{2} \mathrm{~T}^{2}}{\mathrm{~T}^{2} \mathrm{~L}^{2}} \quad \text { (dimensionless) }} \\
& {\left[\frac{\mu}{\rho \mathrm{V}}\right]=\frac{\mathrm{L}^{2} \mathrm{~T}}{\mathrm{~T} \mathrm{~L}}=\mathrm{L}} \\
& {\left[\frac{\mathrm{E}}{\rho \mathrm{V}^{2}}\right]=\frac{\mathrm{L}^{2} \mathrm{~T}^{2}}{\mathrm{~T}^{2} \mathrm{~L}^{2}} \quad \text { (dimensionless) }} \\
& {\left[\frac{\sigma}{\rho \mathrm{V}^{2}}\right]=\frac{\mathrm{L}^{3} \mathrm{~T}^{2}}{\mathrm{~T}^{2} \mathrm{~L}^{2}}=\mathrm{L}} \\
& {\left[\frac{\gamma}{\rho \mathrm{V}^{2}}\right]=\frac{\mathrm{L} \mathrm{T}^{2}}{\mathrm{~T}^{2} \mathrm{~L}^{2}}=\frac{1}{\mathrm{~L}}}
\end{aligned}
$$

3. Eliminate I using appropriate power of $D$

$$
\begin{aligned}
& {\left[\frac{\Delta \mathrm{P}}{\rho \mathrm{V}^{2}}\right]=\mathrm{f}_{4}\left(\frac{\mu}{\rho \mathrm{VD}^{\prime}} \frac{\mathrm{E}}{\rho \mathrm{V}^{2}}, \frac{\sigma}{\rho \mathrm{V}^{2} \mathrm{D}}, \frac{\gamma \mathrm{D}}{\rho \mathrm{V}^{2}}\right)} \\
& {\left[\frac{\mu}{\rho \mathrm{VD}}\right]=\frac{\mathrm{L}}{\mathrm{L}} \text { (dimensionless) }} \\
& {\left[\frac{\sigma}{\rho \mathrm{V}^{2} \mathrm{D}}\right]=\frac{\mathrm{L}}{\mathrm{L}} \text { (dimensionless) }} \\
& {\left[\frac{\gamma \mathrm{D}}{\rho \mathrm{V}^{2}}\right]=\frac{\mathrm{L}}{\mathrm{L}} \text { (dimensionless) }}
\end{aligned}
$$

Rearranging and inverting as necessary

$$
\frac{\mathrm{V}}{\sqrt{\Delta \mathrm{P} / \rho}}=f_{4}\left(\frac{\rho \mathrm{VD}}{\mu}, \frac{\mathrm{V}}{\mathrm{E} / \rho^{\prime}}, \frac{\rho \mathrm{V}^{2} \mathrm{D}}{\sigma}, \frac{\mathrm{V}}{\sqrt{\frac{\gamma g \mathrm{D}}{\gamma}}}\right)
$$

Euler Reynolds Mach Weber Froude

number number number number number

If it is known that all of the parameters are significant, $\Delta \mathrm{P}$ is a function of all four terms.

If viscosity is not significant, the Reynolds number can be eliminated.

If compressibility is not significant, the Mach number can be eliminated.

If surface tension is not significant, the weber number can be eliminated.

If there is no free surface, the Froude number can be eliminated. 


\section{PROBLEMS}

1. A 1:2000 tidal model is operated to satisfy Froude's law. A velocity of $0.02 \mathrm{ft} / \mathrm{s}$ is observed in the model. What is the velocity at the corresponding point in the prototype? What length of time in the model corresponds to one day in the prototype?

2. An overflow spillway 1,600 feet long is designed to pass $120,000 \mathrm{ft} / \mathrm{s}$. A 1:20 model of the cross section of the structure is built in the laboratory. It is assumed that the flow is two dimensional so only a 1-foot section (rather than an 80 -foot section) is built. Calculate the required laboratory flow rate for the 1 -foot section assuming that viscosity and surface tension can be neglected. The pressure at a point in the model is observed to be -1.0 psi $(-0.067$ atmosphere). How should this be interpreted for the prototype? 
3. Derive an expression for the drag force on a smooth object moving through water if this force depends only upon the speed and size of object as well as the density and viscosity of the water.

4. By dimensional analysis develop a discharge relation for the discharge over a broad-crested weir.

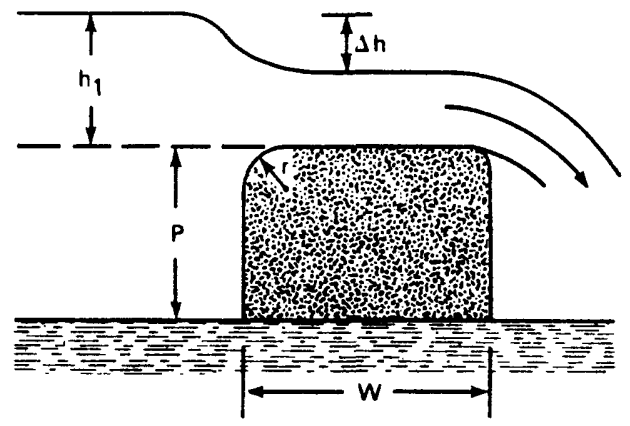


Lesson 4 - The Energy Equation for an Ideal Fluid

Fluid flow may be either steady or unsteady. Steady flow exists when none of the variables in the flow problem change with time. If any of the variables change with time, the condition of unsteady flow exists. The following discussion deals with steady-flow problems.

\section{Streamlines}

A path line is the trace made by a single particle over a period of time. A streamline is a curve that is tangent to the direction of velocity at every point on the curve. For steady flow, a path line and a streamline are identical.

Streamline pictures are both qualitative and quantitative in value. They allow the flow to be visualized as well as regions of high and low velocity and regions of high and low pressure to be located. They also allow the flow to be visualized.

When streamlines are drawn for steady flow, they form a boundary across which fluid particles do not pass. Thus, the space between the streamlines becomes a tube or passageway called a streamtube. The flow in such a tube may be treated as if it were isolated from the adjacent fluid. The use of the streamtube concept broadens the application of fluid-flow principles; for example, it allows treating apparently different problems such as flow in a passageway and flow about an immersed object with the same laws.

\section{The Continuity Equation}

The application of the principle of conservation of mass (matter can neither be created nor destroyed) to a steady flow in a streamtube results in the equation of continuity, which expresses the continuity of flow from section to section of the streamtube. Consider the streamtube shown in figure 4-1 through which passes a steady flow of fluid. At section 1 the crosssectional area is $A_{1}$ and at section 2 the area is $A_{2}$. If the mass of fluid occupying position $\mathrm{BB}^{1}$ moves to position $\mathrm{CC}^{1}$ in time $\mathrm{dt}$, the conservation of mass principle yields

$$
\rho \mathrm{A}_{1} \mathrm{ds} s_{1}=\rho \mathrm{A}_{2} \mathrm{ds} \mathrm{s}_{2},
$$

where $d s_{1}$ and $d s_{2}$ are the displacement lengths at sections 1 and 2 , respectively. Dividing by $\rho$ dt because $\rho$ is constant yields

$$
A_{1} \frac{d s_{1}}{d t}=A_{2} \frac{d s_{2}}{d t}
$$

however, $d s_{1} / d t$ and $d s_{2} / d t$ are the mean velocities of flow past sections 1 and 2 , respectively; therefore,

$$
A_{1} V_{1}=A_{2} V_{2}=Q,
$$

which is the equation of continuity. The product $A x \mathrm{~V}$ is designated as the flow rate, $Q$, and has units of cubic feet per second. 
Figure 4-1.--Steady flow through a streamtube.

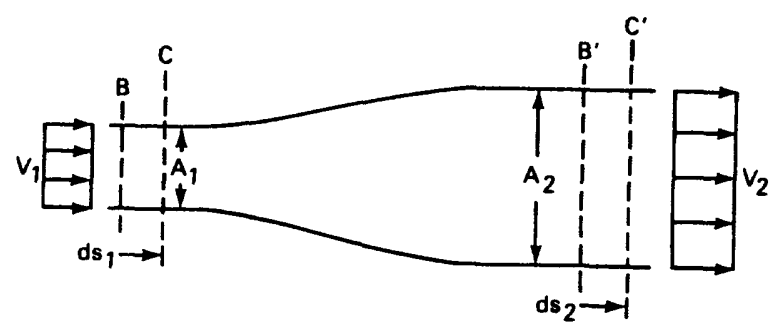

The Energy Equation

The fundamental equation of motion for steady flow may be derived by applying the principle of conservation of energy to individual fluid parcels. At this point it will be assumed that an ideal fluid exists for which no shearing stress occurs. In such a fluid there can be no frictional effects between moving fluid layers or between these layers and the boundary walls, and thus no cause for eddy formation or energy dissipation due to friction. The assumption of an ideal fluid allows a fluid to be treated as an aggregation of small particles that will support pressure forces normal to their faces but will slide over one another without resistance. Thus the motion of these ideal fluid particles is analogous to the motion of a solid body on a resistanceless plane; from this it may be concluded that unbalanced forces existing on particles of an ideal fluid will result in the acceleration of these particles according to Newton's Second Law.

Consider a 1-lb parcel of fluid at Point $A$ in figure 4-2. Compute the amount of energy contained by this parcel of fluid relative to some arbitrary datum. The parcel contains energy of three types--kinetic, potential, and pressure potential. The potential energy of the parcel (relative to the datum) is its weight times the distance above the datum or simply $z_{A}$ foot pound per pound. Notice the units of energy per pound are simply feet. In hydraulics, the term for foot pound per pound is usually called head, or the potential energy head of parcel $A$ is $Z_{A}$ foot. The second form of energy is called pressure potential. If $1 \mathrm{lb}$ of fluid at $A$ was placed into a plastic bag, this fluid could be lifted to the water surface without expending any energy because the fluid is neutrally buoyant and for an ideal fluid there is no resistance to motion. Because the parcel at A could exchange places with the parcel at the water surface without the expenditure of energy, its effective potential energy per pound is $\left(z_{A}+y_{A}\right)$ in which $y_{A}$ is also equal to the pressure at point $A$ divided by the unit weight (equation 1-2). This term is called the pressure head. Notice that the effective potential energy for any parcel of fluid (or streamline) at section $A$ is the same and equal to the sum

Figure 4-2.--Flow of an ideal fluid in an open channel.

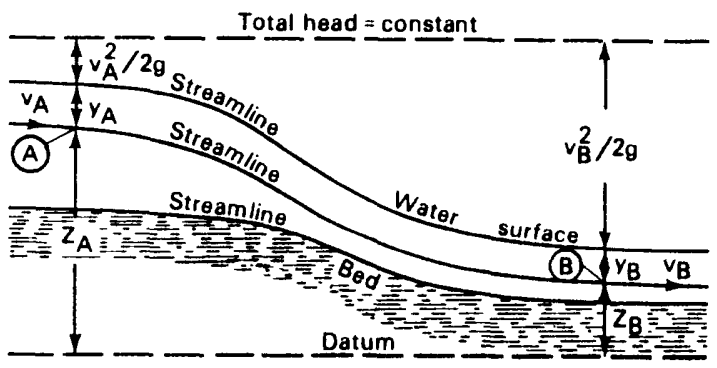


of the water depth plus the elevation of the bed above the datum. The sum of these two terms is called the piezometric (or hydraulic) head and for open channels its value is equal to the elevation of the water surface above the datum.

The kinetic energy of a $1-1 b$ object moving at velocity $v_{A}$ is

$$
\frac{\text { Kinetic energy }}{\text { Pound }}=\frac{\kappa_{E} / \mathrm{Vol}}{w t / \mathrm{Vol}}=\frac{\rho v^{2}}{2 \gamma}=\frac{\mathrm{v}^{2}}{2 \mathrm{~g}} \frac{(\mathrm{ft} / \mathrm{s})^{2}}{\mathrm{ft} / \mathrm{s}^{2}} \text {. }
$$

Notice the units of the kinetic energy per unit weight is also feet and the term is called the velocity head.

The sum of all three energies (heads) is called the total head and is often plotted pictorially as shown on figure 4-2. For an ideal fluid with no resistance to motion, the total energy of a pound of fluid is constant at all points along the streamline. For steady flow, the total head (energy) at section $B$, therefore, must be equal to that at section $A$ or at any other section. Expressed mathematically,

$$
\frac{\mathrm{v}_{\mathrm{A}}^{2}}{2 \mathrm{~g}}+\mathrm{y}_{\mathrm{A}}+\mathrm{z}_{\mathrm{A}}=\frac{\mathrm{v}_{\mathrm{B}}^{2}}{2 \mathrm{~g}}+\mathrm{yB}_{\mathrm{B}}+\mathrm{z}_{\mathrm{B}}=\text { constant. }
$$

Equation 4-2 is usually called the Bernoulli equation or simply the energy equation. Almost all open-channel-flow problems are solved by the application of equations 4-1 and 4-2; therefore, a complete understanding of these equations is essential.

By assuming frictionless motion, the equations are considerably simplified and more easily assimilated by the beginning student. In many cases, these simplified equations allow solution of engineering problems to an accuracy entirely adequate for practical purposes. In real situations where friction is small, the frictionless assumption will give good results where friction is large, it obviously will not. The identification of these situations is part of the art of fluid mechanics. However, as a general rule, accelerative processes are efficient and involve very little loss of energy while deceleration processes involve large losses of energy.

\section{Example:}

The discharge in the channel shown in figure $4-3$ is $280 \mathrm{ft}^{3} / \mathrm{s}$. The depth at section $A$ is 5.0 feet and the width is 8.0 feet. At section $B$ the width is 10.0 feet. Assuming ideal (frictionless) flow, compute the velocity and depth at section $B$.

\section{Solution:}

The first step is to draw the total head line as shown on figure 4-3. Because no energy is expended between sections $A$ and $B$, the total head (energy) line is horizontal. The streamline along the bed is one of an infinite number of streamlines that could be drawn for the flow between sections $A$ and $B$. Next, label the figure to show the kinetic, potential, and pressure potential energy terms at each section for the streamline at the bottom. Next, record the known values of each term of the energy equation on the figure and compute the unknown values by use of equations 4-1 and/or 4-2. 
Figure 4-3.--Example problem of

flow down a ramp.

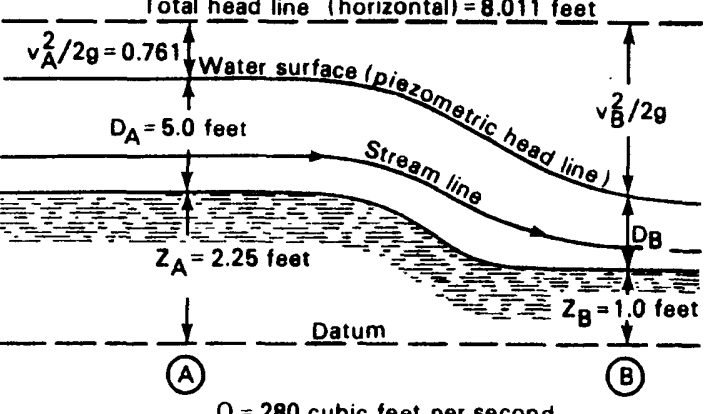

$Q=280$ cubic feet per second

In this example the potential energies of a parcel on the bottom of the channel at sections $A$ and $B$ are 2.25 and $1.00 \mathrm{ft} l \mathrm{~b} / \mathrm{lb}$, respectively, the pressure potential energy of the parcel at $A$ is $5.0 \mathrm{ft} 1 \mathrm{~b} / \mathrm{lb}$, and the other three terms are unknown. For an ideal fluid the velocity at all points in the cross section are equal so $v_{A}=v_{A}$. It is easily seen that the continuity equation can be used to determine the velocity at section $A$ as

$$
Q=280=V_{A}(5)(8.0)=v_{A}(5)(8)
$$

or $\mathrm{v}_{\mathrm{A}}=7.0 \mathrm{ft} / \mathrm{s}$ so the velocity head (kinetic energy) at section $\mathrm{A}$ is seen to be

$$
(7) 2 / 2(32.2)=0.761 \mathrm{ft} 1 \mathrm{~b} / \mathrm{lb} \text {. }
$$

The total energy of a parcel of water passing section $A$ on any streamline is seen to be

$$
0.761+5+2.25=8.011 \mathrm{ft} 1 \mathrm{~b} / \mathrm{lb} \text {. }
$$

For frictionless flow, the total head is constant at all points along a streamline, specifically the total energy of a parcel at cross-section $B$ on any streamline is equal to the total energy of a parcel at section $A$. The total head is 8.011 feet so writing the energy equation from point $A$ to $B$ :

$$
8.011=\frac{\mathrm{vB}^{2}}{2 \mathrm{~g}}+\mathrm{D}_{\mathrm{B}}+1.0 .
$$

This one equation has two unknowns, $v_{B}$ and $D_{B}$. However, the continuity equation also applies at section $B$ so that

$$
Q=280=V_{B} D_{B}(10.0),
$$

or solving for $v_{B}$

$$
\mathrm{v}_{\mathrm{B}}=\mathrm{v}_{\mathrm{B}}=\frac{28}{\mathrm{D}_{\mathrm{B}}}
$$

which can be combined with the energy equation to give

$$
8.011=\left(28 / D_{B}\right)^{2} / 64.4+D_{B}+1.0,
$$

or

$$
7.011=\frac{12.174}{D_{B}^{2}}+D_{B}
$$


This is a cubic equation that may be solved by trial. In other words, different values of $D_{B}$ are assumed until the right-hand side of the equation is equal to 7.011. Below, the value of the right-hand side is tabulated for different depths.

$\begin{array}{cccc}\mathrm{D}_{\mathrm{B}}(\mathrm{ft}) & \frac{12.174}{\mathrm{D}_{2}^{2}}+\mathrm{D}_{2} & \mathrm{D}_{\mathrm{B}}(\mathrm{ft}) & \frac{12.174}{\mathrm{D}_{2}{ }^{2}}+\mathrm{D}_{2} \\ 10.0 & 10.12 & 2.0 & 5.043 \\ 8.0 & 8.19 & 1.8 & 5.557 \\ 7.0 & 7.248 & 1.5 & 6.911 \\ 6.75 & 7.017 & 1.49 & 6.973 \\ & >\star & 1.48 & 7.038 \\ 6.74 & 7.008 & 1.30 & 8.503 \\ 6.0 & 6.338 & 1.00 & 13.174 \\ 4.0 & 4.761 & \end{array}$

Notice that a depth of either 6.743 or 1.484 feet satisfies the equation and is possible for an ideal fluid. These are called alternate depths. Unless some constriction downstream caused the water to back up, the flow would accelerate as shown on the figure and the smaller depth will occur. In this case, the velocity at the section would be

$$
v_{B}=\frac{Q}{A_{B}}=\frac{280}{10(1.484)}=18.87 \mathrm{ft} / \mathrm{s},
$$

and the velocity head is

$$
\frac{(18.87)^{2}}{64.4}=5.527 \mathrm{ft} \mathrm{lb} / \mathrm{lb}
$$

As can be seen, the total head at section $B$ is

$$
\frac{\mathrm{v}_{\mathrm{B}}^{2}}{2 \mathrm{~g}}+\mathrm{D}_{\mathrm{B}}+\mathrm{z}_{\mathrm{B}}=5.527+1.484+1.0=8.011
$$

the same as for section A so energy is conserved. A 1-1b parcel of water on the surface streamline contains $0.761 \mathrm{ft}$ lb of kinetic energy and $2.25+5.0=7.25 \mathrm{ft}$ lb of potential energy as it passes section $A$. As it passes section $B$, it has only $1.0+1.484=2.484 \mathrm{ft}$ lb of potential energy. The difference $4.766 \mathrm{ft}$ lb has been converted to kinetic energy so as it passes section $B$ it contains $0.761+4.766=5.527$ ft $1 \mathrm{~b}$ of kinetic energy. 


\section{PROBLEMS}

1. $500 \mathrm{ft}^{3} / \mathrm{s}$ of water flow in a rectangular open channel that is 20 feet wide and 8 feet deep. After passing through a transition structure, the width of the rectangular channel narrows to 15 feet and the bed raises as shown. The velocity in the contracted section is found to be $6 \mathrm{ft} / \mathrm{s}$.

(a) What is the water depth in the narrow channel?

(b) What are the velocity heads in each section?

(c) Draw and label the total and piezometric (water surface) head lines.

(d) How much does the bed elevation increase in the contracted section?

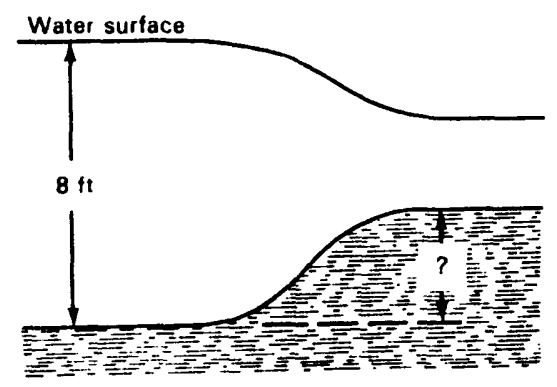

2. Water stands 9 feet deep in a large tank. A hole with an area of 0.1 ft 2 is punched in the side of the tank 5 feet above the bottom.

(a) Compute the discharge from the hole.

(b) Draw and label the total and piezometric head lines.

(c) What is the velocity of the water as it hits the ground?

Note: If the hole is rounded as shown, the answers you compute for an ideal fluid will be correct to within about 1 percent.

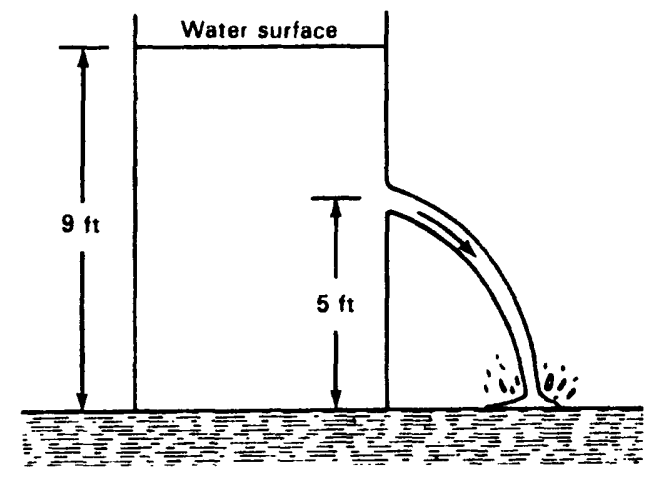


3. Compute the discharge in the 20-foot wide rectangular channel shown below. Draw and label the total head line and the water surface near the gate.

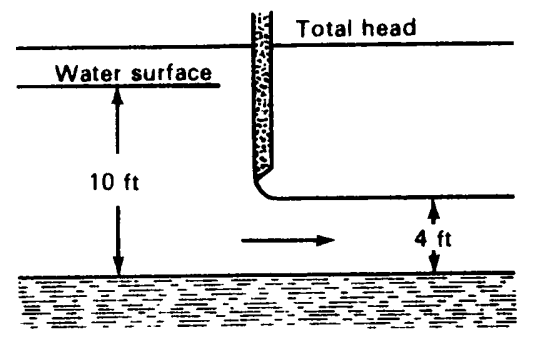

4. Compute the discharge and depth in the contracted section for the indicated rectangular channel.

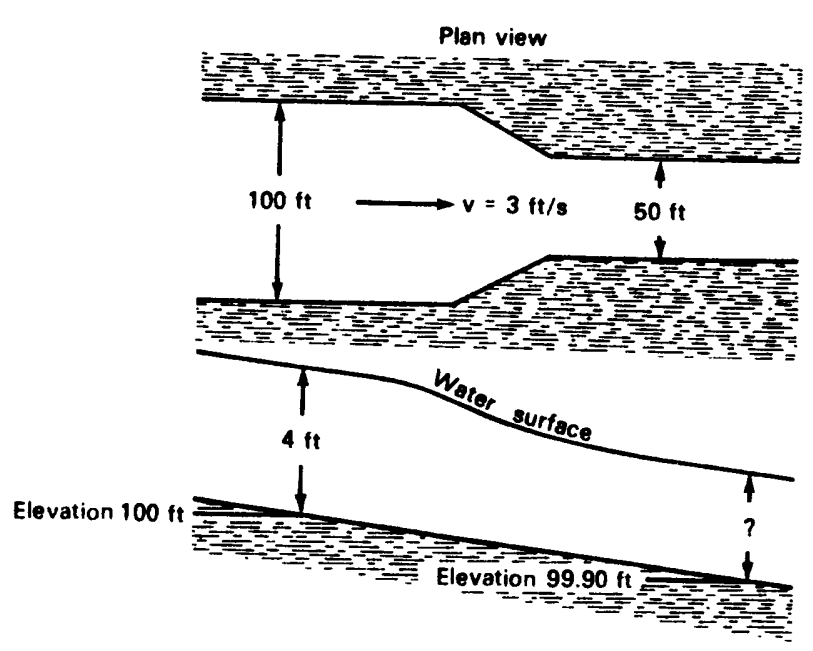




\title{
PART II - STEADY UNIFORM FLOW OF REAL FLUIDS IN OPEN CHANNELS
}

\author{
Lesson 5 - Velocity Profiles
}

\section{General}

In 1883 Osborne Reynolds demonstrated that there are two distinctly different types of fluid flow. He injected a fine threadlike stream of colored liquid at the entrance to a large glass tube through which water was flowing. When the velocity of flow in the tube was small, this colored liquid was visible as a straight line throughout the length of the tube, thus showing that the particles of water moved in parallel straight lines. But, as the velocity of the water was gradually increased by permitting a greater quantity to flow through the tube, there was a point at which the flow abruptly changed. It was then seen that, instead of a single straight line, the particles of the colored liquid were flowing in a very irregular fashion and forming numerous vortices. In a short time the color was diffused uniformly throughout the tube so that no streamlines could be distinguished. Later observations have shown that in this type of flow the velocities and pressures continuously fluctuate.

The first type of flow is known as laminar, streamline, or viscous flow. The significance of these terms is that the fluid appears to move by the sliding of layers or laminations of infinitesimal thickness relative to adjacent layers, that the particles move in definite and observable paths or streamlines, and it is also a flow that is characteristic of a viscous fluid or at least a flow in which viscosity plays a significant part. For laminar flow, the shear stress is determined from the equation

$$
\tau=\mu \frac{\partial v}{\partial y}
$$

The second type of flow, where single water parcels move about within the flow in an erratic manner, is known as turbulent flow. The distinguishing characteristic of turbulence is its irregularity. There is no definite frequency (as in wave action) or any observable pattern (as in the case of eddies).

Large eddies, swirls, and irregular movements of large bodies of fluid, which can be traced to obvious sources of disturbance, do not constitute turbulence but may be described as a disturbed flow. By contrast, turbulent flow commonly occurs in streams that appear to be very smoothly flowing and in which there is no detectable source of disturbance. The fluctuations of velocity and pressure are furthermore comparatively small and can often be detected only by special means of observation.

Reynolds Number

Reynolds was able to generalize his results and predict whether the flow would be laminar or turbulent by use of a dimensionless ratio later called the Reynolds number. The Reynolds number is the ratio of inertial to viscous forces in the flow

$$
\mathrm{R}_{e}=\frac{\mathrm{v} \rho \mathrm{l}}{\mu}=\frac{\mathrm{vl}}{v},
$$


in which $v$ = velocity of flow, $\rho$ = density of fluid, $l$ = a characteristic length dimension (depth for open-channel flow, diameter for pipe flow), $\mu=$ dynamic viscosity, and $v=$ kinematic viscosity $(\mu / \rho)$.

The concept of a critical Reynolds number delineating the regimes of laminar and turbulent flow is indeed a useful one in promoting concise generalization of certain flow phenomena. Applying this concept to the flow of any fluid in cylindrical pipes, it is possible to predict that the flow will generally be laminar if $R_{e}<2,100$ and turbulent if $R_{e}>4,000$. However, it is to be emphasized that the critical Reynolds number is very much a function of boundary geometry. For flow between parallel walls (using mean velocity $V$, and spacing l), $R_{e} \cong 1,000$; for flow in a wide open channel (using mean velocity $\mathrm{V}$ and depth $\mathrm{D}), \mathrm{R}_{e} \cong 500$; for flow about a sphere (using approach velocity $V$ and diameter d), $R_{e} \cong 1$. Also noteworthy is the fact that such critical Reynolds numbers must be determined experimentally; because of the obscure origins of turbulence, analytical methods for predicting critical Reynolds numbers have yet to be developed.

\section{Laminar Elow}

Laminar flow only occurs in open channels when the depths are very small. It is often assumed to occur in sheet flow or flow over the ground after a rainfall. Consider the uniform flow of constant depth $D$ over a very wide plane surface as illustrated on figure 5-1. Assume a unit weight of $\gamma$ for the fluid, that the slope is small, the flow is laminar, and a width of $w$ feet.

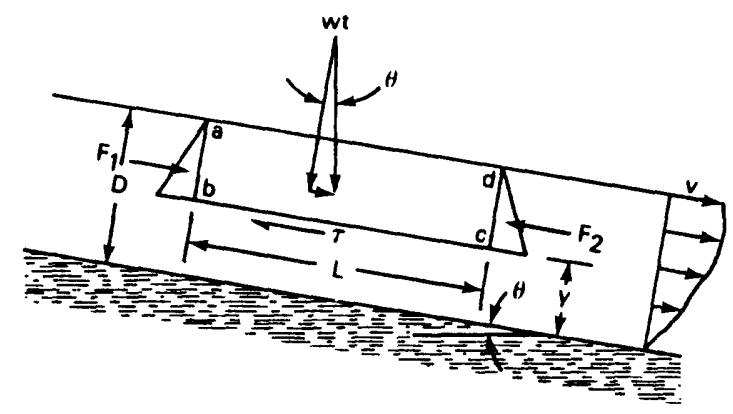

Figure 5-1.--Sheet flow over a wide inclined plane of width $w$.

Because the flow is uniform, the acceleration of the mass of fluid enclosed by abcd is zero and the sum of all forces on it must equal zero. Summation of forces in a direction parallel to the bottom gives

$$
\Sigma F_{S}=0=F_{1}+w t \sin \theta-F_{2}-\tau L w .
$$

Because the flow is uniform, the pressure forces ( $F_{1}$ and $F_{2}$ ) cancel and the component of the weight parallel to the flow must be balanced by the shear force. This gives an expression for shear stress in open-channel flow

$$
\gamma L(D-y) W \sin \theta=\tau L W
$$

or

$$
\tau=\gamma(D-y) \sin \theta,
$$

which is valid in either laminar or turbulent flow. 
For laminar flow, the shear stress is given by equation 1-1 that when substituted into equation 5-2 yields an expression for the variation of velocity with distance from the bed

$$
\tau=\mu \frac{\partial v}{\partial y}=\gamma(D-y) \sin \theta .
$$

Separating the variables and integrating one obtains an expression for the velocity profile in laminar, open-channel flow

$$
v=\frac{\gamma}{\mu} \sin \theta \int(D-y) d y=\frac{\gamma}{\mu} \sin \theta\left(D y-\frac{y^{2}}{y}\right)+c
$$

where $c$ is a constant. Because the velocity must be zero at the bed (fluid clings to a solid surface), the value of $c$ is zero. Thus the velocity distribution in laminar, open-channel flow is given by the parabolic equation

$$
\mathrm{v}=\frac{\gamma}{\mu} \sin \theta\left(D y-\frac{y^{2}}{y}\right) \quad(\text { Laminar }) .
$$

The discharge per unit width is obtained by integrating again

$$
\mathrm{q}=\int_{0}^{\mathrm{D}} \mathrm{v} d y=\frac{y}{\mu} \sin \theta \frac{\mathrm{D}^{3}}{3} .
$$

The mean velocity is found by dividing the unit discharge by the crosssectional area (D (1))

$$
\mathrm{V}=\frac{\mathrm{g}}{\mathrm{D}}=\frac{\gamma}{\mu} \sin \theta \frac{\mathrm{D}^{2}}{3}
$$

\section{Turbulent Flow}

The expression for the shear stress given by equation 5-2 results simply from a force balance and so it is valid in either laminar or turbulent flow. In turbulent flow, however, the random particle movement causes additional momentum transfer (or apparent shear) so that the shear stress relation $1-1$ is not valid. Prandtl developed a theory based on momentum transfer and assumed the shear stress in turbulent flow is given by

$$
\tau_{\text {turb }}=\rho 1^{2}\left(\frac{\partial v}{\partial y}\right)^{2},
$$

in which $l$ is the distance each parcel of fluid moves from its mean position during each excursion. This excursion distance is called the mixing length. Because a boundary limits the excursion length of parcels, the mixing length should be small near the bed or the surface and increase with distance from the boundary. An equation for mixing length that predicts a value of zero at both the bed and the surface and a maximum at middepth is

$$
l=\kappa y \sqrt{1-y / D},
$$


in which $\mathrm{y}$ is measured from the bed upward and $\boldsymbol{k}$ is a constant called the von Karman kappa value. The turbulent shear stress equation with the above equation for mixing length can be substituted into equation 5-2 to obtain the most popular expression for velocity distribution in turbulent flow,

$$
\rho \kappa^{2} y^{2}(1-y / D)\left(\frac{\partial v}{\partial y}\right)^{2}=\gamma(D-y) \sin \theta .
$$

Rearranging

$$
\frac{\partial v}{\partial y}=\sqrt{\frac{{ }_{D} \sin \theta}{\rho}} \frac{1}{\kappa_{y}}=\sqrt{\frac{\tau_{0}}{\rho}} \frac{1}{\kappa_{y}}=\frac{u_{\star}}{\kappa_{y}},
$$

where $\tau_{0}=$ shear stress at the bed. Because the shear at the bed is equal to $\gamma D \sin \theta$ (see equation $5-2$ ), the term $\sqrt{\tau_{0} / \rho}$ has the dimensions of velocity and is called the shear velocity or friction velocity, $u_{\star}=\sqrt{\tau_{0} / \rho}$. The above expression can be integrated by separating the variables to give the Prandt $1-$ von Karman universal velocity distribution law in turbulent flow

$$
v=\frac{u_{\star}}{k} \ln \left(y / y_{0}\right)
$$

where $y_{0}$ is a constant of integration physically equal to the value of $y$ at which the velocity (from equation $5-6$ ) is zero. For points closer to the bed than $y_{0}$, equation $5-6$ is not valid because the flow is laminar, not turbulent. In fact, equation 5-6 indicates that the velocity is negative for values of $y$ less than Yo. 0.4 .

The value of $\kappa$ is generally assumed to have a value of approximately

The discharge per unit width of channel is found by integrating the velocity given by equation $5-6$ over the range yo to $D$ :

$$
q=\int_{Y_{0}}^{D} v d y=\frac{u_{\star}}{\kappa} \int_{Y_{0}}^{D} \ln \left(\frac{y}{y_{0}}\right) d y,
$$

from which

$$
q=\frac{u_{\star} D}{k} \ln \left(\frac{D}{\text { eyo }_{0}}\right)
$$

where $e=2.718 \ldots$ (the base of natural logarithms). The average velocity in the vertical section of a channel is found by dividing $q$ by $D$

$$
\mathrm{V}=\frac{\mathrm{g}}{\mathrm{D}}=\frac{\mathrm{u}_{\star}}{\mathrm{K}} \ln \left(\frac{\mathrm{D}}{\mathrm{ey}_{\mathrm{O}}}\right)
$$

It is easily seen by comparing equations $5-6$ and $5-8$ that $v$ is equal to $\mathrm{V}$ when $\mathrm{y}$ is equal to $\mathrm{D} / \mathrm{e}$, or approximately $0.368 \mathrm{D}$. It is common practice to take single velocity observations in shallow streams at 0.6 the depth measured from the surface. This corresponds closely to $0.368 \mathrm{D}$ in equation $5-8$. 
When the channel boundary is smooth, the value of the constant yo has been found to equal $v / 9 u_{\star}$. Substituting this value into equation $5-6$ yields and converting to common logarithms

$$
v=5.75 u_{\star} \log \left(\frac{9 y u_{\star}}{v}\right)(\text { smooth surfaces) }
$$

for the velocity distribution of turbulent flow over a smooth surface where $v$ is the kinematic viscosity. The 5.75 is equal to $\ln 10 / 0.4$ and

ln $x=(\log x) \ln 10$.

When the boundary is rough, the constant yo has been found to be approximately equal to $\mathrm{k} / 30$ where $\mathrm{k}$ is the effective height of the irregularities forming the surface. Substituting this expression for yo yields the universal velocity distribution for rough boundaries,

$$
v=5.75 u_{\star} \log \left(\frac{30 y}{k}\right) \text { (rough surfaces), }
$$

where $k$ is the effective height of the irregularities forming the surface.

\section{Example:}

A velocity of $3.5 \mathrm{ft} / \mathrm{s}$ is measured at a distance of 1.6 feet above the bottom of a wide open channel that is 4.0 feet deep. The channel slope is $\theta=0.0003$ radian. Assuming a fully developed turbulent flow over a rough surface, compute the velocity at a point 0.5 foot above the bed. See figure $5-2$.

Figure 5-2.--Velocity distribution in a fully developed, rough turbulent flow.

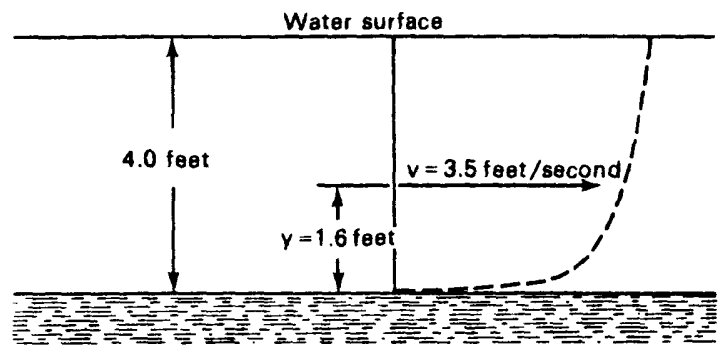

Solution:

The velocity distribution in turbulent, rough flow is given by equation 5-10. To use this equation the value of shear velocity $\left(u_{\star}\right)$ and the effective height of the bed roughness $k$ must be known. The shear velocity has been defined as $\sqrt{\tau_{0} / \rho}$ where the bed shear stress $\tau_{0}$ is given by equation $5-2$ with $y=0$ so

$$
\tau_{0}=62.4(4.0-0.0) 0.0003=0.0749 \mathrm{lb} / \mathrm{ft}^{2}
$$

and the shear velocity is

$$
u_{\star}=\sqrt{\frac{\tau_{0}}{\rho}}=\sqrt{\frac{0.0749}{1.94}}=0.1965 \mathrm{ft} / \mathrm{s} .
$$


Because the velocity is given at one depth, $k$ can be computed from equation 5-10 as follows:

$$
3.5=5.75(0.1965) \log \frac{30(1.6)}{k}
$$

giving

$$
3.098=\log \frac{48}{k}
$$

or

$$
\frac{48}{\mathrm{k}}=10^{3.098}=1,254
$$

and

$$
k=0.0383 \mathrm{ft} .
$$

With $k$ and $u_{*}$ determined, equation 5-10 can be used to compute the velocity at any depth. In particular at $y=0.5$,

$$
v=5.75(0.1965) \log \frac{30(0.5)}{0.0383}=2.93 \mathrm{ft} / \mathrm{s} .
$$

At $y=0.0383 / 30=0.00127$ foot the velocity computed from equation $5-10$ is

$$
u=5.75(0.1965) \log \left(\frac{.00127(30)}{.0383}\right)=0.0
$$

and for values of $y$ less than 0.00127 , equation 5-10 indicates a unreasonable (negative) velocity. 


\section{PROBLEMS}

1. Water flows down an incline that slopes downward 1 foot for each 1,000 feet of horizontal distance. The water depth is 0.02 foot. What is the unit discharge, the maximum velocity, the mean velocity, and the Reynolds number? (Assume laminar flow and a water temperature of $60^{\circ} \mathrm{F}$. ) 
2. A wide channel carries a uniform flow at a depth of 5.0 feet on a slope of 0.0001 . Compute the shear stress at the bed and the friction velocity.

3. The bottom for the channel in problem 2 is smooth and the water temperature is $40{ }^{\circ} \mathrm{F}$. Compute and plot a curve showing the theoretical velocity distribution. What is the mean velocity?

\begin{tabular}{l|l}
\multicolumn{1}{c|}{$y \mathrm{ft}$} & $\mathrm{v}$ \\
0.0000146 & \\
\hline 0.021 & \\
\hline 0.1 & \\
\hline 0.2 & \\
\hline 1.0 & \\
\hline 1.5 & \\
\hline 1.84 & \\
\hline 2.0 & \\
3.0 & \\
\hline 4.0 & \\
\hline 5.0 & \\
\hline
\end{tabular}


4. Show that if velocity measurements in a deep natural stream are taken at depths of $0.2 \mathrm{D}$ and $0.8 \mathrm{D}$, then averaged where $\mathrm{D}$ is the total depth, the result is nearly equivalent to substituting $0.368 \mathrm{D}$ in Equation $5-6$. 
Lesson 6 - The Energy Equation Applied to Real Fluids

The total energy of a pound of water in an open channel can be expressed as the sum of three forms of energy: the potential energy, the pressure potential, and the kinetic energy. The potential energy per pound of fluid at a section is represented as the distance of the channel bed above an arbitrary datum. Because the units of the quantity of energy (foot pound per pound of fluid) is feet, the energy term is commonly referred to as head and the potential energy per pound of fluid is called the potential head. In figure 6-1 the potential head is shown as $z_{1}$ at section 1 and $z_{2}$ at section 2 .

The pressure potential is equal to the depth of flow ( $D_{1}$ and $D_{2}$ on $f i g$. 6-1). The sum of the potential plus the pressure potential energies at a cross section is called the piezometric or hydraulic head.

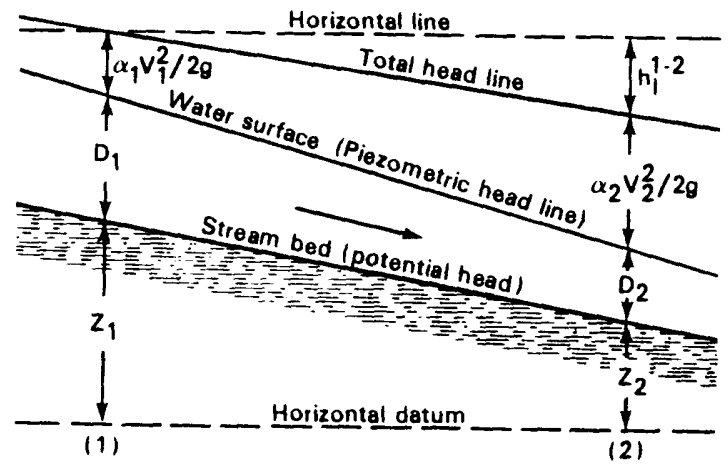

Figure 6-1.--Energy diagram for open-channel flow.

\section{Kinetic Energy}

The kinetic energy per pound of fluid is called the velocity head and is equal to $v^{2} / 2 \mathrm{~g}$ where $v$ is the velocity of the fluid. For an ideal fluid, the velocity of all parcels of fluid passing a section are the same so the velocity head for any streamline or water parcel at a particular section is the same. For a real fluid, the velocity varies over the cross section, small near the boundaries and maximum near the surface and center of the cross section. As a result, a parcel of fluid moving near the boundary has less kinetic energy (velocity head) than a parcel moving near midstream.

The average kinetic energy of all water parcels passing a section is needed to apply the energy principle at a cross section. Because the kinetic energy is proportional to the velocity squared, the average kinetic energy is always greater than kinetic energy of a parcel moving at the average velocity $V$. The average kinetic energy, per pound of fluid, can be computed from the average velocity $\mathrm{V}$, as

$$
\text { kinetic energy }=\frac{\alpha v^{2}}{2 g} \text {, }
$$

where $\alpha$ is defined as

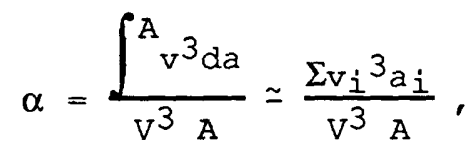


in which $A$ is the total cross-sectional area, $a_{i}$ is the area of a subsection where the velocity is $v_{i}$, and $\alpha$ is called the kinetic energy coefficient or the Coriolis coefficient (Chow, 1959, p. 27). Because the average of the cubes of positive numbers will always be greater than the cube of the average, the value of $\alpha$ will always exceed 1.0 .

The value of $\alpha$ is determined by the variations of velocity in the cross section with more uniform velocities yielding $\alpha$ closer to 1.0 . Typical values of the kinetic-energy coefficient, $\alpha$, for open channels are given by Chow (1959) as shown in table 6-1. For low velocities, the velocity head is small, so $\alpha$ is frequently not considered in practical problems dealing with regular channels.

Table 6.1--Kinetic energy correction coefficients for natural channels.

\begin{tabular}{|c|c|c|c|}
\hline \multirow[b]{2}{*}{ Channel type } & \multicolumn{3}{|c|}{ Value of $\alpha$} \\
\hline & Minimum & Average & Maximum \\
\hline $\begin{array}{l}\text { Regular channels, flumes, spillways } \\
\text { Natural streams } \\
\text { Rivers under ice cover } \\
\text { River valleys, overflooded }\end{array}$ & $\begin{array}{l}1.10 \\
1.15 \\
1.20 \\
1.50\end{array}$ & $\begin{array}{l}1.15 \\
1.30 \\
1.50 \\
1.75\end{array}$ & $\begin{array}{l}1.20 \\
1.50 \\
2.00 \\
2.00\end{array}$ \\
\hline
\end{tabular}

The average energy per pound of real fluid is computed as the sum of the piezometric head $(D+Z)$ and the velocity head as $\alpha v^{2} / 2 g$ and is called the total head, $\mathrm{H}$, where

$$
H=\frac{\alpha v^{2}}{2 g}+D+z
$$

\section{Energy Los:}

In an ideal fluid the total head at any point along the flow is constant because no energy is expended in moving parcels of water from one section to another. In a real fluid, however, energy must be expended in moving the fluid parcels along streamlines so the total head must decrease as a parcel moves downstream. The energy expended in moving the water from section 1 to section 2 in figure $6-1$ is indicated as $h l^{1-2}$ and is called the head loss.

Two modifications must be made in the Bernoulli (energy) equation derived for an ideal fluid to make it applicable to real fluids. First, the velocity head must be corrected for the nonuniform distribution of velocity by use of the $\alpha$ coefficient and, second, the energy expenditure necessary to move the water between sections must be accounted for. Therefore, the energy equation for real fluids moving from section 1 to section 2 is written as

$$
\frac{\alpha_{1} \mathrm{v}_{1}^{2}}{2 \mathrm{~g}}+\mathrm{D}_{1}+\mathrm{z}_{1}=\frac{\alpha_{2} \mathrm{~V}_{2}^{2}}{2 \mathrm{~g}}+\mathrm{D}_{2}+\mathrm{z}_{2}+\mathrm{hl}^{1-2} \text {. }
$$




\section{Example:}

Compute the discharge through the bridge constriction shown in figure 6-2 . The kinetic energy correction coefficients are 1.45 and 1.08 at sections 1 and 3 , respectively, and all cross sections are rectangular. The head loss between sections 1 and 2 is 0.25 foot due to boundary friction, and the head loss between sections 2 and 3 is 0.35 foot because of entrance losses and boundary friction. The bed at section 1 is 0.34 foot above the bed at section 3 .
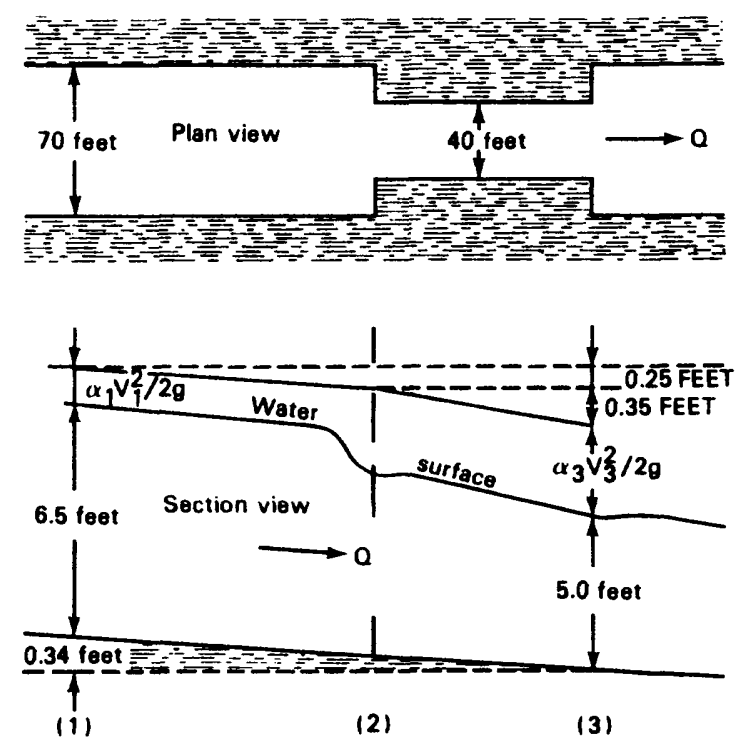

Figure 6-2.--Typical flow through a bridge constriction.

Solution:

The first step, as always, is to roughly sketch the energy line and label the known and unknown parts. As is seen in figure 6-2, the total energy expenditure by a pound of water moving from section 1 to 3 is $0.25+0.35=0.60 \mathrm{ft}$ 1b. Assuming the datum is at the channel bottom at section 3 , the potential energy at section 1 is seen to be 0.34 foot. Because both depths are given, the total piezometric heads are known at both sections leaving only the two velocity heads as unknowns. The continuity equation may be used to express each velocity head in terms of the discharge and then the energy equation will contain only one unknown, $Q$.

Apply the continuity equation

$$
\begin{aligned}
& \mathrm{V}_{1}=\frac{\mathrm{Q}}{\mathrm{A}_{1}}=\frac{\mathrm{Q}}{6.5(70)}=\frac{\mathrm{Q}}{455} \\
& \mathrm{~V}_{3}=\frac{\mathrm{Q}}{5.0(40)}=\frac{\mathrm{Q}}{200} .
\end{aligned}
$$

Then applying the energy equation

$$
\left(\frac{Q}{455}\right)^{2} \frac{1.45}{64.4}+6.5+0.34=\left(\frac{Q}{200}\right)^{2} \frac{1.08}{64.4}+5.0+0+0.25+0.35,
$$


simplifying

$$
1.24=\frac{Q^{2}}{64.4}(4.19-1.09) \times 10^{-7},
$$

giving

$$
Q^{2}=4.00 \times 10^{6} \text { or } Q=2,000 \mathrm{ft}^{3} / \mathrm{s} .
$$

The relative size of the terms in the energy equation may be evaluated by computing the size of the velocity heads. At section 1 the velocity is

$$
V_{1}=\frac{Q}{A_{1}}=4.39 \text { and } \frac{\alpha_{1} V_{1} 2}{2 g}=0.43 \mathrm{ft} \text {. }
$$

At section 3

$$
v_{3}=\frac{Q}{A_{3}}=10.0 \text { and } \frac{\alpha_{3} V_{3}{ }^{2}}{2 g}=1.68 \mathrm{ft} .
$$


1. The discharge over the spillway is $150 \mathrm{ft}^{3} / \mathrm{s}$ per foot of width.

(a) Assuming $\alpha=1.0$, compute the head loss between points $A$ and $B$ and between points $B$ and $C$.

(b) Accurately sketch and label the total head line.

(c) Calculate the temperature rise of the water passing from point A to C. (1 BTU will raise the temperature of $1 \mathrm{lb}$ of water 1 ${ }^{\circ} \mathrm{F}$ and $1 \mathrm{BTU}=778 \mathrm{ft} \mathrm{lb}$ of energy.)

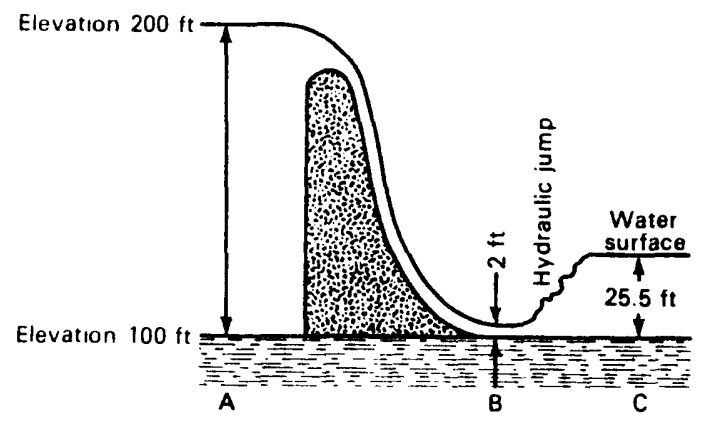


2. The measuring flume has rectangular sections throughout and the head loss between points $A$ and $B, h l$, is

$$
h_{l}=0.1 \frac{v_{b}^{2}}{2 g}
$$

(a) Compute the discharge assuming all $\alpha$ 's are 1.0 .

(b) The head loss between points $B$ and $C$ is given by the same expression as above except the coefficient, 0.1 , is different. Compute the coefficient for the expansion loss.

(c) Accurately sketch and label the total head line.

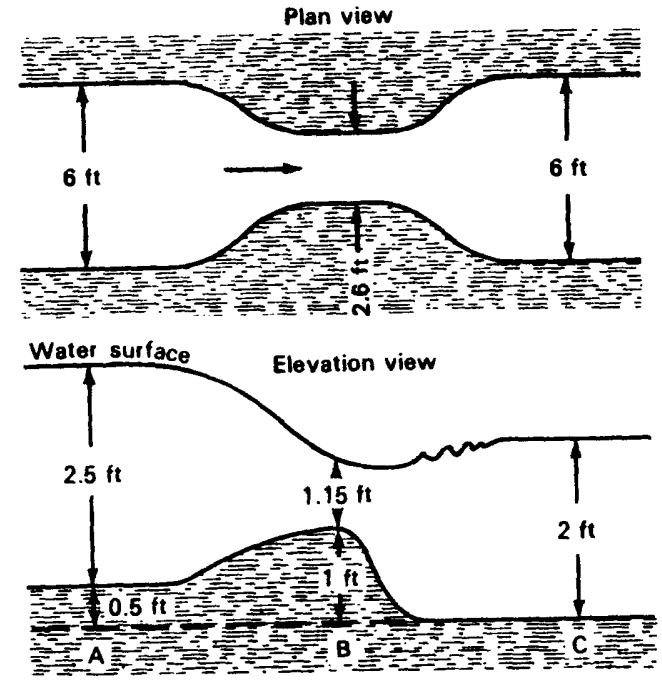


3. A flow of $2.5 \mathrm{ft}^{3} / \mathrm{s} / \mathrm{ft}$ occurs in an infinitely long open channel with a bottom slope of $10 \mathrm{ft} / \mathrm{mi}$. The head loss per unit length is known to obey the law:

$$
\mathrm{hl}_{\mathrm{l}}=\frac{\mathrm{V}^{2}}{120 \mathrm{D}}
$$

By writing the energy equation between two points 1 mile apart, assuming $\alpha=1.0$ and observing that the depth and velocity cannot increase indefinitely, compute the depth of flow. 
4. A flow of $50 \mathrm{ft}^{3} / \mathrm{s} / \mathrm{ft}$ exists in the river and the head loss per unit length is given by

$$
\mathrm{hl}=\frac{\mathrm{V}^{2} \mathrm{~L}}{120 \mathrm{D}}
$$

Compute the water depth at point A assuming $\alpha=1.0$.

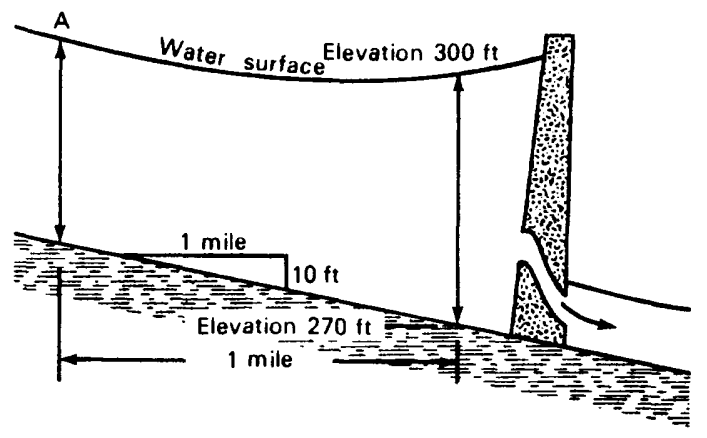


As indicated previously, real fluids differ from ideal fluids mainly because of their resistance to movement, which results in an energy loss as the water moves along the channel. Accounting for this energy loss, or head loss, is a major difficulty in hydraulic computations. Consider a flow in a prismatic channel as illustrated in figure 7-1.

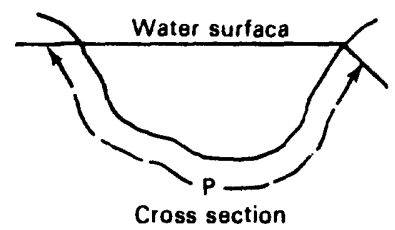

Cross section

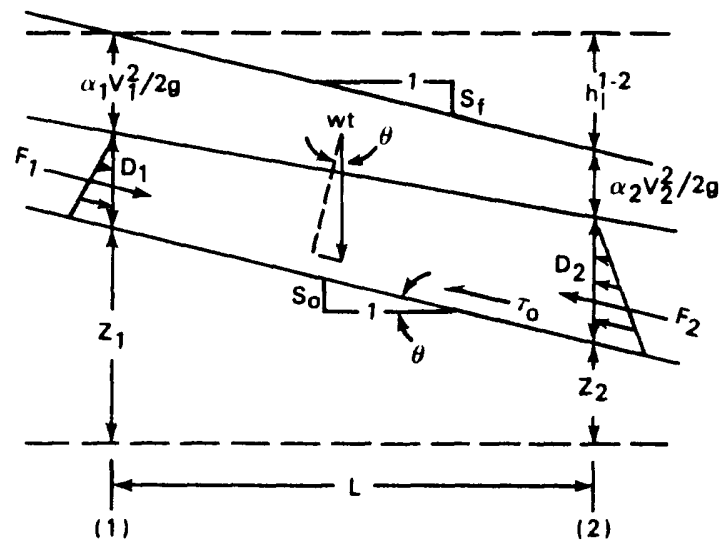

Figure 7-1.--Flow in a prismatic open channel.

Applying Newton's law to the water in this section of river, one obtains

$$
\Sigma F=M I=F_{1}+w t S_{0}-F_{2}-P L \tau_{0}
$$

in which $I=$ acceleration of the water mass, $S_{0}=$ slope of bed (nearly equal to $\sin \theta$ for small angles), $\mathrm{P}=$ perimeter of the wetted area. The components of forces parallel to the bed are summed and set equal to the mass of water in the section times its acceleration. The forces $F_{1}$ and $F_{2}$ are the forces caused by the hydrostatic pressure at the ends of the section, wt is the weight of the water.

The term PL $\tau_{0}$ quantifies the resistance of the water to movement through the channel. It is the shearing force on the control volume pictured in figure $7-1$.

The energy expended in overcoming friction when the control volume moves downstream a distance of ds may be computed as the product of the resistance force times the distance moved:

$$
\text { Energy Loss }=\text { PL } \tau_{0} \text { ds ft } 1 b .
$$

But the energy expended per pound of fluid in the control volume is the head loss occurring over the distance ds and it is computed as the energy loss divided by the weight of fluid so

$$
\mathrm{hl}=\frac{\mathrm{PL} \tau_{\mathrm{O}} \mathrm{ds}}{\gamma \mathrm{LA}}=\frac{\tau_{\mathrm{O}} \mathrm{d} s}{\rho \mathrm{g} \mathrm{R}}
$$


where the hydraulic radius, $R$, is defined as the area divided by the wetted perimeter and $\gamma=\rho g$. The slope of the total energy line must be equal to the head loss per unit length so

$$
s_{f}=\frac{h l}{d s}=\left(\frac{\tau_{0}}{\rho}\right) \frac{1}{g R}
$$

or rearranging

$$
u_{\star}=\sqrt{\frac{\tau_{0}}{\rho}}=\sqrt{g R S_{f}} .
$$

Solving equation 7-2 for the shear stress, yields

$$
\tau_{\mathrm{o}}=\rho g \mathrm{R} \mathrm{S}_{\mathrm{f}}=\gamma R \mathrm{~S}_{\mathrm{f}} .
$$

If the energy expenditure is due only to boundary friction, the slope of the total energy line will be directly related to the boundary shear as indicated in equation 7-3. This equation is valid for either uniform or nonuniform flow as well as both steady and unsteady flow.

A special case occurs for steady uniform flow. In this case, equation 7-1 can be solved directly to obtain 7-3 by noting that force $F_{1}$ is equal and opposite to $F_{2}$ and that the acceleration is zero. In this case,

$$
\tau_{0}=\frac{w t S_{O}}{P I}=\gamma R S_{O} \text {, }
$$

in which $S_{O}$ is equal to $S_{f}$ because the flow is uniform.

It has been observed in many experiments and in many different situations that boundary shear is proportional to the square of the velocity for turbulent flow. This empirical observation can be expressed as

$$
V=C^{\prime} \sqrt{\frac{\tau_{0}}{\rho}}=C^{\prime} u_{\star}=C^{\prime} \sqrt{g R S_{f}}
$$

by use of equation 7-2 because the density is constant.

As early as 1769, the French engineer Antoine Chezy ran extensive tests on an earthen canal and the Seine River and concluded that

$$
\mathrm{V}=\mathrm{c} \sqrt{\mathrm{RS}} \text {. }
$$

Chezy apparently never had a course in dimensional analysis so he did not worry about the fact that the dimensions of $\sqrt{\mathrm{RS}}$ and $\mathrm{V}$ are not the same. As a result, he left out the gravity term. On the other hand, the concept of gravitational acceleration was relatively new. At any rate, Chezy's equation today is often written as

$$
v=\frac{C}{\sqrt{g}} \sqrt{g R S}=\frac{C}{\sqrt{g}} u_{\star}
$$

in which $C$ is called the Chezy resistance coefficient. 
After Chezy's formula became generally known, there was a lot of interest in developing formulas to predict the value of $C$. The most enduring of the resulting empirical prediction formulas is usually attributed, wrongly according to Henderson (1966, p. 96), to Robert Manning. After some modification, Manning's formula became

$$
\mathrm{C}=\frac{1.49}{\mathrm{n}} \mathrm{R}^{1 / 6}
$$

in which $\mathrm{n}$ is the Manning coefficient. According to Chow (1959, p. 98), Manning developed his formula by combining seven formulas all based on Bazin's data and verified it by 170 observations. Substituting equation 7-7 into equation 7-5, the more common form of the Manning expression is

$$
V=\frac{1.49 R^{1 / 6} u_{\star}}{n \sqrt{g}}=\frac{1.49}{n} R^{2 / 3} s_{f}^{1 / 2}
$$

Combining the continuity equation with equation 7-8

$$
\mathrm{Q}=\frac{1.49}{\mathrm{n}} \mathrm{AR}^{2 / 3} \mathrm{~S}_{\mathrm{f}}^{1 / 2}
$$

Notice that Manning was not too concerned about dimensional analysis either. Equation $7-7$ has the units $\mathrm{ft} / \mathrm{s}$ on the left and $\mathrm{ft} / 3$ on the right; thus, the units of $n$ must be s/ft1/3 making $n$ to appear to be a function of time, which is not realistic. Assuming the 1.49 contains the square root of the acceleration of gravity, Manning's $n$ has the units of $\mathrm{ft}^{1 / 6}$. These units are more logical because the resistance the resistance should increase as the size of the roughness projections of the bed increase. Converting Manning's equation to the SI system, the units of $1.49 / \mathrm{n}$ is converted to $\mathrm{m}^{1 / 3} \mathrm{~s}$ from $f t^{1 / 3}$ s, so

$$
\left[\frac{1.49}{\mathrm{n}} \mathrm{ft}^{1 / 3} \mathrm{sec}\right]\left[\frac{1 \mathrm{~m}}{3.28 \mathrm{ft}}\right]^{1 / 3}=\frac{1}{\mathrm{n}} \mathrm{m}^{1 / 3} \mathrm{~s},
$$

or in the SI system

$$
\mathrm{V}=\frac{1}{\mathrm{n}} \mathrm{R}^{2 / 3} \mathrm{~s}_{\mathrm{f}}^{1 / 2}
$$

where the units of $\mathrm{V}$ are $\mathrm{m} / \mathrm{s}$ and the units of $\mathrm{R}$ are meters. The numerical value of $n$ is considered to be the same in either system of units, and the conversion is included in the formula.

The Manning (7-8) and Chezy (7-6) equations are the most common equations used in the United States to describe resistance to flow in open channels. Another expression developed for use in pipes is sometimes used in open channels. This is the Darcy-Weisbach equation which can be written for open channels as

$$
V=\sqrt{\frac{8}{f}} \sqrt{g R S_{f}}=\sqrt{\frac{8}{f}} u_{\star} .
$$

in which $f$ is called the Darcy-Weisbach friction factor or simply the friction factor. 
All three velocity equations, the Manning, the Chezy, and the Darcyweisbach, are based on the assumption that the shear stress is proportional to the velocity squared and the energy dissipation is caused entirely by boundary resistance.

\section{Example:}

Compute the depth of uniform flow in a trapezoidal channel with a 10foot bottom width and side slopes of 1 vertical to 2 horizontal when the discharge is $4,000 \mathrm{ft}^{3} / \mathrm{s}$. The channel slope is 0.002 and Manning's $\mathrm{n}=0.013$.

\section{Solution:}

Manning's equation relates discharge to area, hydraulic radius, and friction slope

$$
Q=\frac{1.49}{n} \mathrm{AR}^{2 / 3} \mathrm{~S}_{\mathrm{f}}^{1 / 2}
$$

Discharge is given and the friction slope is equal to the bed slope because the flow is uniform. The area and hydraulic radius can be expressed as functions of depth because the geometry is given. The area is computed as the area of a rectangle 10 feet wide and $D$ feet high plus two triangles 2 feet wide at the top and $D$ feet high so

$$
A=10 D+2(1 / 2 D(2 D))=10 D+2 D^{2} \text {. }
$$

The slope distance along the sides will be the square root of the sum of the squares of the two other sides of the triangle so

$$
P=10+2 \sqrt{D^{2}+(2 D)^{2}}=10+2 D \sqrt{5} .
$$

Substituting these expressions into Manning's equation gives one complex equation and one unknown that must be solved by trial. A solution may be obtained by constructing a table as shown below in which values of depth are assumed and discharges are computed from Manning's equation. The depth is selected as the value that gives a discharge of $4,000 \mathrm{ft}^{3} / \mathrm{s}$. It is also convenient to

\begin{tabular}{|c|c|c|c|c|c|}
\hline D & A & $P$ & $\mathrm{R}=\mathrm{A} / \mathrm{P}$ & $\mathrm{R}^{2 / 3}$ & 0 \\
\hline 6 & 132 & 36.83 & 3.58 & 2.34 & 1,585 \\
\hline 8 & 208 & 45.78 & 4.54 & 2.74 & 2,925 \\
\hline 9 & 252 & 50.25 & 5.02 & 2.93 & 3,784 \\
\hline 9.1 & 256.6 & 50.70 & 5.06 & 2.95 & 3,878 \\
\hline 9.2 & 261.3 & 51.14 & 5.11 & 2.97 & 3,973 \\
\hline 9.3 & 266.0 & 51.59 & 5.16 & 2.98 & 4,068 \\
\hline
\end{tabular}
simplify Manning's equation as follows

$$
Q=\frac{1.49}{0.013} \mathrm{AR}^{2 / 3} \sqrt{0.002}=5.13 \mathrm{AR}^{2 / 3} .
$$

As can be determined by interpolation, a depth of 9.23 feet will deliver 4,000 $\mathrm{ft}^{3} / \mathrm{s}$ at uniform flow in the given channel. 


\section{PROBLEMS}

1. Explain why a uniform flow cannot occur in either a frictionless or a horizontal channel.

2. The figure shown is a cross section of a canal forming a portion of the Colorado River Aqueduct that carries $1,600 \mathrm{ft}^{3} / \mathrm{s}$ of water. The canal is concrete lined with an $n$ value of 0.014 . What must be the grade of the canal in feet per mile?

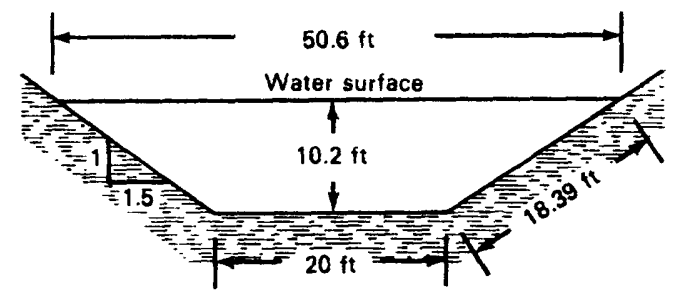

3. What would be the capacity of the canal of problem 2 if the grade were 1.2 $\mathrm{ft} / \mathrm{mi}$ ? 
4. If the flow in the canal of problem 2 was reduced to $800 \mathrm{ft}^{3} / \mathrm{s}$, what would be the depth of water?

5. Compute the value of the Chezy $C$ and the Darcy-Weisbach $f$ for the canal of problem 2 . 
6. Construct a rating curve for the indicated channel. A rating curve defines the relation of discharge to depth, or stage.

$S=0.0025$

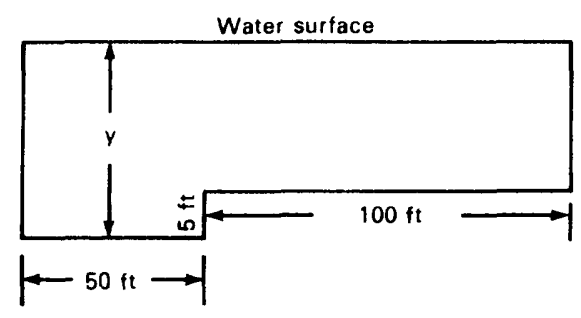

\begin{tabular}{|c|c|c|c|c|}
\hline$v$ & $A$ & & \multirow{2}{*}{$A$} & \multicolumn{2}{|c|}{$n=0.03$} \\
\hline $1 \mathrm{ft}$ & & & $V$ & $Q$ \\
\hline $5 \mathrm{ft}$ & & & & \\
\hline $5.1 \mathrm{ft}$ & & & & \\
\hline $6 \mathrm{ft}$ & & & & \\
\hline $10 \mathrm{ft}$ & & & & \\
\hline
\end{tabular}


Stream channels are rarely, if ever, uniform in nature. Contractions and expansions of stream width and depth occur in random fashion as one proceeds along the course of a stream channel. Despite these complexities, the principles of hydraulics of steady, uniform flow can usually be applied with only a few modifications to obtain satisfactory results.

The Geological Survey uses the Manning equation to determine discharges in natural channels and the conveyance of the channel section, $k$, is defined as

$$
\mathrm{K}=\frac{1.49}{\mathrm{n}} \mathrm{AR}^{2 / 3}
$$

So discharge in a channel may be expressed as

$$
\mathrm{Q}=\mathrm{VA}=\mathrm{K} \sqrt{\mathrm{S}},
$$

which is commonly referred to as the slope-conveyance method of computing discharge. The conveyance is a measure of the carrying capacity of the channel section because it is directly proportional to the discharge, $Q$. The slope $S$ should be the slope of the energy grade line, $S_{f}$; but if the flow is uniform, the slopes of the bed, water surface, and energy grade line are all equal. In field applications the flow is assumed to be steady, which is essentially true for the peak discharge of a flood wave moving down a channel.

The expression $A R^{2 / 3}$ is called the section factor for uniform flow. From equations $8-1$ and $8-2$ it is seen that the section factor may be expressed as

$$
\mathrm{AR}^{2 / 3}=\frac{\mathrm{nQ}}{1.49 \sqrt{\mathrm{S}_{\mathrm{f}}}}
$$

The right side of equation $8-3$ contains the values of $n, Q$, and $S_{f}$, but the left depends only on the geometry of the wetted area. Therefore, it shows that for a given condition of $n, Q$, and $S_{f}$, there is only one possible depth for maintaining a uniform flow. The single depth that can deliver a discharge of $Q$ given a particular $n$ value and slope is called the normal depth.

Equation 8-3 is very useful for the computation and analysis of uniform flow. When the discharge, slope, and roughness are known, equation 8-3 gives the section factor, $\mathrm{AR}^{2 / 3}$, from which the normal depth can be determined either by trial-and-error computation or by use of design charts for regular sections. If the values of $\mathrm{n}, \mathrm{S}_{\mathrm{f}}$, and $\mathrm{D}$ are given, the discharge can be computed directly from Manning's equation. 


\section{PROBLEMS}

1. Determine the conveyance, normal discharge, and velocity in channels having the following sections for normal depth $=6$ feet, $\mathrm{n}=0.015$, and $\mathrm{S}_{f}=0.0020$.

(a) A rectangular section 20-feet wide.

(b) A triangular section with a bottom angle of 60 degrees.

(c) A trapezoidal section with a bottom width of 20 feet and side slopes of 2 horizontal on 1 vertical. 
2. If the discharge in the channel of problem $1-\mathrm{C}$ is $1,000 \mathrm{ft}^{3} / \mathrm{s}$, compute the normal depth.

\begin{tabular}{|c|c|c|c|c|c|}
\hline Depth & $\frac{1.49}{n} \sqrt{s_{f}}$ & $A=20 D+2 D^{2}$ & $P=20+2 D \sqrt{5}$ & $\mathrm{R}$ & $Q$ \\
\hline & & & & & \\
\hline & & & & & \\
\hline & & & & & \\
\hline & & & & & \\
\hline & & & & & \\
\hline & & & & & \\
\hline & & & & & \\
\hline
\end{tabular}


Lesson 9 - Flow in Channel Sections with Variable Roughness

The cross section of a channel may be composed of several distinct subsections with each subsection different in roughness from the others. For example, an alluvial channel subject to seasonal floods generally consists of a main channel and two side overbank channels. The overbank channels are usually found to be rougher than the main channel; so the mean velocity in the main channel is greater than the mean velocities in the overbank sections or in the overbank flow region. For such composite sections, the routine calculation of hydraulic radius from the total area divided by the total wetted perimeter and the direct application of Manning's equation will result in large errors. This is because such calculations imply that the effect of boundary resistance is uniformly distributed throughout the flow cross section, which is clearly not the case. Furthermore, accurate estimation of the effective value of $\mathrm{n}$ is virtually impossible because $\mathrm{n}$ for each subsection may be very different.

For composite sections the Manning formula may be applied separately to each subsection in determining the mean velocity for that subsection. Then the discharges in each subsection can be computed and the total discharge is the sum of the discharges in each subsection.

This logical (but not necessarily precise) method of treating such problems is derived by assuming that the total section is composed of parallel channels separated by vertical boundaries across which there is no shear. Because the water-surface elevation is generally horizontal across a channel, the slope of each of the subsections is identical. Writing Manning's equation for each subsection and summing, it is seen that the slope can be factored out because it is constant. Factoring out the slope indicates that the total discharge is equal to the slope times the sum of the conveyances for each subsection.

The general procedure for computing the discharge in a composite section, therefore, is to compute the conveyance for each subpart of the cross section wherein the roughness and depth are approximately constant and to sum the conveyances for each subsection to compute the total conveyance of the composite section. The discharge is then equal to the composite conveyance times the square root of the slope.

Figure 9-1 illustrates river cross section with overbank flow. The question naturally arises: how nonuniform must a section be before subdivision is necessary? Probably the safest approach is to compute the discharge at a

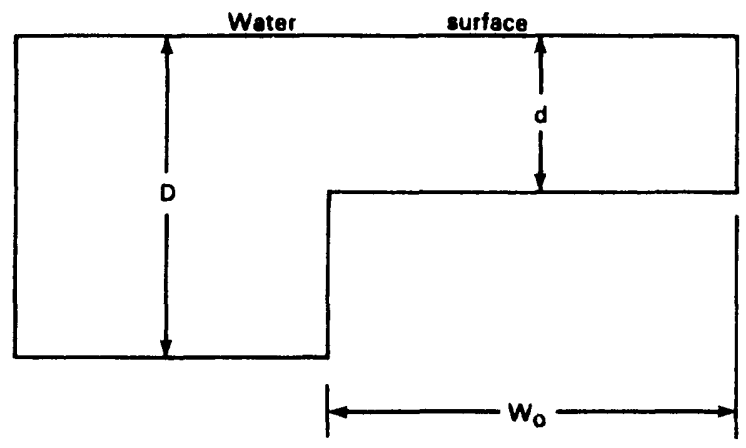

Figure 9-1.--Cross section with overbank flow. 
number of depths both by subdividing the section and by considering it as a single section. A plot of each of these discharges versus depth should indicate whether or not a subdivided section should be used. On the other hand, the Geological Survey has developed some criteria based on wide experience. In general, subdivide the cross section if

$$
\frac{\mathrm{D}}{\mathrm{d}} \geq 2
$$

or

$$
\frac{W_{0}}{d} \geq 5
$$

where the symbols are defined on figure 9-1. Davidian (1984) presents a more detailed discussion of subdivision considerations.

In applying the energy equation to a stream cross section that has been subdivided, the kinetic-energy correction coefficient is determined using

$$
\alpha=\frac{\Sigma v_{i}{ }^{3} a_{i}}{v^{3} A},
$$

in which $\mathrm{v}_{i}$ is the velocity in each subsection of area $a_{i}$ and $\mathrm{V}$ is the average velocity for the entire cross section, A. Equation 6-1 is somewhat inconvenient when working with a subdivided section because the velocity in each subsection is not normally computed. Computing the velocity as the discharge divided by the area where the discharge is computed as the conveyance times the square root of the slope (equation 8-2), one obtains

$$
v_{i}=\frac{k_{i} \sqrt{s_{f}}}{a_{i}}
$$

and

$$
V=\frac{K \sqrt{S_{f}}}{A},
$$

in which $\mathrm{K}$ is the total conveyance of the section.

Substituting equations $9-2$ and $9-3$ into equation 6-1 yields an equation for $\alpha$ in terms of the areas and conveyances of each subsection. These values are usually computed instead of the velocity; and the slope, being constant, cancels out of the equation giving

$$
\alpha=\frac{\sum_{i=1}^{N} k_{i}^{3} / a_{i}^{2}}{k^{3} / A^{2}}
$$

where $\mathrm{N}$ is the total number of subsections. Notice that $\alpha$ can be computed without knowing the stream slope. It depends only on the depth, geometry, and roughness as used to determine the conveyance. 


\section{Example:}

Given the channel information shown below, compute the kinetic energy correction coefficient, $\alpha$, and the slope for a discharge of $2,600 \mathrm{ft} / \mathrm{s}$

\begin{tabular}{|c|c|c|c|}
\hline & $\begin{array}{l}\text { Area } \\
f t^{2} \\
\end{array}$ & $\begin{array}{c}\begin{array}{c}\text { Perimeter } \\
\text { ft }\end{array} \\
\end{array}$ & $\mathrm{n}$ \\
\hline 1 Right overbank & 162.5 & 37.1 & 0.060 \\
\hline 2 Main channel & 390.0 & 45.7 & 0.035 \\
\hline $\begin{array}{c}3 \text { Left overbank } \\
\text { Total }\end{array}$ & $\begin{array}{l}108.3 \\
660.8\end{array}$ & 26.0 & 0.070 \\
\hline
\end{tabular}

Solution:

Applying equation 9-4 to a three-section channel,

$\alpha=\left(k_{1}^{3} / a_{1}^{2}+k_{2}^{3} / a_{2}{ }^{2}+k_{3}^{3} / a_{3}^{2}\right) /\left(k_{1}+k_{2}+k_{3}\right)^{3} /\left(a_{1}+a_{2}+a_{3}\right)^{2}$.

It is convenient to construct a table as follows:

$$
\begin{aligned}
& \text { R ft } \\
& \mathrm{k} E \mathrm{t}^{3 / \mathrm{s}} \\
& \mathrm{k}^{3} / \mathrm{a}^{2} \\
& 1 \text { Right } \\
& 4.38 \\
& 10,803 \\
& 0.047 \times 10^{9} \\
& 2 \text { Main } \\
& 8.53 \\
& 69,334 \\
& 2.191 \times 10^{9} \\
& 3 \text { Left } \\
& 4.17 \\
& 5,968 \\
& 0.018 \times 10^{9} \\
& \text { Total } \\
& \mathrm{K}=86,105 \\
& 2.257 \times 10^{9} \\
& \alpha=\frac{2.257 \times 10^{9}}{(86,105)^{3} /(660.8)^{2}}=\frac{2.257 \times 10^{9}}{1.462 \times 10^{9}}=1.54 \\
& Q=K \sqrt{s_{f}}=2,600 \mathrm{ft}^{3} / \mathrm{s}=86,105 \sqrt{s_{f}} \\
& s_{f}=\left(\frac{2,600}{86,105}\right)^{2}=0.000912 \mathrm{ft} / \mathrm{ft}
\end{aligned}
$$




\section{PROBLEMS}

1. A flood occurs in the channel shown below. The roughness of the main channel (B) is 0.015 , but dense bush exists on the right flood plain so that $n=0.12$, and a field of corn exists on the left so that $n=0.06$. The slope of the water surface and the bed is known to be 0.00031 . Compute the conveyance, discharge, and velocity by applying Manning's equation to the total section $(n=(0.06+0.015+0.12) / 3)$. Compute the conveyance, discharge, and velocity in each subsection. What is the flood discharge?

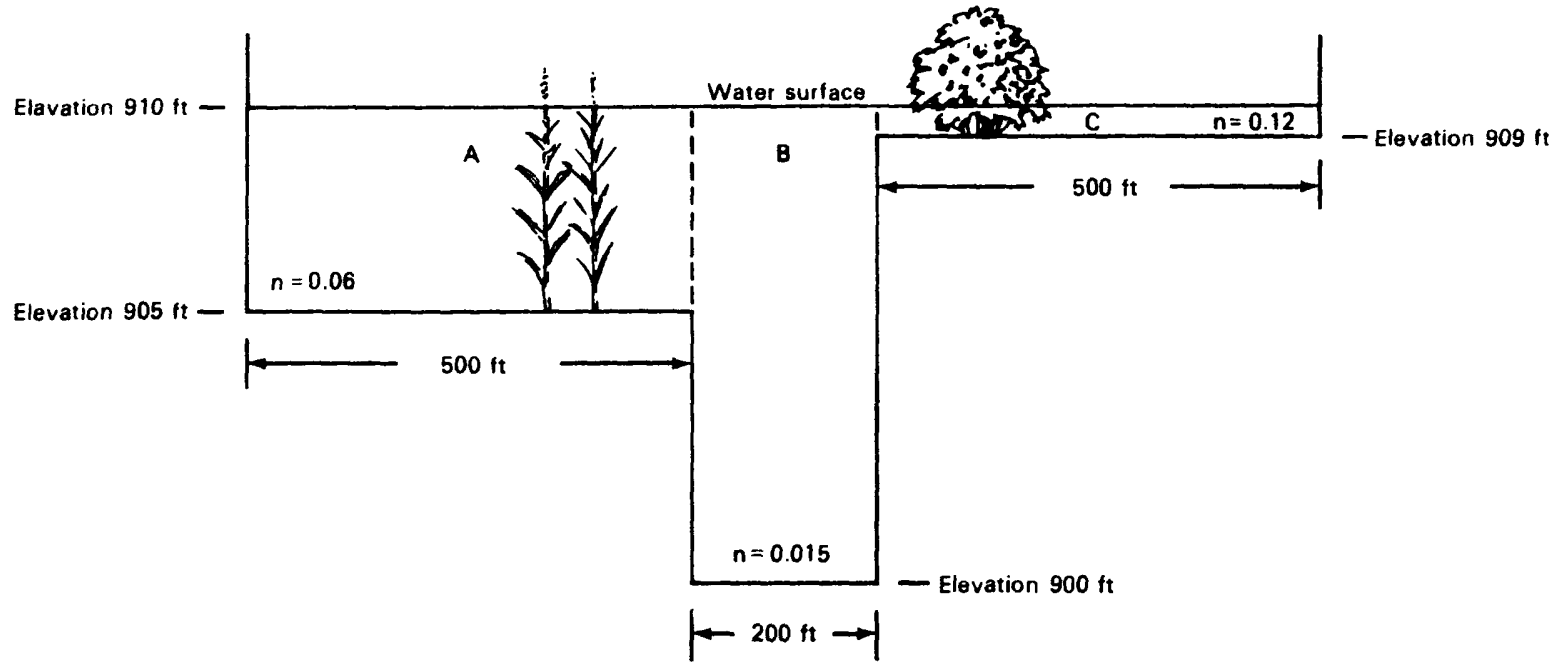


2. Compute the velocity head coefficient, $\alpha$, for the flow in problem 1 . 
Lesson 10 - The Momentum Principle

The impulse-momentum principle provides a third basic tool for the solution of fluid-flow problems. Sometimes its application leads to the solution of problems that cannot be solved by the energy and continuity principles alone, but more often all three tools must be used together.

Consider the steady flow of water, $Q$, with velocity, $V_{1}$, into a black box. For steady flow, continuity requires that a steady flow of $Q$ must exit the box with a velocity $\mathrm{V}_{2}$. While passing through the box, individual water parcels are accelerated (or decelerated) from $v_{1}$ to $v_{2}$. Newton's law says that the acceleration of a mass requires a force, that is,

$$
\overrightarrow{\mathrm{F}}=\mathrm{MI}=\mathrm{M} \frac{\Delta \overrightarrow{\mathrm{V}}}{\Delta \mathrm{t}}=\mathrm{M} \frac{\overrightarrow{\mathrm{V}}_{2}-\overrightarrow{\mathrm{V}}_{1}}{\Delta \mathrm{t}} \text {, }
$$

where $M$ is the mass being accelerated. In this case, it is the mass of water in the box

$$
M=\rho \text { Vol, }
$$

in which vol is the volume of water in the box. The value of $\Delta t$ must be the time required for a water parcel to pass through the box so

$$
\Delta t=\frac{\mathrm{Vol}}{\mathrm{Q}}
$$

combining the equations and allowing for several forces

$$
\Sigma \vec{F}=\rho \operatorname{Vol} \frac{\left(\vec{V}_{2}-\vec{V}_{1}\right) Q}{V_{01}}=\rho Q\left(\vec{V}_{2}-\vec{V}_{1}\right)
$$

Because forces and velocities are vector quantities (containing a magnitude and direction), equation $10-1$ is a vector equation. This means it can be applied in the three coordinate directions using only components of the velocities and forces. If $\mathrm{V}_{2}$ is larger than $\mathrm{v}_{1}$, the parcels are accelerated and the force on the parcels is in the positive direction.

Equation 10-1 is valid and precise, no matter what the fluid, as long as all forces, including shearing forces, are considered.

Interesting hydraulic problems seldom occur for which water is flowing into and out of a black box. On the other hand, most problems can be analyzed using the black box principle when a control surface is constructed around an element of the flow. Within the control surface or control volume, the internal pressures and shearing forces existing at the surfaces of adjacent elements cancel. Only the forces acting on the control surface must be considered.

\section{Example:}

A 2-foot by 2-foot rectangular pier is to be placed in a horizontal rectangular channel 8 -feet wide. Laboratory tests indicate that the drag force, $F_{d}$, on the pier can be computed as

$$
F_{d}=2.1 \mathrm{~A}_{\mathrm{f}} \mathrm{V}_{1}^{2}
$$


in which $A_{f}$ is the frontal area and $V_{1}$ is the approach velocity. A flow of $240 \mathrm{ft}^{3} / \mathrm{s}$ exists in the channel for which the normal depth is 5 feet. As will be shown later, normal depth will exist downstream of the pier and the flow constriction at the pier will increase the water depth upstream of the pier. Compute the depth upstream of the pier by use of the momentum principle.

Ignore the shearing force along the bed and the weight component of the water in the control volume.

Solution:

The most difficult part of momentum problems is usually selecting the control volume. In this case, the control volume is shown in figure 10-1 by dashed lines in which the line $a-b$ is along, but just above the bed, $b-c$ is just far enough downstream of the pier to be outside the very local disturbances, $c-d$ is above the pier, and $d-a$ is upstream of the pier just far enough to be outside the very localized effects of the flow around the pier. Along each boundary of the control volume, forces on the boundary due to water pressure or structural members must be accounted for. Along boundary $a-b$ three forces are present: the water pressure force $F_{p}$, the shear force of the bed on the water $F_{\tau}$, and the drag force of the pier on the water $F_{d}$. The pressure force on the bottom is balanced by the weight of the water in the control volume and acts vertically. Because we are only interested in the horizontal components of the forces, these two forces can be neglected. It is assumed that the shearing force of the bed on the water $F_{\tau}$ is small enough to be ignored. Along lines $b-c$ and $d-a$ the hydrostatic pressure force of the water on the control volume must be accounted for. No forces occur along line c-d.

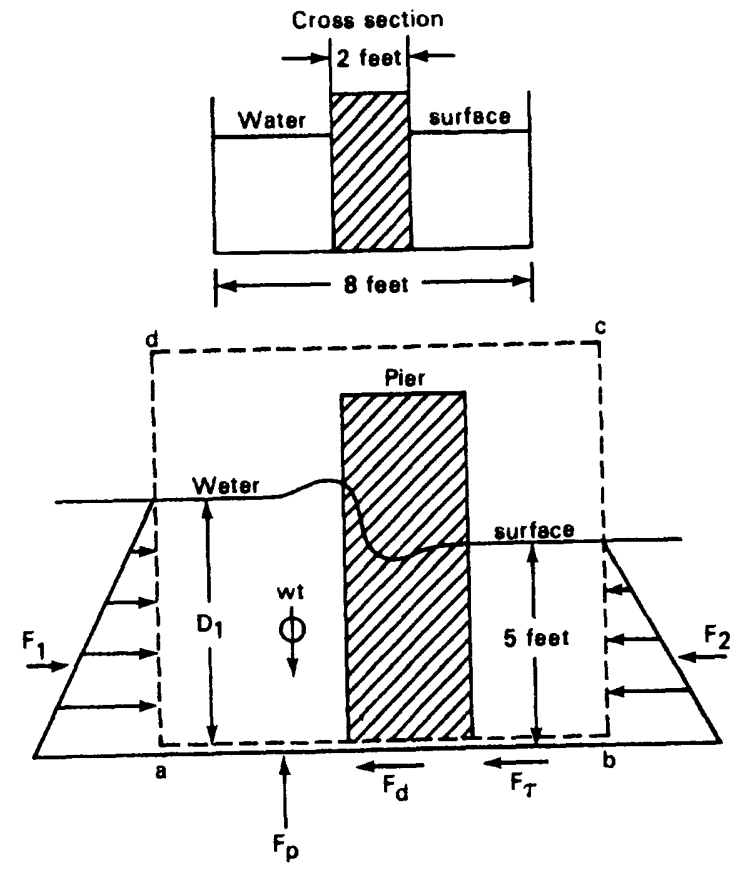

Figure 10-1.--Control volume for applying the conservation of momentum equation for the flow past a pier. 
The problem gives the value of the drag force as

$$
F_{\mathrm{d}}=2.1\left(2.0 \mathrm{D}_{1}\right) \mathrm{V}_{1}{ }^{2}=4.2 \mathrm{D}_{1} \mathrm{~V}_{1}{ }^{2},
$$

and the hydrostatic forces $F_{1}$ and $F_{2}$ are easily determined from equation 2-1 or

$$
F=\gamma \mathrm{DD}^{2} / 2
$$

for which

$$
F_{1}=62.4 \text { (8) } \frac{D_{1}^{2}}{2}=249.6 D_{1}^{2}
$$

and

$$
F_{2}=62.4 \text { (8) } \frac{5^{2}}{2}=6,240 \quad 1 \mathrm{~b} .
$$

Likewise, the velocities $V_{1}$ and $V_{2}$ are computed from the continuity equation as

$$
v_{1}=240 / 8 D_{1}=30 / D_{1}
$$

and

$$
v_{2}=240 / 8(5)=6.0 \mathrm{ft} / \mathrm{s} .
$$

The momentum equation (equation $10-1$ ) can now be applied as

$$
\Sigma F=249.6 \mathrm{D}_{1}^{2}-4.2 \mathrm{D}_{1} \mathrm{~V}_{1} 2-6,240=240(1.94)\left(6.0-30 / \mathrm{D}_{1}\right) \text {, }
$$

where forces and velocities to the right are positive. The direction of the forces is the reaction of the force on the water in the control volume. For example, the pier is assumed to push upstream on the water in the control volume.

$$
\begin{aligned}
& \text { Substituting for the value of } v_{1} \text { in terms of } D_{1} \\
& \qquad 249.6 D_{1}^{2}-3,780 / D_{1}-6,240=2,793.6-13,968 / D_{1},
\end{aligned}
$$

simplifying

$$
249.6 \mathrm{D}_{1}^{2}+10,188 / \mathrm{D}_{1}=9,033,
$$

from which the depth $D_{1}$ can be obtained by trial and error as follows:

$\begin{array}{lc}D_{1}(\mathrm{ft}) & 249.6 \mathrm{D}_{1}{ }^{2}+10,188 / \mathrm{D}_{1} \\ 5.0 & 8,277.6 \\ 5.2 & 8,708.4 \\ 5.3 & 8,933.5 \\ & >5.34 \mathrm{ft}\end{array}$




\section{PROBLEMS}

1. The passage is 4-feet wide normal to the paper. The flow rate is 120 $\mathrm{ft}^{3} / \mathrm{s}$. What will be the horizontal force exerted by the water on the structure?

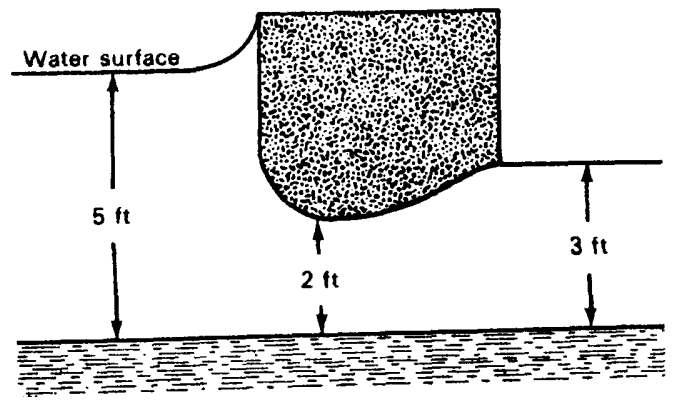

2. The flow rate passing over the thin, sharp-crested weir in a channel 1 -foot wide is 3.5 $\mathrm{ft}^{3} / \mathrm{s}$. Calculate the magnitude and direction of the force exerted by the water on the weir plate. Is the indicated downstream depth reasonable?

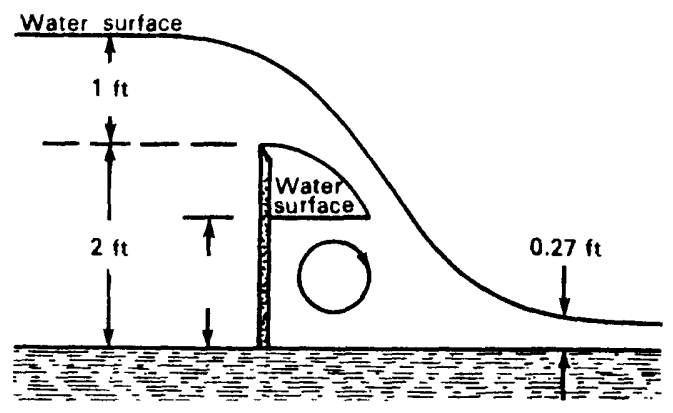


3. Water flows in a horizontal open channel at a depth of 2 feet the flow rate is $40 \mathrm{ft}^{3} / \mathrm{s} / \mathrm{ft}$ of width. Calculate the depth just downstream from the hydraulic jump and the head loss across the jump.

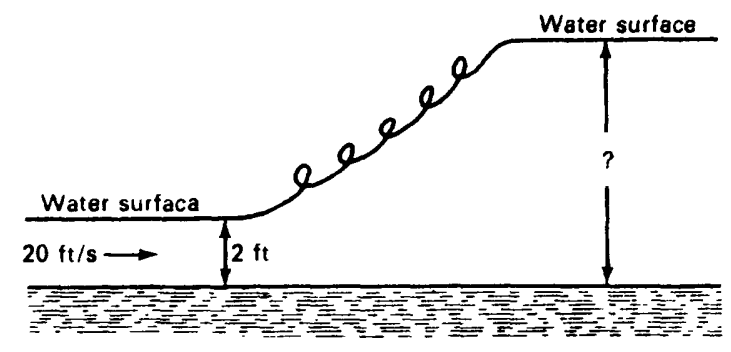


Specific energy is defined as the energy per pound of water at any section of a channel measured with respect to the channel bottom. Consider, for example, the energy of two rivers of the same size and slope but one is 10 feet above sea level and one is 5,000 feet above sea level. Both rivers have the same velocity, assuming they have equivalent roughness, even though the total energy (measured relative to sea level) of the river at 5,000 feet elevation is much greater than the river at lower elevation. Likewise, the total energy of flow in a cross section measured relative to some datum below the bottom of the channel is not a very good measure of the energy available for movement in the channel. By contrast, specific energy is determined directly from the energy equation but excluding the potential energy term, $z$, that is

$$
E=D+\frac{\alpha V^{2}}{2 g}
$$

which indicates that the specific energy is equal to the sum of the depth of water and the velocity head. Because the velocity is equal to the discharge divided by the area, equation 11-1 may also be written as

$$
E=D+\frac{\alpha Q^{2}}{2 g A^{2}}
$$

It is seen that, for a given channel section and discharge, the specific energy in a channel section is a function of the depth of flow only.

When the depth of flow is plotted against the specific energy for a given cross section and discharge, the specific energy curve (fig. 11-1) is obtained. This curve has two limbs: $C A$ and $C B$. The limb $C A$ approaches the horizontal axis asymptotically toward the right. The limb CB approaches the line $O F$ as it extends upward and to the right. The line OF passes through the origin and is at an angle of $45^{\circ}$. At any point on the specific energy curve, the ordinate represents the depth and the abscissa represents the specific energy, which is equal to the sum of the depth, D, and the velocity head, $\alpha v^{2} / 2 g$.

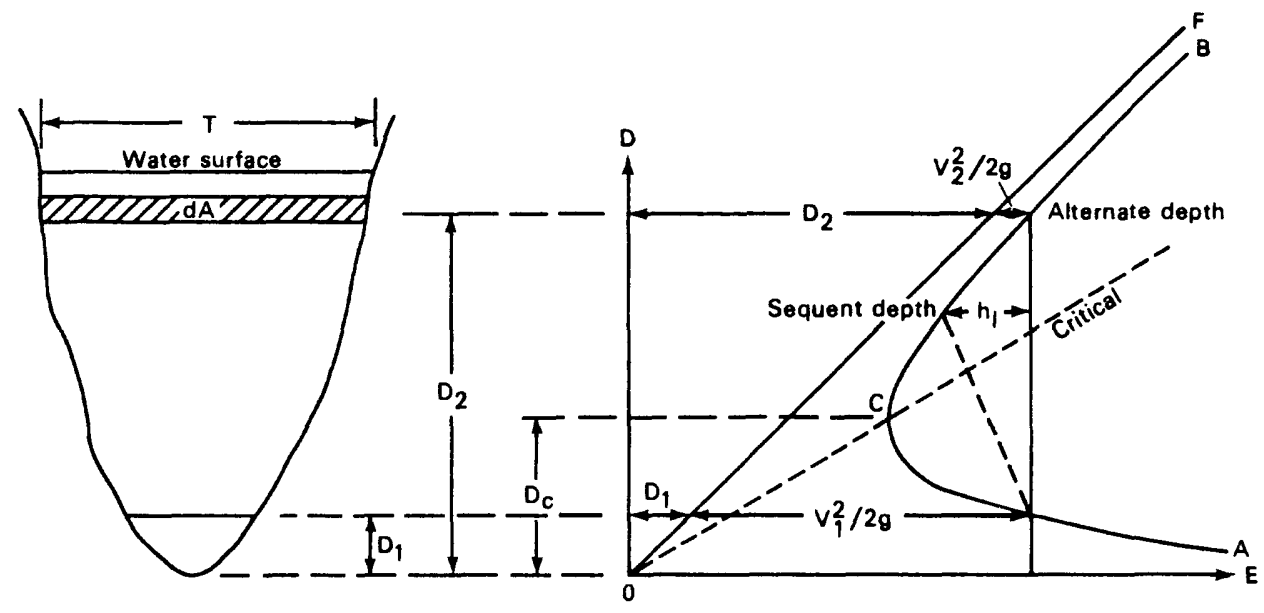

Figure 11-1.--Specific energy curve. 
The curve shows that, for any specific energy greater than the minimum value, there are two possible depths, a low depth, $D_{1}$, and a high depth, $D_{2}$. These two depths are called alternate depths. At point $C$, the specific energy is a minimum. It will be proven later that this condition of minimum specific energy corresponds to a critical state of flow. At the critical state the two alternate depths become one, which is known as the critical depth, $D_{C}$. When the depth of flow is greater than the critical depth, the velocity of flow is less than the critical velocity for the given discharge, and hence, the flow is subcritical. When the depth of flow is less than the critical depth, the flow is supercritical. Hence, $D_{1}$, is the depth of a supercritical flow, and $D_{2}$ is the depth of a subcritical flow.

The critical state of flow is defined as the state of flow at which the specific energy is a minimum for a given discharge. A theoretical criterion for critical flow may be developed from this definition as follows: depth

Assuming $\alpha$ to be 1 and differentiating equation $11-2$ with respect to

$$
\frac{d E}{d D}=1-\frac{Q^{2}}{g A^{3}} \frac{d A}{d D}=1-\frac{Q^{2}}{g A^{3}} T=1-\frac{V^{2}}{g(A / T)}=1-F_{r}^{2}
$$

because the discharge is constant and the change of area with respect to depth $(d A / d D)$ is equal to the top width. The quantity $A / T$ is recognized as the

hydraulic depth and the quantity $\frac{V}{\sqrt{g D}}$ is defined as the Froude number, $F_{r}$.

Rearranging equation $11-3$ and recognizing that the rate of change of specific energy with respect to depth is zero at critical depth, it follows that:

$$
\frac{v_{c}^{2}}{2 g}=\frac{D_{C}}{2}
$$

Thus at the critical state of flow, the velocity head is equal to one-half the hydraulic depth. Equation 11-4 may be also written as

$$
\frac{V_{C}}{\sqrt{g D_{C}}}=1=F_{r}
$$

which means the Froude number, $F_{r}$, is equal to 1 at critical flow. Finally, at critical flow, equation 11-5 may also be written as

$$
v_{c}=\sqrt{g D_{c}}
$$

which is the velocity of a small gravity wave. In other words, at critical velocity the channel velocity is precisely equal to the velocity of a small gravity wave. For stream velocities equal to or greater than critical, gravity waves do not propagate upstream.

For rectangular channels, the ratio of area to top width is constant and equal to the depth therefore, equations 11-4, 11-5, and 11-6 can all have the hydraulic depth replaced by the channel depth $\mathrm{D}_{\mathrm{C}}$. Also, in a rectangular channel, the discharge per unit width, $q$, is equal to the velocity times the depth. Therefore, equation $11-6$ could be rewritten as

$$
q=v_{c} D_{c}=\sqrt{g D_{c}^{3}} \text { or } D_{c}=\sqrt[3]{q^{2} / g} \text {. }
$$


of great significance is the fact that critical depth is dependent upon flow rate only the many other variables of open-channel flow are not relevant to the computation of this important parameter. Equation 11-7 also suggests the use of critical depth as a means of flow measurement if critical flow can be created or identified in a channel, the depth may be measured and the flow rate determined from equation 11-7. This is the basis for designing "critical depth flumes" (Kilpatrick and Schneider, 1983).

Combining equations $11-1$ and $11-6$, for a rectangular channel with $\alpha=1$, yields

$$
E=D_{C}+\frac{g D_{C}}{2 g}=\frac{3}{2} D_{C} .
$$

For sections where $\alpha$ is not unity, it is seen from equation $11-3$ that the Froude number may be defined as

$$
F_{r}=\frac{V}{\sqrt{g D / \alpha}}
$$

provided $\alpha$ is constant. If $\alpha$ varies with depth, special precautions should be taken in applying these equations.

Change of the state of flow from subcritical to supercritical or vice versa occurs frequently in open channels. Such change is manifested in a corresponding change in the depth of flow from a high stage to a low stage or vice versa. If the change takes place rapidly over a relatively short distance, the flow is rapidly varied. The hydraulic drop and the hydraulic jump are the two types of rapidly varied flow that may be described as follows:

Hydraulic drop. A rapid change of flow from a subcritical to supercritical will result in a steep depression in the water surface. Such a phenomena is generally caused by an abrupt change in the channel slope or cross section or both (see fig. 11-2). At the transitory region of the hydraulic drop, a reverse curve usually appears, connecting the water surfaces before and after the drop. The point of inflection on the reverse curve marks the approximate position of the critical depth at which the specific energy is a minimum and the flow passes from subcritical to supercritical.

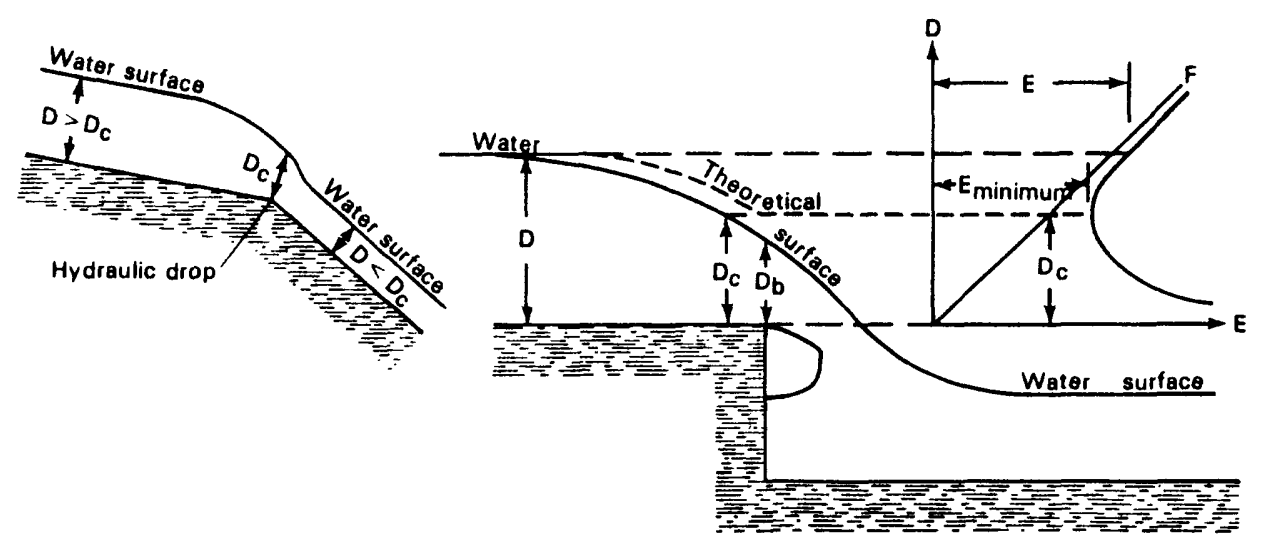

Figure 11-2.--Flow changes from subcritical and supercritical. 
The free overfall is a special case of the hydraulic drop. It occurs where the bottom of a flat channel is discontinued as in figure 11-2. There will be no reverse curve in the water surface until it strikes some surface at a lower elevation. If the specific energy at the upstream section is $\mathrm{E}$, as shown on a specific energy curve, potential energy will be converted to kinetic energy as the water approaches the brink and the total specific energy will decrease until it finally reaches a minimum energy content Emin. The specific energy curve shows that the section of minimum energy, or the critical section, should occur at the brink. The brink depth cannot be less than the critical depth because a further decrease in depth would require an increase in specific energy, which is impossible unless compensating external energy is applied. Nevertheless, it should be remembered that equations 11-7 and 11-8 are based on the assumption of parallel flow, which is only approximately applicable to rapidly varied flow. The flow at the brink is actually curvilinear, and the curvature of flow is pronounced hence, the brink depth is not exactly equal to the critical depth. The brink section is the true section of minimum energy, but it is not the critical section as computed by the principle based on parallel flow assumptions. It has been found that for small slopes the computed critical depth is about 1.4 times the brink depth, or

$$
\mathrm{D}_{\mathrm{C}}=1.4 \mathrm{Db}
$$

and that $\mathrm{D}_{\mathrm{C}}$ is located a distance of about three to four times the critical depth upstream from the brink in the channel. The actual water surface as well as the theoretical surface are shown in figure 11-2.

\section{Example:}

Flow passes through critical depth as it leaves an 8-foot square box culvert (see fig. 11-3). What is the discharge if the critical depth at the outlet is measured as 2.5 feet?

Figure 11-3.--Critical flow at the outlet of a box culvert.

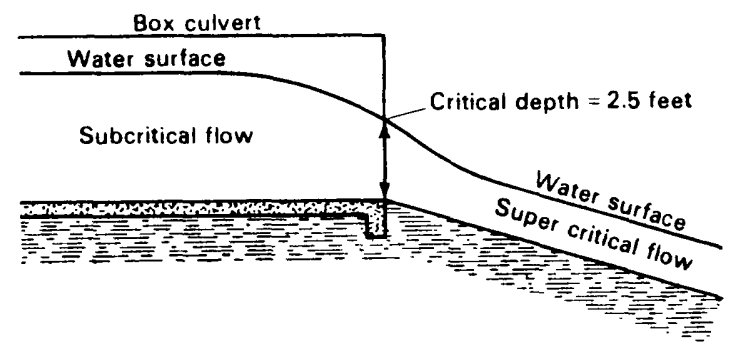

Solution:

Because critical flow occurs at the outlet, the Froude number is 1.0 or

$$
E_{r}=1.0=\frac{v_{C}}{\sqrt{g D_{C} / \alpha}}
$$

assuming $\alpha=1.0$

$$
V_{C}=\sqrt{g D_{C}}=\sqrt{32.2(2.5)}=8.97 \mathrm{ft} / \mathrm{s}
$$

so the discharge is 


$$
Q=V A=8.97(8)(2.5)=179.4 \mathrm{ft}^{3} / \mathrm{s} .
$$

Likewise equation $11-7$ could be used:

$$
Q=8 q=8 \sqrt{32.2(2.5)^{3}}=179.4 \mathrm{ft}^{3} / \mathrm{s} .
$$

Hydraulic Jump. A change of flow from supercritical to subcritical almost always occurs abruptly and the water surface has an abrupt increase in elevation. This local phenomenon is known as the hydraulic jump. It frequently occurs in a channel below a regulating sluice, at the foot of a spillway, or at the place where a steep channel slope changes to a flat slope.

Sometimes when the flow is only slightly supercritical, the jump will not rise abruptly but the flow will pass from a low stage to a high stage through a series of undulations gradually diminishing in size. Such a low jump is called an undular jump.

When the flow is highly supercritical, on the other hand, the change in depth is great and sudden and the jump is called a direct jump. The direct jump involves a large amount of energy loss through dissipation in the turbulent body of water in the jump. Therefore the energy content of the flow after the jump is much less than that before the jump and the energy equation is of little value in predicting the downstream depth.

The water depth before the jump is always less than the depth after the jump. The depth before the jump is called the initial depth and the depth after the jump is called the sequent or conjugate depth. The initial and sequent depths can be shown on the specific energy curve (fig. 11-1). They should be distinguished from the alternate depths, which are the two possible depths for the same specific energy on the specific energy curve. The initial and sequent depths are actual depths before and after the jump in which the energy loss is $\mathrm{hl}$. In other words, the specific energy, $\mathrm{E}_{1}$, at the initial depth is greater than the specific energy, $\mathrm{E}_{2}$, at the sequent depth by an amount equal to the energy loss, hl. If there were no energy losses, the initial and sequent depths would become identical with the alternate depths in a prismatic channel. 


\section{PROBLEMS}

1. $800 \mathrm{ft}^{3} / \mathrm{s}$ flow in a rectangular channel of 20-foot width having $\mathrm{n}=0.017$. Compute the specific energy at the intervals shown in the table. Plot the specific energy diagram using the same scales for $D$ and E. Determine from the diagram (a) the critical depth, (b) the minimum specific energy, (c) the specific energy when the depth is 7 feet, and (d) the depths when the specific energy is 8 feet. What type of flow exists when the depth is: (e) 2 feet, (f) 6 feet; what are the channel slopes necessary to maintain these depths? What type of slopes are these, and (g) what is the critical slope? Show graphically that $\mathrm{D}_{\mathrm{C}}=2 \mathrm{E} / 3$.

\begin{tabular}{|c|c|c|}
\hline D & $v^{2} / 2 g$ & $E$ \\
\hline 1 & & \\
\hline 1.5 & & \\
\hline 2 & & \\
\hline 3 & & \\
\hline 3.5 & & \\
\hline 4 & & \\
\hline 5 & & \\
\hline 6 & & \\
\hline 7 & & \\
\hline 8 & & \\
\hline 9 & & \\
\hline 10 & & \\
\hline
\end{tabular}


2. A hydraulic jump occurs in the channel of problem 1. The upstream depth is 2 feet. Compute the downstream depth. Label your plot of problem 1. Compute the energy loss. 
3. A uniform flow at a depth of 5 feet occurs in a long rectangular channel of 10-foot width and having a discharge of $289 \mathrm{ft}^{3} / \mathrm{s}$ : (a) Calculate the minimum height of hump that can be built on the floor of this channel to produce critical depth. What happens if the hump is larger than your computed value? lower? (b) Without the bottom hump, what is the maximum width of contracted section to produce critical depth?

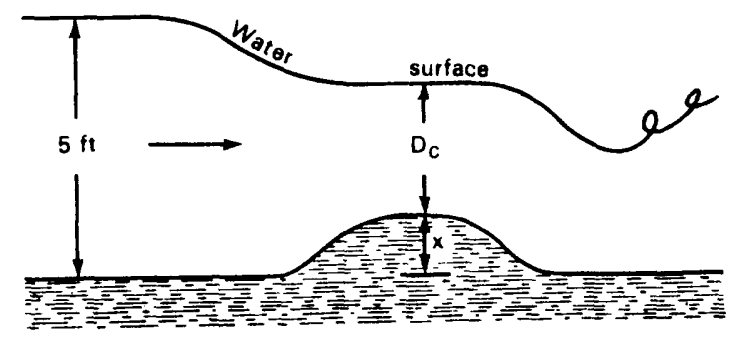


PART IV - GRADUALLY VARIED FLOW IN OPEN CHANNELS

Lesson 12 - Determination of Flow Resistance in Open Channels

Measure of Flow Resistance

The Manning equation for the mean velocity $V$ is defined as

$$
V=\frac{\phi}{n} R^{2 / 3} S^{1 / 2}
$$

where $\phi$ equals 1.0 when using metric units and 1.486 when using inch-pound units, $R$ is the hydraulic radius, $S$ is the friction slope, and $n$ is the Manning coefficient. In applying the Manning equation to open-channel flow, the greatest difficulty lies in determining the coefficient, $n$. The value of $n$ indicates not only the flow resistance caused by the sides and bottom of the channel, but also all other types of irregularities of the channel that add to flow resistance. Choosing the proper value of $n$ remains largely a matter of engineering judgment and experience. To the untrained beginner, the selection of a resistance coefficient can be no more than a guess with different individuals obtaining different results.

The following discussion will emphasize ways to estimate Manning's $n$, but this coefficient is directly related to other measures. The DarcyWeisbach equation for open conduits is written as

$$
V=\left(\frac{8 g}{f}\right)^{1 / 2} \sqrt{R S}
$$

where $f$ is the Darcy-Weisbach friction factor. The Chezy equation is written as

$$
V=C \sqrt{R S}
$$

where $C$ is the Chezy resistance coefficient.

Comparing equations $7-9,7-8$, and $7-11$, it is seen that

$$
\mathrm{n}=1.49 \mathrm{R}^{1 / 6}\left(\frac{\mathrm{f}}{8 \mathrm{~g}}\right)^{1 / 2}=\frac{1.49 \mathrm{R}^{1 / 6}}{\mathrm{C}}
$$

or that

$$
\sqrt{\frac{8}{f}}=\frac{1.49 R^{1 / 6}}{n \sqrt{g}}=\frac{C}{\sqrt{g}}
$$

It is not uncommon to think of a channel as having a single value of $n$ for all occasions. In reality, the value of Manning's $n$ is highly variable and proper selection is dependent upon a basic understanding of the factors affecting this variation. The factors having the greatest influence upon the Manning coefficient in both artificial and natural channels are listed below:

Surface roughness

Vegetation

Channel irregularity

Channel alignment

silting and scouring 
Obstructions

Size and shape of channel

Stage and discharge

Seasonal change

Suspended material and bedload

It should be noted that these factors are somewhat interdependent; hence, the influence of one factor may include the effect of another. All the above factors, however, should be studied and evaluated. They provide a basis for determining the proper value of $n$ for a given channel. As a general guide, it may be assumed that conditions tending to induce turbulence and cause retardance of the flow will increase the $\mathrm{n}$ value while those tending to reduce turbulence and retardance will decrease the $\mathrm{n}$ value.

\section{Approaches for Estimating Resistance in Stable Channels}

Stable-bed channels are those in which bedload transport is negligible and the channel boundary is rigid. Possibly the chief contributors to hydraulic resistance for these channel types is grain roughness and internal distortion of the flow (form resistance) generated by relict or remnant bed forms of previous floods.

In order to provide guidance in determining the proper value of the Manning coefficient, four general approaches will be discussed namely:

1. Understanding the factors that affect the value of $n$ and thus acquiring a basic knowledge of the problem. The Cowan procedure illustrates this approach.

2. Consulting a table of typical $n$ values for channels of various types. Abbreviated tables presented by Chow (1959) will illustrate this approach.

3. Comparative methods that are based on examining and becoming acquainted with the appearance of some typical channels whose Manning coefficients are known.

4. A number of formula are presented that compute the value of $\mathrm{n}$ from measures of the bed material size and other geometric data.

\section{Cowan's Procedure for Estimating Manning's Coefficient}

Recognizing several primary factors affecting the Manning coefficient, Cowan (1956) developed a procedure for estimating the value of $\mathrm{n}$. By this procedure, the value of $\mathrm{n}$ may be computed as

$$
\mathrm{n}=\left(\mathrm{n}_{0}+\mathrm{n}_{1}+\mathrm{n}_{2}+\mathrm{n}_{3}+\mathrm{n}_{4}\right) \mathrm{m}_{5} \text {, }
$$

where no is a basic $n$ value for a straight, uniform, smooth channel, in the natural materials involved, $\mathrm{n}_{1}$ is a value added to no to correct for the effect of surface irregularity, $\mathrm{n}_{2}$ is a value added to account for variations in shape and size of cross sections, $n_{3}$ is a modifying value for obstructions, $\mathrm{n}_{4}$ is a correction value for the retarding effect of vegetation, and $\mathrm{m}_{5}$ is a correction factor for channel meanders.

Arcement and Schneider (1984) modified and extended the Cowan method to develop procedures to aid engineers in the selection of Manning coefficients 
for channels especially with overbank flow. Their method is especially applicable for flow through heavily vegetated flood plains in which $\mathrm{n}$ values as large as 0.2 have been documented.

In the selection of the modifying values associated with the five primary factors, it is important that each factor be examined and considered independently. In considering each factor, it should be kept in mind that $n$ represents a quantitative expression of retardation of flow. A discussion and tabulated guide to the selection of modifying values for each factor is given under the following procedural steps.

Eirst step.--Selection of basic $n$ value, no. This step requires the selection of a no value for a straight uniform channel in the natural materials involved. The selection involves consideration of what may be regarded as a hypothetical channel. The conditions of straight alignment, uniform cross section, and smooth side and bottom surfaces without vegetation should be kept in mind. Thus the $\mathrm{n}_{0}$ will be visualized as varying only with the materials forming the sides and bottom of the channel. The value of $n_{0}$, for natural or excavated channels, may be selected from the table below. Where the bottom and sides of a channel are of different materials, this fact may be considered in selecting no.

\begin{tabular}{ll}
\multicolumn{1}{c}{ Character of channel } & $\mathrm{n} 0$ \\
Channels in earth & 0.02 \\
Channels cut into rock & 0.025 \\
Channels in fine gravel* & 0.024 \\
Channels in coarse gravel* & 0.028 \\
Channels in very coarse gravel* & 0.032 \\
Channels in cobbles* & 0.036 \\
& \\
* See table 12-3. &
\end{tabular}

Second step.--Selection of modifying value for surface irregularity, $n_{1}$. The selection is to be based on the degree of roughness or irregularity of the surfaces of channel sides and bottom. Consider the actual surface irregularity first, in relation to the degree of surface smoothness obtainable with the natural materials involved, and second, in relation to the depths of flow under consideration. The table below may be used as a guide to the selection.

Degree of

irregularity

Smooth

Minor

Moderate
Surfaces comparable to

The best obtainable for the materials involved.

Good dredged channels; slightly eroded or scoured side slopes of canals or drainage channels.

Fair to poor dredged channels; moderately sloughed or eroded side slopes of canals or drainage channels.

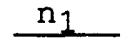

0.000

0.010 
Badly sloughed banks of natural channels; badly eroded or sloughed sides of canals or drainage channels; unshaped, jagged, and irregular surfaces of channels excavated in rock.

Third Step.--Selection of modifying value for variations in shape and size of cross sections, $n_{2}$. In considering changes in size of cross sections, judge the approximate magnitude of increase and decrease in successive cross sections as compared to the average. Changes of considerable magnitude, if they are gradual and uniform, do not cause significant turbulence. Greater turbulence is associated with alternating large and small sections where the changes are abrupt. The degree of effect of size changes may best be visualized by considering it as depending primarily on the frequency with which large and small sections alternate and, secondarily, on the magnitude of the changes.

In the case of shape variations, consider the degree to which the changes cause the greatest depth of flow to move from side to side of the channel. Shape changes causing the greatest turbulence are those for which shifts of the main flow from side to side occur in distances short enough to produce eddies and upstream current in the shallower portions of those sections. Selection of modifying values may be based on the following guide.

Character of variations in

size and shape of cross sections

Changes in size or shape occurring

Large and small sections alternating occasionally, or shape changes causing occasional shifting of main flow from side to side of the channel.

0.005

Large and small sections alternating frequently or shape changes causing frequent shifting of main flow from side to side of the channel. gradually.

$\mathrm{n}_{2}$
0.000
0.005
0.010
to
0.015

Fourth step.--Selection of modifying value for obstructions, $n_{3}$. The selection is to be based on the presence and characteristics of obstructions such as debris deposits, tree stumps, exposed tree roots, large boulders, fallen and lodged logs. Care should be taken that conditions considered in other steps are not reevaluated or double counted by this step.

In judging the relative effect of obstructions, consider: the degree to which the obstructions occupy or reduce the average cross- sectional area at various stages; the character of the obstructions (sharp-edged or angular objects induce greater turbulence than curved, smooth-surfaced objects); the position and spacing of obstructions both transversely and longitudinally in the reach under consideration. The following table may be used as a guide to the selection. 


\author{
Relative \\ effect of \\ obstructions
}

Negligible

Minor

Appreciable

Severe

\begin{tabular}{c}
$n_{3}$ \\
\hline 0.000 \\
0.010 to 0.015 \\
0.020 to 0.030 \\
0.040 to 0.060
\end{tabular}

Eifth step.--Selection of modifying value for vegetation, $n_{4}$. The retarding effect of vegetation is due primarily to the turbulence induced as the water flows around and between the limbs, stems, and foliage, and, secondarily, to the reduction in cross-sectional area. As depth and velocity increase, the force of the flowing water tends to bend the vegetation. Therefore, the ability of vegetation to cause turbulence is partly related to its resistance to bending. Furthermore, the amount and character of foliage is important (that is, growing season versus dormant season). In judging the retarding effect of vegetation, critical consideration should be given to the following: the height in relation to the depth of flow; the capacity to resist bending; the degree to which the cross section is occupied or blocked out; the transverse and longitudinal distribution of vegetation and the different types; and densities and heights in the reach under consideration. The following table may be used as a guide in the selection.

\section{Vegetation and flow conditions}

Dense growths of flexible turf grasses or weeds (for example, Bermuda and blue grasses) where the average depth of flow is two to three times the height of vegetation.

Supple seedling tree switches such as willow, cottonwood, or salt cedar where the average depth of flow is three to four times the height of the vegetation.
Degree of effect

Low $\mathrm{n}_{4}$

0.005 to 0.010

Turf grasses where the average flow is

Moderate

0.010 to 0.025

one to two times the height of the

vegetation.

Stemmy grasses, weeds, or tree seedlings

with moderate cover where the average

depth of flow is two to three times the

height of the vegetation.

Brushy growths, moderately dense, similar to willows 1 to 2 years old, dormant season, along side slopes of channel with no significant vegetation along the channel bottom, where the hydraulic radius is greater than 2 feet. 


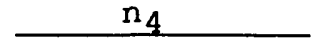

Turf grasses where the average depth of flow is about equal to the height of the vegetation.

Dormant season, willow or cottonwood trees 8 to 10 years old, intergrown with some weeds and brush, none of the vegetation in foliage, where the hydraulic radius is greater than 2 feet.

Growing season, bushy willows about 1 year old intergrown with some weeds in full foliage along side slopes, no significant vegetation along channel bottom, where the hydraulic radius is greater than 2 feet.

Turf grasses where the average depth of flow is less than one-half the

height of the vegetation.

Growing season, bushy willows about 1

year old, intergrown with weeds in

full foliage along side slopes; dense

growth of cattails along channel

bottom; any value of hydraulic radius up to 10 or 15 feet.

Growing season, trees intergrown with weeds and brush, all in full foliage; any value of hydraulic radius up to 10 or 15 feet.

Sixth step.--Determination of the modifying value for meandering of channel, m5. The modifying value for meandering may be estimated in the following way. Let

$l_{S}=$ the straight length of the reach under consideration, and

$l_{m}=$ the meander length of the channel in the reach.

Compute the modifying value $\mathrm{m}_{5}$ in accordance with the following table.

Ratio $l_{m} / l_{s} \quad$ Degree of meandering $\quad m_{5}$

$\begin{array}{lll}1.0 \text { to } 1.2 & \text { Minor } & 1.00 \\ 1.2 \text { to } 1.5 & \text { Appreciable } & 1.15 \\ 1.5 \text { and greater } & \text { Severe } & 1.30\end{array}$

Where lengths for computing the ratio $l_{m} / l_{s}$ are not readily obtainable, the degree of meandering can usually be judged reasonably well by field inspection. 
Seventh step.--Computation of $n$ for the reach. The value of $n$ for the reach under consideration is obtained by adding the values determined in steps 1 through 5 and multiplying this total by the modifying value found in step 6.

This method was developed from a study of 40 to 50 small to moderate sized channels. Therefore, the method is questionable when applied to large channels where the hydraulic radii exceed, say, 15 feet. In the case of flood plains, the estimate of $n$ would be based on all factors except meandering (that is, $m_{5}$ would be taken equal to 1.00 ).

Tables of Manning's $n$

The following table 12-1 contains parts of a table presented by Chow (1959) and gives a list of $n$ values for various types of channels. For each type of channel, the minimum, normal, and maximum values of $n$ typically observed are shown. The normal values for artificial channels given in the table are recommended only for well-maintained channels. This table was compiled from a variety of sources and will be found useful as a guide to the quick selection of the $n$ value to be used in a given problem. The tabular approach is somewhat like the Cowan approach in that the Manning coefficient is selected based on a written description of boundary texture and form. 
Table 12-1.--Values of the Manning resistance coefficient

(from Chow, 1959)

Type of channel and description

Minimum Normal

Maximum

A. Closed conduits flowing partly full

A-1. Metal

A-2. Nonmetal

a. Brass, smooth

b. Steel

1. Lockbar and welded

2. Riveted and spiral

c. Cast iron

1. Coated

2. Uncoated

d. Corrugated metal

1. Subdrain

2. Storm drain

a. Iucite

b. Glass

c. Cement

1. Neat, surface

2. Mortar

d. Concrete

1. Culvert, straight, and free of debris

0.009

.010

.013

.010

.011

.017

.021

.008

.009

.010

.011

.010

.011

connections, and some debris

3. Sewer with manholes, inlet, etc., straight

4. Unfinished, rough wood form

e. Wood

1. Stave

2. Laminated, treated

f. Clay

1. Common drainage tile

2. Vitrified sewer with manholes, inlet, etc.

g. Glazed brickwork mortar

h. Sanitary sewers coated with sewage slimes, with bends and connections

i. Paved invert, sewer, smooth bottom

j. Rubble masonry, cemented
.013

.015

.010

.015

.011

.013

.011

.012

.012

.013

.016

.016

.018

.015

.017

.017

.020

.012

.014

.020

.017

.015

.017

.015

.017

.015

.020

.019

.030
0.010

0.013

.014

.017

.014

.016

.021

.030

.010

.013

.013

.015

.013

.011

.013

.014 
Table 12-1.--Values of the Manning resistance coefficient (from Chow, 1959)--continued

Type of channel and description

Minimum

Norma 1

Maximum

B. Lined or built-up channels

B-1. Metal

a. Unpainted smooth steel

surface

.011

.012

.014

b. Corrugated

.021

.025

.030

B-2. Nonmetal

a. Concrete

1. Finished, with gravel on bottom

.015

.017

.019

.020

2. Gunite, good section

.016

.022

.023

3. Gunite, wavy section

.018

.020

4. On good excavated rock

.017

.025

5. On irregular excavated rock

.022

.027

b. Concrete bottom float

finished with sides of

1. Dressed stone in mortar

2. Dry rubble or riprap

.015

.020

.017

.020

c. Gravel bottom with sides of

1. Formed concrete

.017

.030

.035

2. Dry rubble or riprap

.023

.020

.025

d. Asphalt

1. Smooth

.033

.036

2. Rough

e. Vegetal lining

.013

.013

.016

.016

.030

.500

C. Excavated or dredged

a. Earth, straight and uniform

1. Clean, recently

$$
\text { completed }
$$

.016

2. With short grass, few weeds

.022

.018

.020

b. Earth, winding and sluggish

1. No vegetation

.023

.027

.033

2. Dense weeds or aquatic plants in deep channels

3. Cobble bottom and clean sides

.025

.030

.030

.035

.040

.030

.040

.050

c. Dragline-excavated or

dredged

1. No vegetation

2. Light brush on banks

.025

.028

.033

.035

.050

.060

d. Rock cuts

1. Smooth and uniform

.025

.035

.040

2. Jagged and irregular

.035

.040

.050

e. Channels not maintained,

weeds and brush uncut

1. Dense weeds, high as

flow depth

.050

.080

.120

2. Clean bottom, brush on sides

.040

.050

.080

3. Dense brush, high stage

.080

.100

.140 
Table 12-1.--Values of the Manning resistance coefficient

(from Chow, 1959)--continued

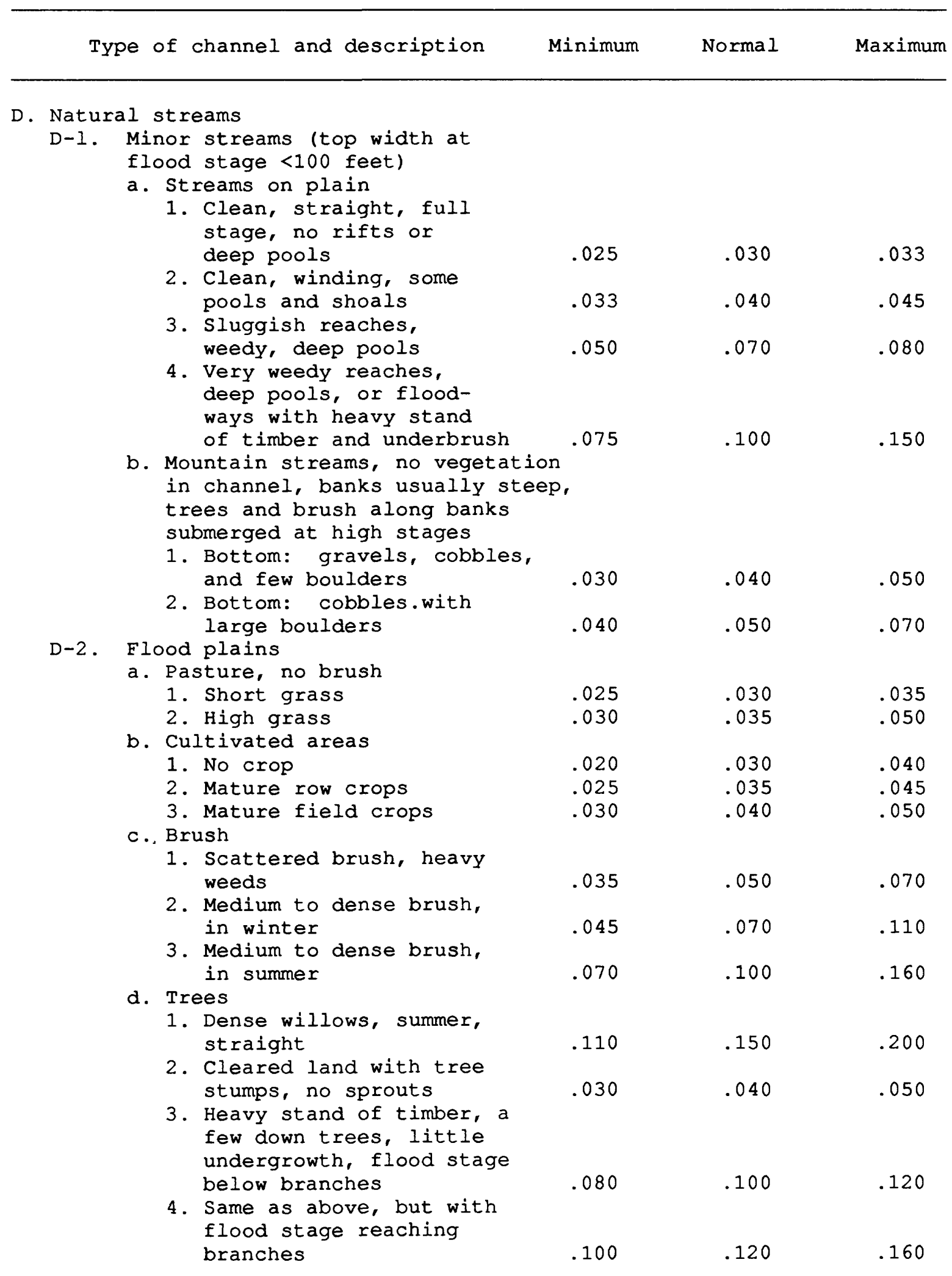


Table 12-1.--Values of the Manning resistance coefficient

(from Chow, 1959)--continued

Type of channel and description Minimum Normal Maximum

D-3. Major streams (top width at flood

stage $>100$ feet). The $n$ value is

less than that for minor streams

of similar description, because

banks offer less effective

resistance

a. Regular section with no

boulders or brush

b. Irregular and rough section

$.025 \quad-0 \quad .060$

$.035 \quad .100$

\section{Comparative Methods}

Photographs of a number of typical channels, accompanied by descriptions of the channel conditions and the corresponding $n$ values, are contained in a report by Barnes (1967). These photographs represent a wide range of channel conditions and facilitate selection of an $n$ value for a given problem.

Sites used in Barnes (1967) were selected for study after a major flood had occurred in a given region. Each site met the following criteria:

1. the peak discharge of the flood was measured by the current-meter method or determined from a well-defined stage-discharge relation;

2. good high-water marks were available to define the water-surface profile at the time of the peak;

3. a fairly uniform reach of channel was available near the gage; and

4. the flood discharge was within the channel banks--that is, extensive flow in flood plains did not exist.

A transit stadia survey of each reach was completed shortly after the flood. The necessary information was obtained in this survey to plot accurately to a common datum the water-surface profile as determined by high-water marks, a plan view of the reach, and cross sections at intervals along the reach.

Photographs of the reach were taken during the time of the survey. The photographs shown in Barnes (1967) thus represent conditions in the reach immediately after the flood. 
A size description of the bed material at some of the sites is included in the reach description. The bed samples were, in general, taken several years after the flood for which the Manning coefficient was determined and, therefore, may not be representative of the bed material at the time of the peak. Frequency distributions of the bed material size were determined by sieve analysis where the medium size of the material was less than $50 \mathrm{~mm}$ and, where the material was too large to sieve, by measuring the intermediate axis of particles selected at random from the bed surface.

\section{Equations for Manning's n Based on Measures of Roughness}

A number of equations have been developed for predicting Manning's $n$ based on a measure of the bed particle size, usually in the form of a representative particle diameter, $d_{p}$, which is larger than $p$ percent of the bed material. This measure of roughness is typically related to $n$ either directly or as a dimensionless ratio of roughness, $\mathrm{R} / \mathrm{d}_{\mathrm{p}}$, which is often called the relative roughness (or relative smoothness). These equations are generally applicable to gravel or cobble bed streams, and only a few of these equations are presented in table 12-2. Table 12-3 contains reference sizes for bed material of various descriptions. The table is not complete in that only the major size classes are shown.

\section{Special Considerations in Mobile-Bed Channels}

Mobile-bed channels are those in which the bedload transport rate is significant and in which the channel boundary deforms. Two types of mobilebed channels will be considered those whose beds are composed of sand and those whose beds are composed of coarser material (that is, gravel, cobbles, and boulders).

\section{Gravel-Bed Channels}

In contrast to sand-bed channels, which can have a variety of bed forms, apparently only dunes or bars can develop under subcritical flows on the channel bottoms of gravel-bed rivers. When the channel boundary is stable, the resistance to fully turbulent flow in straight, regular reaches of coarse gravel-bed rivers have been found to be largely dependent on the relative roughness. Equations listed in table 12-2 are generally applicable. For channels with active bedload transport where the boundary is mobile and bed forms develop, flow resistance was found by Griffiths (1981) to depend on a mobility parameter as

$$
\mathrm{n}=0.042\left(\frac{\sqrt{9 d_{50}}}{\mathrm{v}}\right)^{0.34}
$$

where mobile boundary conditions were assumed to occur if

$$
\text { d } 50<11 \mathrm{RS} \text {. }
$$

Notice that as the velocity increases, and more material is moving, the resistance to flow decreases. This relation of decreasing resistance with increased bed-material movement is often observed. The rolling bed-material particles act much as marbles on the floor reducing the resistance between the flowing water and the stationary bed. 
Table 12-2.--Equations for resistance based on bed-material size

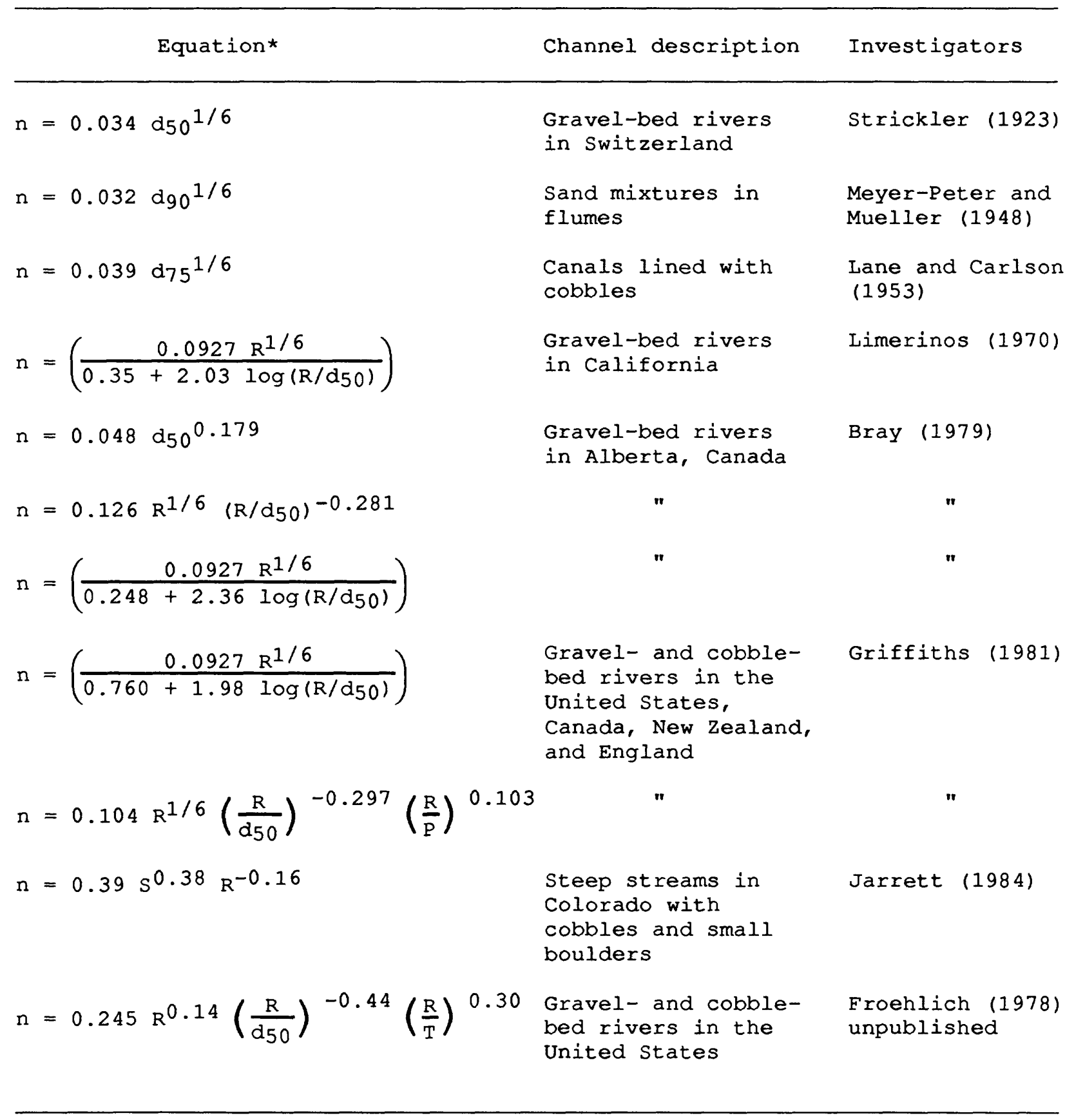

*All length dimensions are in feet 
Table 12-3.--Sediment grade scale (Guy, 1969)

\begin{tabular}{|c|c|c|}
\hline $\begin{array}{l}\text { Sediment in } \\
\text { millimeters }\end{array}$ & $\begin{array}{l}\text { Size in } \\
\text { inches }\end{array}$ & Class \\
\hline $\begin{array}{l}>256 \\
256-128 \\
128-64 \\
32-16 \\
8-4 \\
1-0.50 \\
0.50-0.25 \\
0.25-0.125 \\
0.062-0.031 \\
0.016-0.008 \\
0.004-0.0020 \\
0.0010-0.0005\end{array}$ & $\begin{array}{l}40-20 \\
10-5 \\
5-2.5 \\
1.3-0.6 \\
0.3-0.16 \\
-0-1 \\
- \\
- \\
- \\
- \\
- \\
-\end{array}$ & $\begin{array}{l}\text { Boulders } \\
\text { Large cobbles } \\
\text { Small cobbles } \\
\text { Coarse gravel } \\
\text { Fine gravel } \\
\text { Coarse sand } \\
\text { Medium sand } \\
\text { Fine sand } \\
\text { Coarse silt } \\
\text { Fine silt } \\
\text { Coarse clay } \\
\text { Fine clay }\end{array}$ \\
\hline
\end{tabular}

\section{Sand-Bed Channels}

Resistance to flow in sand-bed channels varies between wide limits because the configuration of the channel bed is a function of the flow itself. Estimation of flow resistance in sand-bed channels is a complex subject that cannot be treated adequately here. For further detail the reader is referred to Simons and Senturk (1977). Flume experiments and field observations have shown that bed forms can be classified on the basis of a lower, a transition, or an upper flow regime. The bed forms that occur are ripples, ripples on dunes, dunes, washed-out dunes, plane or flat bed, antidunes, and chutes and pools. These specific bed forms and the regime classification, as indicated in figure 12-1, are associated with a specific mode of sediment transport and a specific range of resistance to flow. An example of the effect of bedmaterial size and Froude number on the bed form and Manning's $n$ is given in figure 12-2. In an 8-foot wide laboratory sand channel, it is noted that ripples generally cause Manning's $n$ to range from 0.020 to 0.028 ; dunes, from 0.020 to 0.033 ; washed-out dunes, from 0.013 to 0.025 ; antidunes, from 0.014 to 0.020 ; and chute and pools from 0.020 to 0.026 (Guy, 1970).

It is important to note that different bed forms and flow regimes may occur side by side in a stream cross section or one after another in time. The relatively large resistance to flow in the lower regime results mostly from form roughness whereas most of the resistance in the upper regime results from grain roughness and wave formation and subsidence. Resistance to flow for a plane bed is less when the bed material is moving than when the bed material is not moving. 

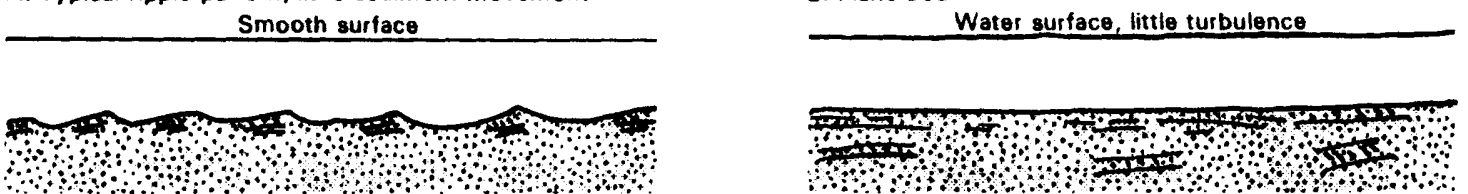

\section{B. Dunes and superposed ripples}
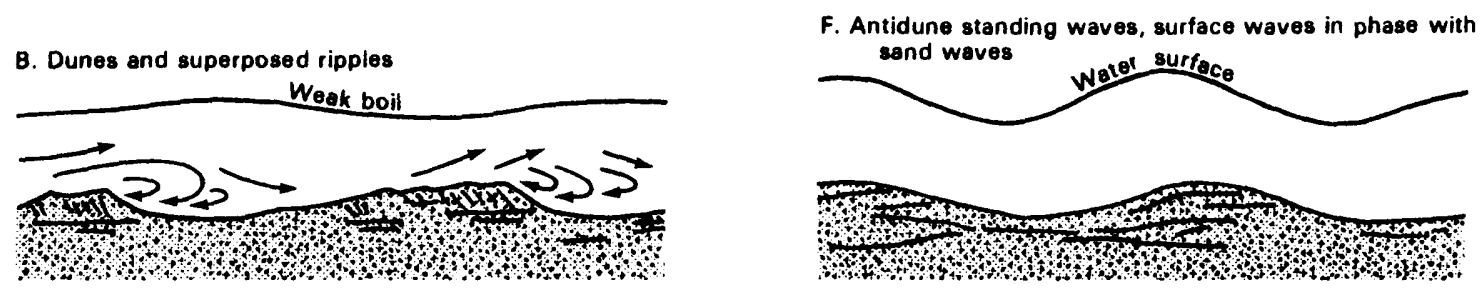

C. Dunes, surface waves out of phase with sand waves
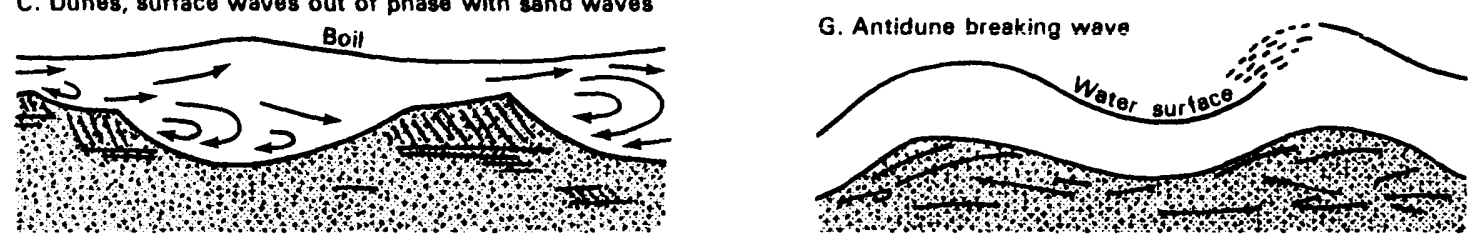

D. Washed-out dunes or transition Water surface
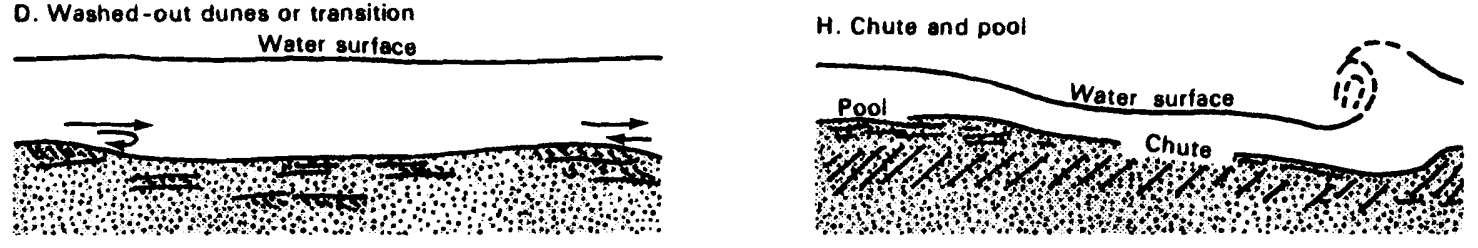

Figure 12-1.--Eight types of roughness found in sand-bed channels. Types A through $C$ are representative of the lower flow regime where the Froude number is usually $<0.4$, $E$ through $H$ are representative of the upper flow regime where the Froude number is usually $>0.7$, and $D$ represents the transition regime. Modified from Simons and Richardson (1966, p. J5). 


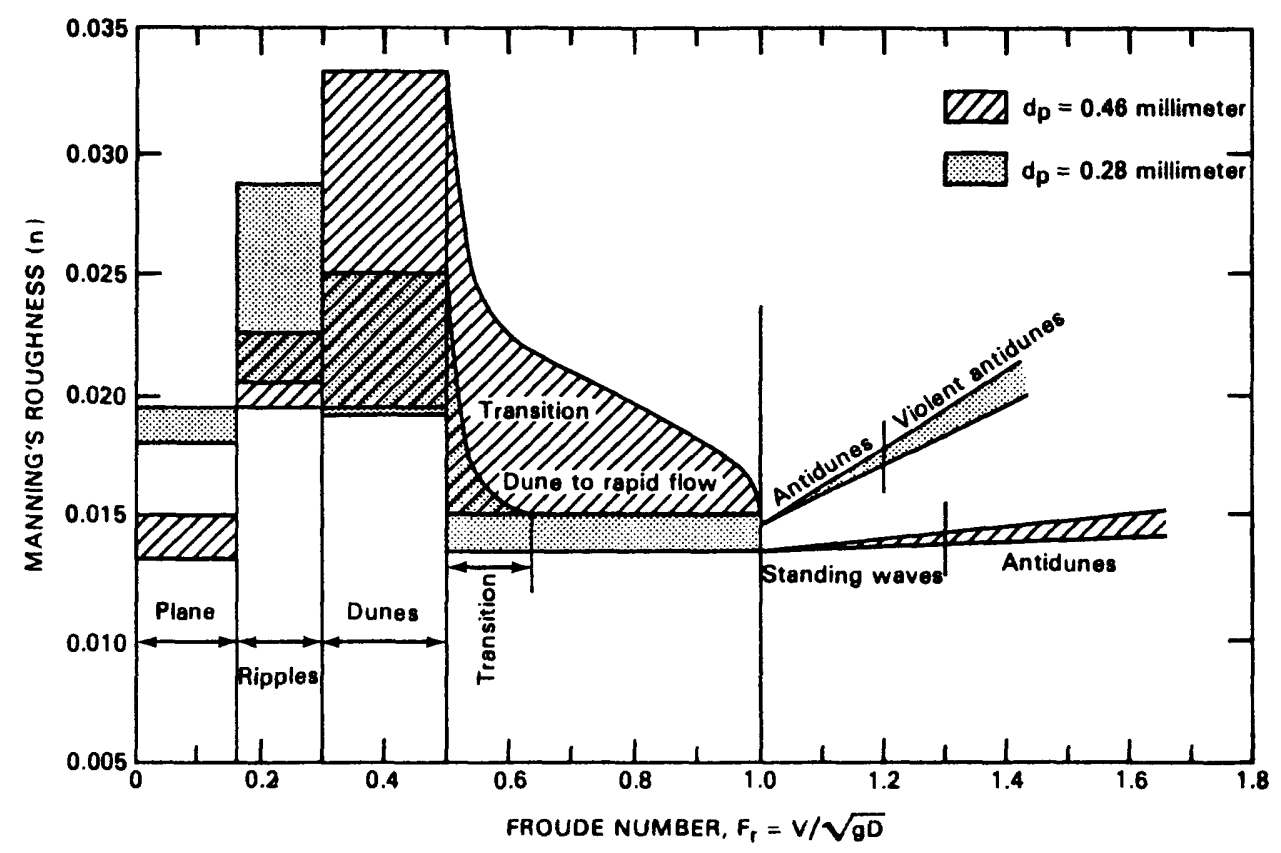

Figure 12-2.--Effect of size of bed material and Froude number on the bed form and Manning's $n$ for a range of flow conditions with sands of $0.28-$ and 0.45-millimeter median diameter in an 8-foot wide flume. Modified from Guy (1970).

The Manning coefficient for a plane bed with motion depends primarily on the size of the bed material. Values of Manning's $n$ for plane bed flow may be selected from the following table, which shows the relation between median grain size ( $\left.d_{50}\right)$ and the Manning $n$.

$\begin{array}{cc}\text { Median Grain Size } & \text { Manning's n } \\ 0.2 \mathrm{~mm} & 0.012 \\ .4 & .020 \\ .6 & .023 \\ .8 & .025 \\ 1.0 & .026\end{array}$

After the discharge and velocity are computed from the Manning equation, it must be shown that the bed configuration is actually in the assumed flow regime. This can be done by using figure 12-3 below, which relates unit stream power to the type of flow. In the lower flow regime the form resistance of the dunes greatly increases the value of $n$. 


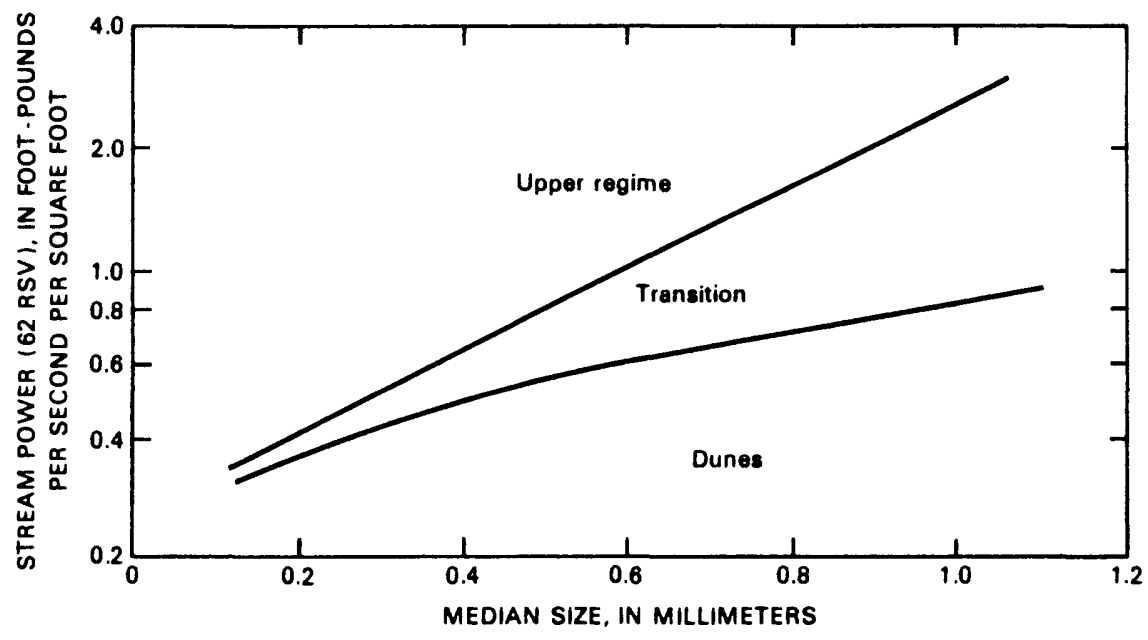

Figure 12-3.--Relation of stream power and median grain size to the bed form. 


\section{PROBLEMS}

1. At a gaging station on the Mississippi River near New Orleans, a discharge of $1,200,000 \mathrm{ft}^{3} / \mathrm{s}$ was measured when the cross-sectional area was $202,000 \mathrm{ft}^{2}$, the wetted perimeter was 2,700 feet, and the slope was 0.168 $\mathrm{ft} / \mathrm{mi}$. Assuming uniform flow, compute the Chezy discharge coefficient, $c$, the Manning, $n$, and the friction factor, $f$.

2. Use the Cowan method to estimate the Manning $\mathrm{n}$ for the channel reach described below.

Reach description: Straight, approximately 660 feet long. Cross section has very little variation in shape; variation in size is moderate, but changes are gradual. Side slopes are fairly regular, but the channel bottom is uneven and irregular. Soils in the channel consist of a yellowish-gray clay along the bottom and light-gray silty clay loam along the banks. Banks are covered with a heavy growth of poplar trees 2 to 3 inches in diameter, large willows, and climbing vines during the summer growing season. There is a thick growth of water weed on the channel bottom. At bankfull stage, average depth and top width are about 8.5 and 40 feet, respectively.

3. Using three appropriate equations, compute the Manning $n$ for the following two channels.

\section{Channel A}

Area (ft2)

Top width (ft)

Wetted perimeter (ft)

d50 (ft)
6,976
429
435

0.44

\section{Channel B}

599

115

117

0.31 
Uniform open-channel flow is a limiting condition that is approached asymptotically but never attained. That is, any local nonuniformity of the channel boundary will produce a nonuniformity of the flow that--though continuously decreasing in magnitude--theoretically extends extremely far upstream or downstream.

Assume, for example, that a canal of constant cross section and bottom slope is designed to carry a discharge, Q, at a normal depth, $D_{0}$, which is greater than the critical depth, $D_{C}$, as indicated by the dashed line in figure 13-1. If the sluice gate in the channel is partly closed, the depth will increase directly upstream until the head on the gate corresponds to the discharge, $Q$. Then, however, the decrease in velocity resulting from the increase in depth causes the rate of energy dissipation to be less than that for normal uniform flow conditions. As a result, the free surface and the total head lines must have slopes that are less than that of the bed. Because the total head line has a slope that is flatter than the bed slope, the specific energy increases in the downstream direction. For subcritical flow, an increase in specific energy results in an increase in depth as shown on figure 13-1. Because the degree of departure from uniformity decreases as the depth approaches normal depth, the resulting lines of total head and surface elevation approach their limits asymptotically far upstream as shown on the figure. The vertical scale on figure $13-1$ is greatly exaggerated, backwater effects commonly extend many miles upstream in natural channels. Nonuniformity of this type is called gradually varied flow to distinguish it from rapidly varied flow (for example, in the immediate vicinity of a hydraulic jump).

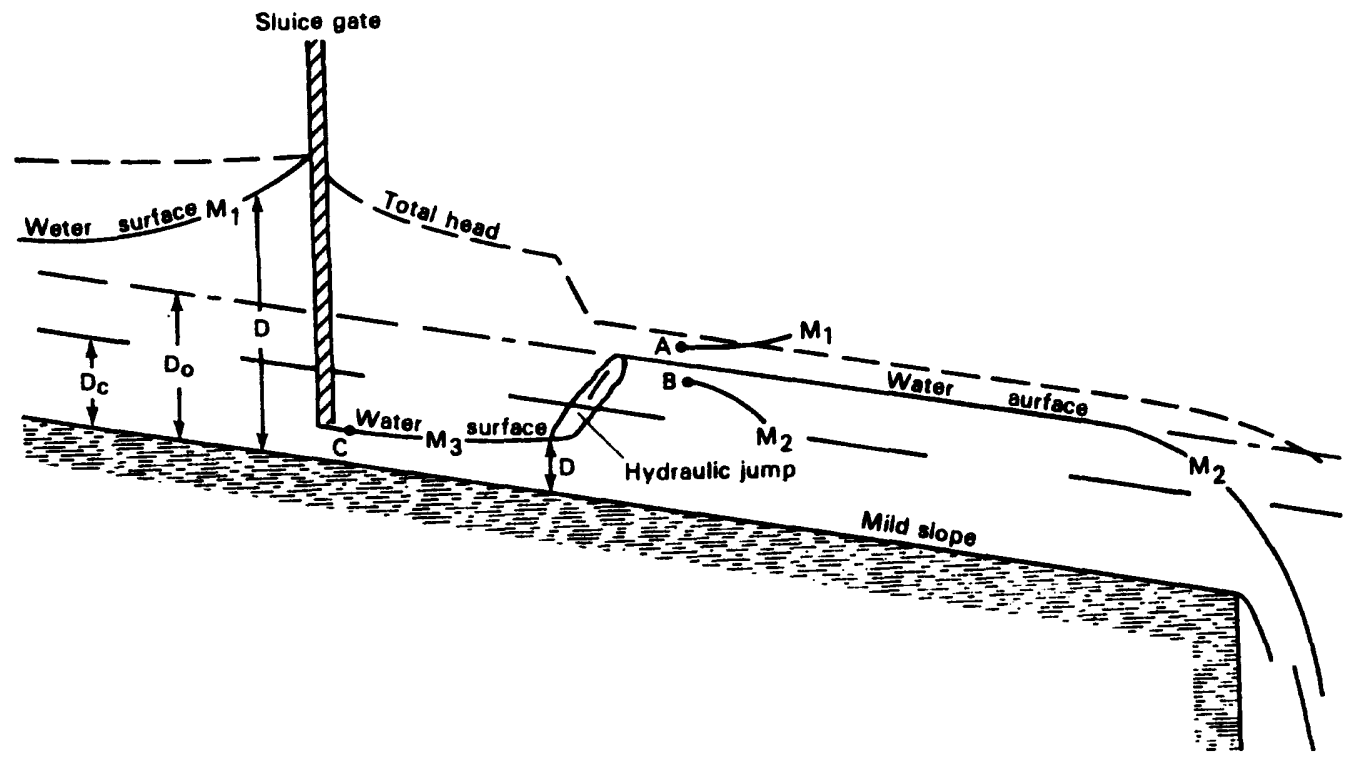

Figure 13-1.--Gradually varied flow in an open channel-longitudinal scale greatly reduced. 
Directly downstream from the sluice gate, at point $C$, the depth is less than either the critical or the normal depth. Because the velocity is higher than normal (depth less than normal), the slope of the total energy line is greater than the slope of the bed. This large slope of the total head line indicates a decreasing specific energy with increasing distance downstream. For supercritical flow, a reduction in specific energy results in an increase in depth as shown in figure 13-1. The depth tends to increase with distance in the downstream direction approaching the critical depth as a limit. If the flow reached the critical depth, a paradox would develop because the flow would need to continue decreasing its specific energy; however, the critical depth would be the point of minimum specific energy. This situation cannot exist so before the flow reaches the critical depth, a sudden change occurs in the form of a hydraulic jump. The flow shifts suddenly from a supercritical depth to a subcritical depth resulting in a large decrease in total energy.

The depth just downstream of the hydraulic jump is at the normal depth. This is proven by assuming first that the flow depth downstream of the hydraulic jump is less than normal depth. The velocity would be larger than normal so the head loss per foot would be larger than normal and the specific energy would decrease with distance downstream. Decreasing specific energy results in decreasing depth (for subcritical flow) so the flow departs further from normal rather than approaching it. Furthermore, if the water depth is greater than normal just downstream of the hydraulic jump, the velocity would be less than normal so the energy dissipation per unit length of the channel (the slope of the total head line) would be less than the bed slope and the specific energy would increase with the distance downstream. Because the flow is subcritical, the water depth would also continually increase, resulting in another impossible situation. Therefore, the water depth downstream of the jump must be at the normal depth for the channel.

The flow at the brink is at critical depth as was seen before. Just upstream of the overfall the velocity will be larger than normal and the head loss will be larger than normal therefore, because the flow is subcritical, the depth will decrease with increasing distance downstream. The watersurface profile would approach the normal depth asymptotically with distance upstream from the brink.

Water-surface profiles of all types can be sketched for various combinations of channel reaches and transitions. Keep in mind that if the depth is greater than critical (subcritical flow), the surface profile will be controlled by a downstream transition because the velocity is less than the celerity of even the smallest disturbance. If, on the contrary, the depth is less than critical (supercritical flow), the surface profile will be controlled by an upstream transition because disturbances cannot travel upstream in supercritical flow. Any disturbance that is large enough to travel upstream in supercritical flow, will, in doing so, change the depth to a value larger than the critical value (as does the hydraulic jump), and the control will shift downstream.

In figure 13-2 water-surface profiles are categorized in terms of the bottom surface slope (whether steep, critical, or mild) and the water depth whether it is greater than both critical and normal (case 1), between critical and normal (case 2), or less than both critical and normal (case 3). A more complete version of this table can be found in Vennard (1962).

To qualitatively sketch water-surface profiles, the following approach may be used. First, if the depth is greater than normal, specific energy will increase in the downstream direction. Likewise, if the depth is less than 


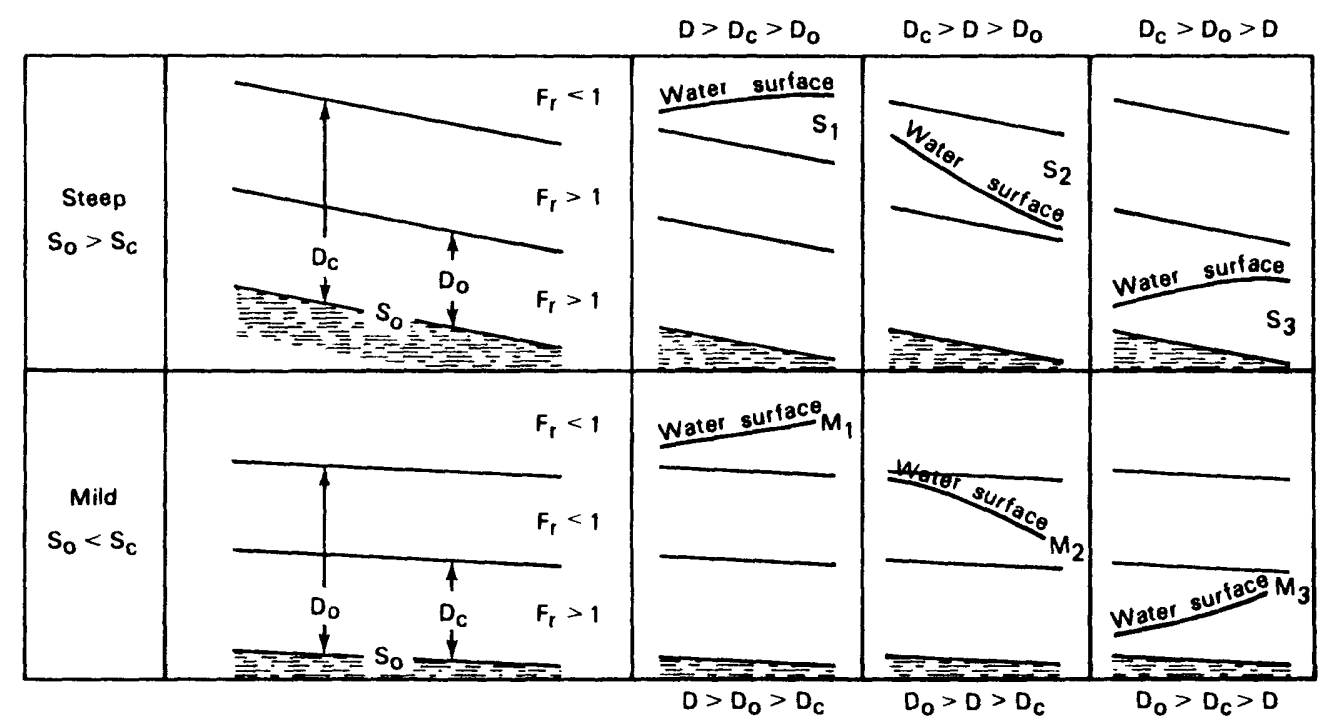

Figure 13-2.--Surface profiles of varied flow.

normal, specific energy will decrease. Second, if the depth is greater than critical, an increase in specific energy results in an increase in depth and if the depth is less than critical, an increase in specific energy results in a decrease in depth. In sketching the water-surface profiles, first draw the bed, critical depth, and normal depth in their proper relative positions. Next, consider what happens to the depth if the water surface is in any of the three zones: above both normal and critical depth, between the two, or below both depths. Then draw the water-surface shape from figure 13-2 in each zone indicating the direction of depth change, provided the water surface is within the zone. These shapes will be found very helpful in sketching the watersurface profile because the true water-surface shape must be continuous and have the indicated shapes in each zone.

On figure 13-1, for example, suppose the channel slope is mild and the water level is at point $A$ that is above normal depth. Because the depth is greater than normal depth, the flow gains specific energy as it moves downstream (it will have a smaller velocity and energy loss per unit length than normal). Because point $A$ is also at a depth greater than critical depth, an increase in specific energy is accompanied by an increase in depth. Therefore, the depth will increase in the downstream direction as shown by the shape of the $M_{1}$ water-surface profile. Because the depth passes through critical at the drop off and the shape of the $M_{1}$ curve is concave up, it is impossible for the jump to raise the water above the normal depth.

On the other hand, if the water level is at point $B$, the depth is less than normal depth. This causes the velocity to be greater than normal and the flow loses specific energy as it moves downstream. Point $B$ is still greater than the critical depth and so the decrease in specific energy causes the depth to decrease as shown by the $M_{2}$ profile. This curve is consistent with the true water-surface profile provided that the brink is not too far away. 
Finally, if the depth were at point $C$, the flow will lose specific energy as it moves downstream and the flow is supercritical so the reduction in specific energy causes an increase in depth as shown by the $M_{3}$ watersurface profile.

Qualitatively drawing the water-surface profiles aids visualizing many natural flow phenomena and understanding these profiles can be useful in stream-gaging applications. 


\section{PROBLEMS}

1. A wide channel flows from a reach where the slope is 0.001 to a reach where the slope is 0.0005 . The discharge is $100 \mathrm{ft}^{3} / \mathrm{s} / \mathrm{ft}$ and the roughness is 0.015. Compute the critical depth, the critical slope, and the two normal depths. Draw the critical depth, normal depths, and the water-surface profile through the transition between slopes. Label the water-surface profile.

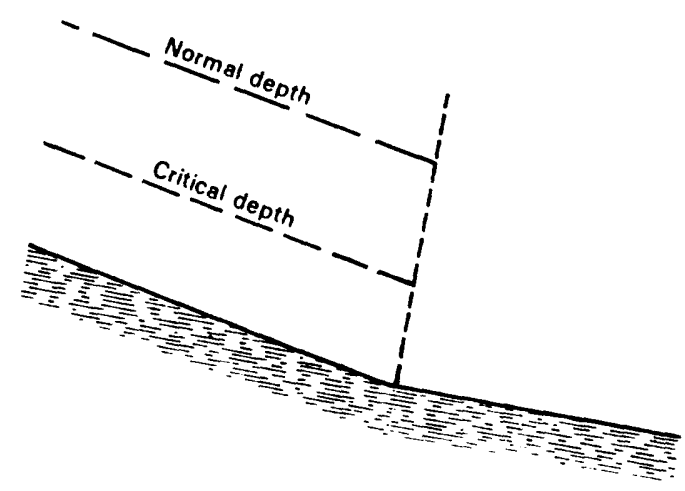


2. A wide channel flows from a reach where the slope is mild to a reach where the slope is 0.003 . The discharge and roughness are the same as in problem 1. Compute the normal depth in the steeper reach and draw the water-surface profile.

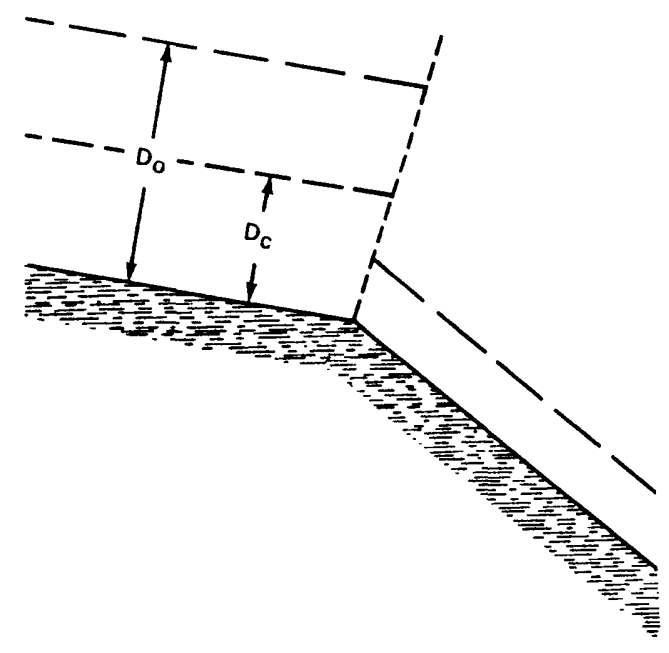

3. Repeat problem 2 except the upstream reach slope is mild and the downstream slope is steeper than the upstream reach but still mild.

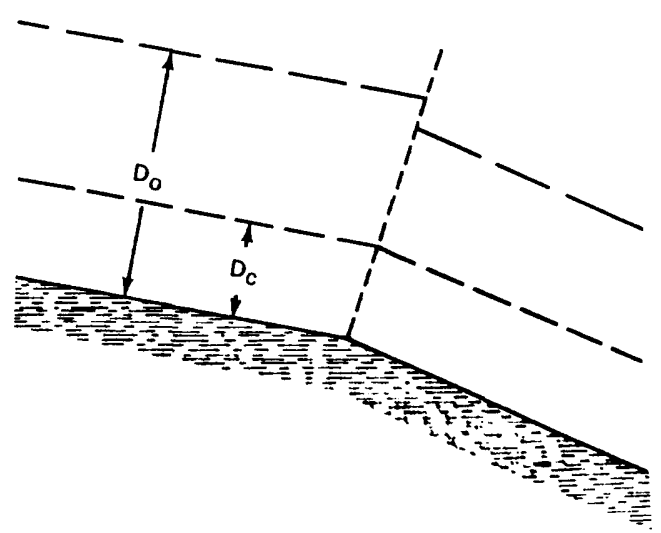


4. Repeat problem 2 except both slopes are steep; that is, the flow passes from a steep slope to a steeper slope.

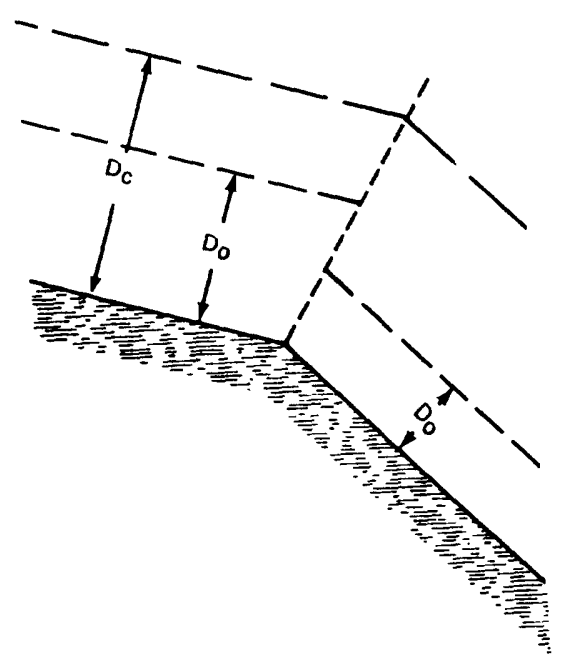




\section{Lesson 14 - Local Energy Losses in Natural Channels}

The Manning, Chezy, or Darcy-Weisbach equations can be used to compute the slope of the energy grade line (energy loss per unit distance) for channels where all resistance to flow is caused by boundary friction. Boundary friction will be the dominant source of resistance in prismatic channels with no local disturbances. Natural channels are seldom prismatic, however, and so energy losses are generally greater than in prismatic channels such as flumes or lined canals. Examples of disturbances that increase energy losses in natural channels include boulders, fallen trees, bridge constrictions, bends, and natural contractions and expansions. Generally speaking, the resistance caused by small obstructions is lumped in with boundary friction and the resistance coefficient is modified to account for the greater energy loss.

Major disturbances such as expansions and contractions are generally accounted for separately and the energy loss, he, is assumed to occur instantaneously. The energy is converted to turbulence or to turbulent eddies that in turn convert the energy to heat as they dissipate while moving downstream. Figure 14-1 shows the usual way of drawing the water surface and energy grade line in the vicinity of a local disturbance. The true shapes probably look more like the dashed curves.
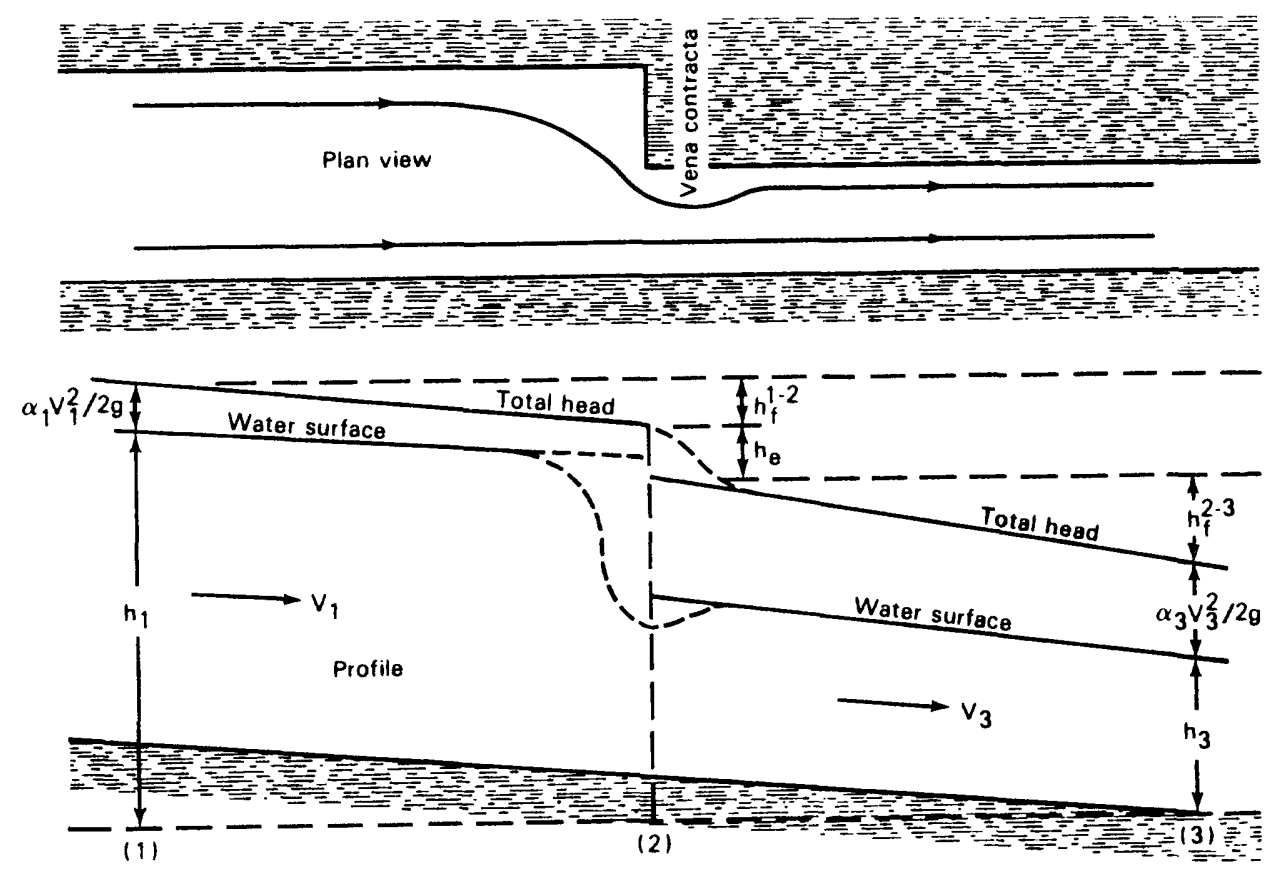

Figure 14-1.--Energy grade lines at a local obstruction.

Applying the energy equation between points 1 and 3 (point 2 is not a good point because the location of the total head is indeterminate), one obtains

$$
\frac{\alpha_{1} v_{1}^{2}}{2 g}+h_{1}=\frac{\alpha_{3} v_{3}^{2}}{2 g}+h_{3}+h_{f}^{1-2}+h_{f}{ }^{2-3}+h_{e}
$$


in which $h_{1}$ and $h_{2}$ represent the sum of the potential plus pressure potential energies (the hydraulic head), and $h_{f}$ represents the head loss due to frictional resistance. The local energy loss, her is generally computed as a percentage of the velocity head. Percentages (loss coefficients, $k_{v}$ ) for various geometric forms of obstructions are tabulated in handbooks of hydraulics. Here we are mostly interested in head losses at expansions and contractions. The head loss at either an expansion or contraction is usually computed as

$$
h_{e}=k_{e} \frac{\left|\alpha_{1} v_{1}^{2}-\alpha_{3} v_{3}^{2}\right|}{2 g},
$$

where the absolute value of the difference in velocity heads allows the same expression to be used for either an expansion or contraction. For a sudden contraction the value of $\mathrm{k}_{e}$ is usually found to be about 0.5 . Its value decreases as the transition becomes more gradual or streamlined. For a sudden expansion the value of $\mathrm{k}_{e}$ is usually found to be 1.0 which implies that all the kinetic energy $\left(\alpha_{1} v_{1}^{2} / 2 g\right)$ in excess of that in the expanded channel is lost to turbulence. As the expansion is streamlined, the value of $\mathrm{k}_{e}$ decreases but usually not very much. As can be seen by plotting the energy and hydraulic grade lines for an expansion, if the value of $k_{e}$ is 1.0 , there is no increase in water surface elevation as the flow passes through the expansion. You probably recall that this is what is usually observed in the field. For subcritical flow, however, the water level will always decrease as the flow passes through a contraction.

Local energy losses become important when computing flow from changes in water-surface elevations such as occur at width constrictions. Figure 14-1 could be used as the definition sketch for flow through a bridge opening; for example, where section 1 is a short distance upstream of the bridge, section 2 is at the upstream side of the embankment, and section 3 is at the downstream edge of the opening. After a flood, peak water-surface elevations can be determined at sections 1 and 3 , usually from high-water marks. The discharge can then be estimated as the value that allows the energy equation 14-1 to balance. Rewriting equation 14-1 in expanded form, in which the friction slope is expressed as a function of discharge and conveyance and the local entrance loss is expressed by equation 14-2, one obtains

$$
\frac{\alpha_{1} \mathrm{~V}_{1}^{2}}{2 \mathrm{~g}}+\mathrm{h}_{1}=\frac{\alpha_{3} \mathrm{~V}_{3}^{2}}{2 \mathrm{~g}}+\mathrm{h}_{3}+\frac{\mathrm{Q}^{2}}{\mathrm{~K}_{1}{ }^{2}} \mathrm{~L}_{12}+\frac{\mathrm{Q}^{2}}{\mathrm{~K}_{3}{ }^{2}} \mathrm{~L}_{23}+\mathrm{k}_{\mathrm{e}}\left(\frac{\alpha_{3} \mathrm{~V}_{3} 2}{2 \mathrm{~g}}-\frac{\alpha_{1} \mathrm{~V}_{1} 2}{2 \mathrm{~g}}\right) \text {, }
$$

in which $\mathrm{L}_{12}$ and $\mathrm{L}_{23}$ are the distances from section 1 to 2 and 2 to 3 , respectively, $V_{1}=Q / A_{1}$ and $V_{2}=Q / A_{3}$. Because the areas and conveyances are all functions of the geometric shape of the section, roughness, and depth, equation 14-3 contains only one unknown (Q) besides the roughness coefficients in reach $1-2$ and $2-3$ as well as the contraction loss coefficient $k_{e}$. Measurement of the water-surface elevations $h_{1}$ and $h_{3}$ as well as the channel shape and assuming the roughness coefficients and $\mathrm{k}_{e}$ allows the peak discharge to be computed (by trial and error) from the energy equation 14-3. 
PROBLEM

1. After a flood the data in the table were measured at a bridge site. Section 1 was located 40 feet upstream of the bridge opening and section 3 was located 15 feet downstream of the bridge opening, but still within the zone of contracted flow. Assuming a contraction loss coefficient of 0.5 , compute the peak discharge. Assuming a true discharge of $575 \mathrm{ft}^{3} / \mathrm{s}$

(Matthai, 1968, p. 43), compute the actual value of $k_{e}$. Draw and label the total and hydraulic grade lines on the sketch.

\begin{tabular}{|c|c|c|c|c|}
\hline Section & $\begin{array}{c}\text { Water-surface } \\
\text { elevation (ft) }\end{array}$ & $\begin{array}{c}\text { Area } \\
\mathrm{ft}^{2}\end{array}$ & $\begin{array}{c}\text { Conveyance } \\
\mathrm{ft} 3 / \mathrm{s}\end{array}$ & $\alpha$ \\
\hline 1 & 10.81 & 148.2 & 10,840 & $\begin{array}{l}1.39 \\
1.0\end{array}$ \\
\hline
\end{tabular}

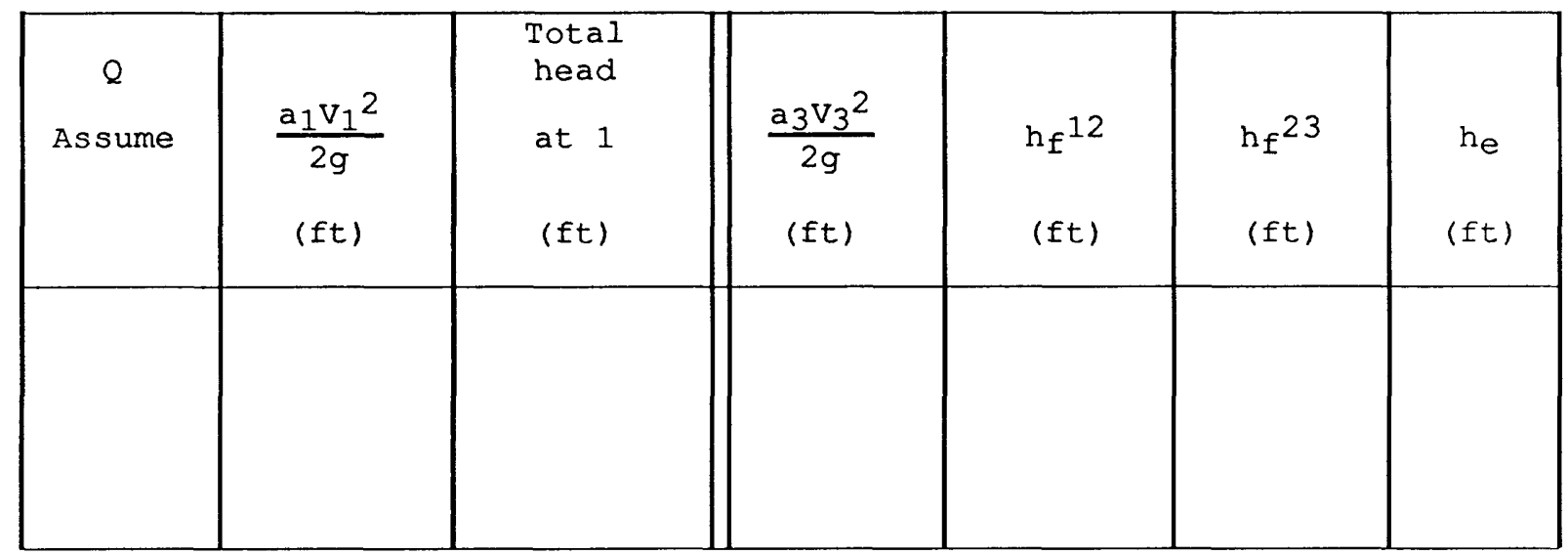


Methods of Computation

A common problem in open-channel hydraulics is to determine the watersurface profile of a stream under specific discharge and channel conditions. The term "backwater curves" is applied to such profiles.

Backwater curves are used to determine grade lines for flood-protection works, highways, and bridges. They are used to determine tailwater ratings for hydroelectric power plants, canal headworks, and energy dissipaters. They are also used to determine areas subject to flooding.

The computation of water-surface profiles basically involves solution of the energy equation for gradually varied flow. Broadly classified, there are three methods of computation:

1. the graphical-integration method,

2. the direct-integration method, and

3. the step method.

Explanations of both the graphical- and direct-integration methods may be found in Chow (1959) as well as other texts. Only the standard-step method will be discussed here.

Step method computations require the channel to be divided into short lengths, or reaches, which have relatively small variations in conveyance. In a series of steps starting from a point of control, each reach is solved in succession. For subcritical flow the computations proceed upstream from a downstream control and for supercritical flow the computations must proceed downstream from an upstream control. It is very helpful, almost necessary, to qualitatively analyze the problem using the methods developed in lesson 13 before detailed computations begin.

The standard-step method allows computation of backwater curves in both nonprismatic natural channels and nonuniform artificial channels as well as in uniform channels. This method involves solving for the water-surface elevation at various locations along a channel. The energy balance used in the standard-step method is accomplished by writing energy equation between the upstream section, $u$, and the downstream section, $d$, in figure 15-1 as

$$
h_{u}+\alpha_{u} \frac{v_{u}^{2}}{2 g}=h_{d}+\alpha_{d} \frac{v_{d}^{2}}{2 g}+h l
$$

and solving for the water-surface elevation at the unknown section by trial and error.

Except for representing the hydraulic head, $h$, as the sum of the potential and pressure potential heads $(D+Z)$, equation $15-1$ is identical to the standard energy equation 6-2. The total energy loss in the reach, hl, is computed as

$$
h_{l}=h_{f}+h_{e}
$$

where $h_{f}=\bar{S}_{f} L=$ energy loss due to friction and 
Figure 15-1.--Water-surface profile computation.

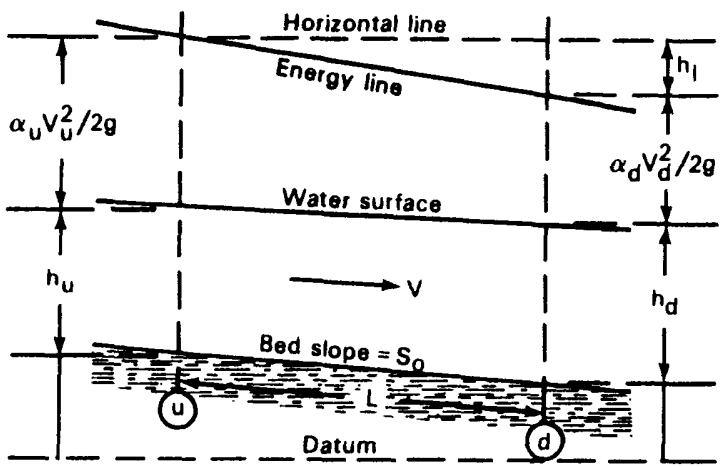

$$
h_{e}=k_{e}\left|\alpha_{u} \frac{v_{u}^{2}}{2 g}-\alpha_{d} \frac{v_{d}^{2}}{2 g}\right|=\begin{aligned}
& \text { eddy losses due } \\
& \text { to expansion or } \\
& \text { contraction of } \\
& \text { the flow. }
\end{aligned}
$$

Eddy losses allow a three-dimensional flow to be modeled using a one-dimensional theory. In nonprismatic channels, eddy losses may be appreciable.

Solving equation 15-1 for the hydraulic head at the upstream section (assuming subcritical flow), one obtains

$$
h_{\mathrm{u}}=\mathrm{h}_{\mathrm{d}}+\frac{\alpha_{\mathrm{d}} \mathrm{V}^{2}}{2 \mathrm{~g}}-\frac{\alpha_{\mathrm{u}} \mathrm{V}_{\mathrm{u}}^{2}}{2 \mathrm{~g}}+\mathrm{h}_{\mathrm{f}}+\mathrm{h}_{\mathrm{e}} \text {. }
$$

The equation computes the upstream water-surface elevation from the downstream elevation when backwater computations are made for subcritical flow because the control is downstream.

The computation is carried out in steps, going from one cross section to the next. The general computational procedure is as follows:

1. Starting at a cross section with a known water-surface elevation, compute the necessary cross-sectional properties.

2. Estimate the unknown water-surface elevation at the next cross section.

3. Calculate the hydraulic properties that correspond to the estimated water-surface elevation.

4. Determine the energy losses that correspond to the estimated watersurface elevation.

5. Calculate the water-surface elevation using the energy equation (equation 15-3) and the energy losses computed in step 4 . 
6. Compare the estimated and computed water-surface elevations. If they are close enough, go to step 1 where the just computed watersurface elevation is considered to be known. If they are not close enough, estimate a new water-surface elevation and go to step 3 .

\section{Eriction-Loss Computation}

Friction loss in a channel reach is computed by integrating the friction slope along the reach:

$$
h_{f}=\int_{x_{1}}^{x_{2}} s_{f} d x
$$

Equation $15-4$ is approximated by

$$
h_{f}=\bar{s}_{f} L_{,}
$$

where $\bar{S}_{f}=$ the average friction slope for the reach, and

$\mathrm{L}=$ the reach length.

The product of $\bar{S}_{f}$ and $I$ approximates the area under the actual $S_{f}$ curve on figure 15-2. In general, the shape of the friction slope curve is unknown and depends on the type of water-surface profile (that is, M1, M2, etc.).

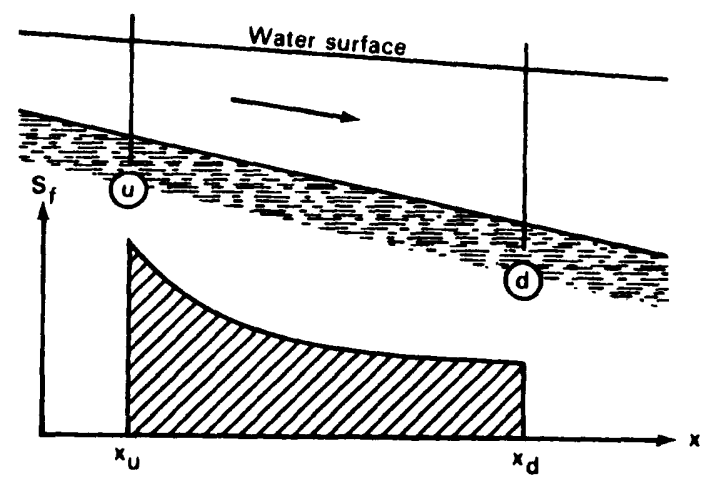

Figure 15-2.--Variation of friction slope with distance along the channel.

Possible ways of calculating $\bar{S}_{f}$ include the following:

Weighted Average

$$
\begin{aligned}
& \bar{s}_{f}=(1-\theta) S_{f_{d}}+\theta S_{f_{u}} \\
& \text { for } \theta=\quad 1 / 2 ; \text { Arithmetic Average } \\
& \quad \pi / 4 ; \text { Elliptic Average }
\end{aligned}
$$

Geometric Mean

$$
\bar{s}_{f}=\sqrt{s_{f_{d}} s_{f_{u}}}
$$


Harmonic Mean

$$
s_{f}=\frac{2 s_{f_{d}} s_{f_{u}}}{s_{f_{d}}+s_{f_{u}}}
$$

Average Conveyance

$$
\bar{s}_{f}=\left(\frac{Q_{u}+Q_{d}}{K_{u}+K_{d}}\right)^{2}
$$

Any of the friction slope equations will produce satisfactory estimates of friction loss provided that the reach lengths are sufficiently short so that the conveyances at either end do not vary too much. The advantage sought in using alternative friction slope formulas is to maximize reach lengths without sacrificing profile accuracy. Table 15-1 presents the results of various investigations in a form that will enable proper selection of a friction slope formula. The Geometric Mean equation is the preferred frictionslope formula for all profile types in the Geological Survey step-backwater computer programs.

Table 15-1.--criteria used to select friction slope equation

\begin{tabular}{lll}
\hline Profile type & Is $s_{f_{u}}>s_{f_{d}}$ & Equation used \\
\hline Subcritical & Yes (M1, s1) & $\begin{array}{l}\text { Arithmetic Average } \\
\text { No (M2) } \\
\text { Elliptic Average }\end{array}$ \\
Supercritical & Yes (S2) & $\begin{array}{l}\text { Arithmetic Average } \\
\text { Geometric Mean }\end{array}$ \\
\hline
\end{tabular}

$$
\begin{aligned}
& \text { where } s_{f_{d}}=\begin{array}{l}
\text { the known friction slope at the downstream cross } \\
\text { section, and }
\end{array} \\
& s_{f_{u}=} \begin{array}{c}
\text { the estimated friction slope at the upstream cross } \\
\text { section. }
\end{array}
\end{aligned}
$$

\section{Example:}

A 100-foot wide rectangular channel has a slope of 0.0006 and a Manning's $n=0.03$. At a discharge of $1,669.2 \mathrm{ft} 3 / \mathrm{s}$ the observed depth is 4.5 feet. What is the depth 300 feet upstream? Assume all $\alpha$ 's $=1.0$ and expansion/contraction loss coefficients of 0.0 because it is a prismatic channel. 
Solution:

The first step is to qualitatively determine the type of backwater profile present. First, compute the Froude number to see if subcritical or supercritical flow exists.

$$
\begin{aligned}
& V=\frac{Q}{A}=\frac{1,669.2}{4.5(100)}=3.71 \mathrm{ft} / \mathrm{s} \\
& F_{r}=\frac{V}{\sqrt{g D}}=\frac{3.71}{\sqrt{32.2(4.5)}}=0.31
\end{aligned}
$$

Because the Froude number is less than 1, the flow is subcritical and the problem is well posed because the control will be downstream and backwater profiles should be computed in the upstream direction. Also, the critical depth is less than 4.5 feet and less than 5.0 feet.

Next, compute the normal depth. For normal depth the friction slope and the bed slope are equal so

$$
Q=\frac{1.49}{0.03} A^{2 / 3 \sqrt{0.0006}}=1.22(100 \mathrm{D})\left(\frac{100 \mathrm{D}}{100+2 \mathrm{D}}\right)^{2 / 3}
$$

Solving by trial and error as shown below

\begin{tabular}{ccc} 
& $D$ & 0 \\
\cline { 2 - 2 } & 4.5 & $1,408.9$ \\
4.6 & $1,459.7$ \\
Normal depth $\rightarrow \quad 4.8$ & $1,563.2$ \\
& 5.0 & $1,669.2$ \\
5.2 & $1,777.6$
\end{tabular}

The normal depth of 5.0 feet is larger than the critical depth so the slope is mild. The local depth is less than the normal depth and greater than critical depth so an M2 profile exists that is concave down as can be seen on table 13-1. In other words, the depth 300 feet upstream will be larger than 4.5 feet and less than the normal depth of 5.0 feet.

The exact value of the depth is computed from the energy equation as expressed in equation 15-1 or 15-3. Because the right side of equation 15-3 is a function of the unknown upstream head, $h_{u}$, a trial-and-error solution will be required, and it is convenient to organize the computations by use of a table such as $15-2$.

The first step is to compute each term in equation 15-3 that pertains to the downstream section (which is called section 1) as follows:

The conveyance at the downstream section is

$$
K=\left(\frac{1.49}{0.03}\right)(450)\left(\frac{450}{109}\right)^{2 / 3}=57,518 \mathrm{ft}^{3} / \mathrm{s},
$$

so the friction slope is

$$
S f=\left(\frac{Q}{K}\right)^{2}=\left(\frac{1,669.2}{57,518}\right)^{2}=0.000842,
$$


Table 15-2.--Computation sheet for backwater analysis

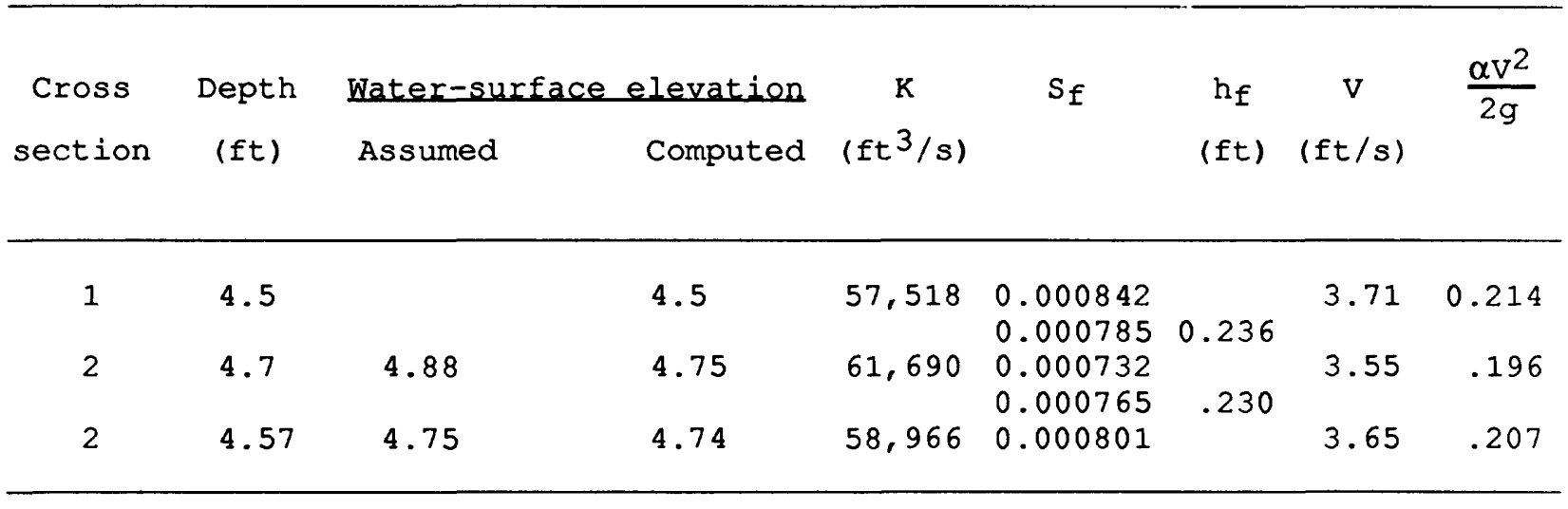

the velocity is

$$
\mathrm{v}=\frac{1,669.2}{450}=3.71 \mathrm{ft} / \mathrm{s},
$$

and the velocity head is

$$
\frac{\alpha v^{2}}{2 g}=\frac{1.0(3.71)^{2}}{64.4}=0.214 \mathrm{ft} .
$$

These values are recorded in table 15-2 on the line marked section 1 with a known water-surface elevation and depth of 4.5 feet.

The next step is to assume a depth at the upstream section. Because we know the depth will increase upstream (M2), an assumption of 4.7 feet is made. The bed raises $0.0006 \times 300=0.18$ foot so the assumed water-surface elevation $\left(h_{u}\right)$ is 4.88 . The next step is to compute the conveyance, velocity, etc., for section 2 (the upstream section) just as for section 1 . The results of these computations are shown as the third line of table 15-2.

With the third line completed, compute the head loss terms and record the results on line 2 because the values represent the head loss between the two sections. The friction slope at section 1 is 0.000842 and at section 2 for the assumed depth of 4.7 feet is 0.000732 . The average slope is computed as the geometric mean

$$
\bar{s}_{f}=\sqrt{0.000842(0.000732)}=0.000785
$$

so the friction loss between section 1 and 2 is

$$
\mathrm{h}_{\mathrm{f}}^{1-2}=0.000785(300 \mathrm{ft})=0.236 \mathrm{ft} .
$$

The loss term is recorded on line 2 of table 15-2. The next step is to compute the water-surface elevation at the upstream section by use of equation 15-3 using data contained in table 15-2 


$$
\mathrm{h}_{\mathrm{u}}+0.196=0.214+4.5+0.236+0.0
$$

or $h_{u}=4.75$, which is recorded as the computed water-surface elevation at section 2. A poor assumption was made because the computed and assumed elevations at section 2 are not equal.

Another try is made by assuming the water-surface elevation at section 2 is equal to the computed value of 4.75 feet. The conveyance, velocity, etc., are recomputed with the new assumed depth of $4.75-0.18=4.57$ and the results recorded on the fifth line of table 15-2. The head loss terms are recomputed for the reach using data contained in lines 1 and 5 and the results are recorded between the sections on line 4. The second estimate of the upstream water-surface elevation is then computed as before as

$$
h_{u}=0.214+4.5+0.230-0.207=4.74 \text {, }
$$

which may be close enough to the assumed value. So the approximate watersurface elevation 300 feet upstream of the measurement point is 4.74 feet and the depth is 4.56 feet, which is greater than 4.50 as it should be for an M2 curve. The conveyance at sections 1 and 2 differ by only 3 percent so the method used in averaging the two friction slopes (geometric mean used here) is not very important. If the conveyance at the two sections differed by more than 20 percent, the computations probably should be made for sections that were closer together. For example, to get the water-surface elevation 300 feet upstream, one might first compute it at 150 feet and then at 300 feet. 


\section{PROBLEM}

1. A channel with a trapezoidal cross section as shown below has a constant slope of 0.0016 and carries a discharge of $400 \mathrm{ft}^{3} / \mathrm{s}$. Manning's $n$ has been computed to be 0.025 . Compute the normal depth. Compute the backwater profile created by a dam that backs up the water to a depth of 5.0 feet immediately behind the dam. Use the standard-step method. Estimate the average friction slope, $\bar{S}_{f}$, as a geometric mean. Assume that $\mathrm{k}_{e}=0.0$ for contractions and expansions, and $\alpha=1.0$. Locate cross sections 500 feet apart. Compute the profile until the depth is within 0.10 feet of the normal depth. What type of profile is this (e.g., M1, M2, etc.).

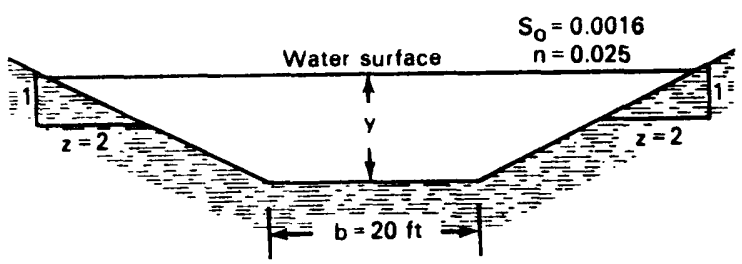

For a channel with a trapezoidal cross section:

$$
\begin{aligned}
& \text { Area }=(b+z y) y \\
& \text { Wetted perimeter }=b+2 y \sqrt{1+z^{2}} \\
& \text { Hydraulic radius }=\frac{(b+z y) y}{b+2 y \sqrt{1+z^{2}}}
\end{aligned}
$$




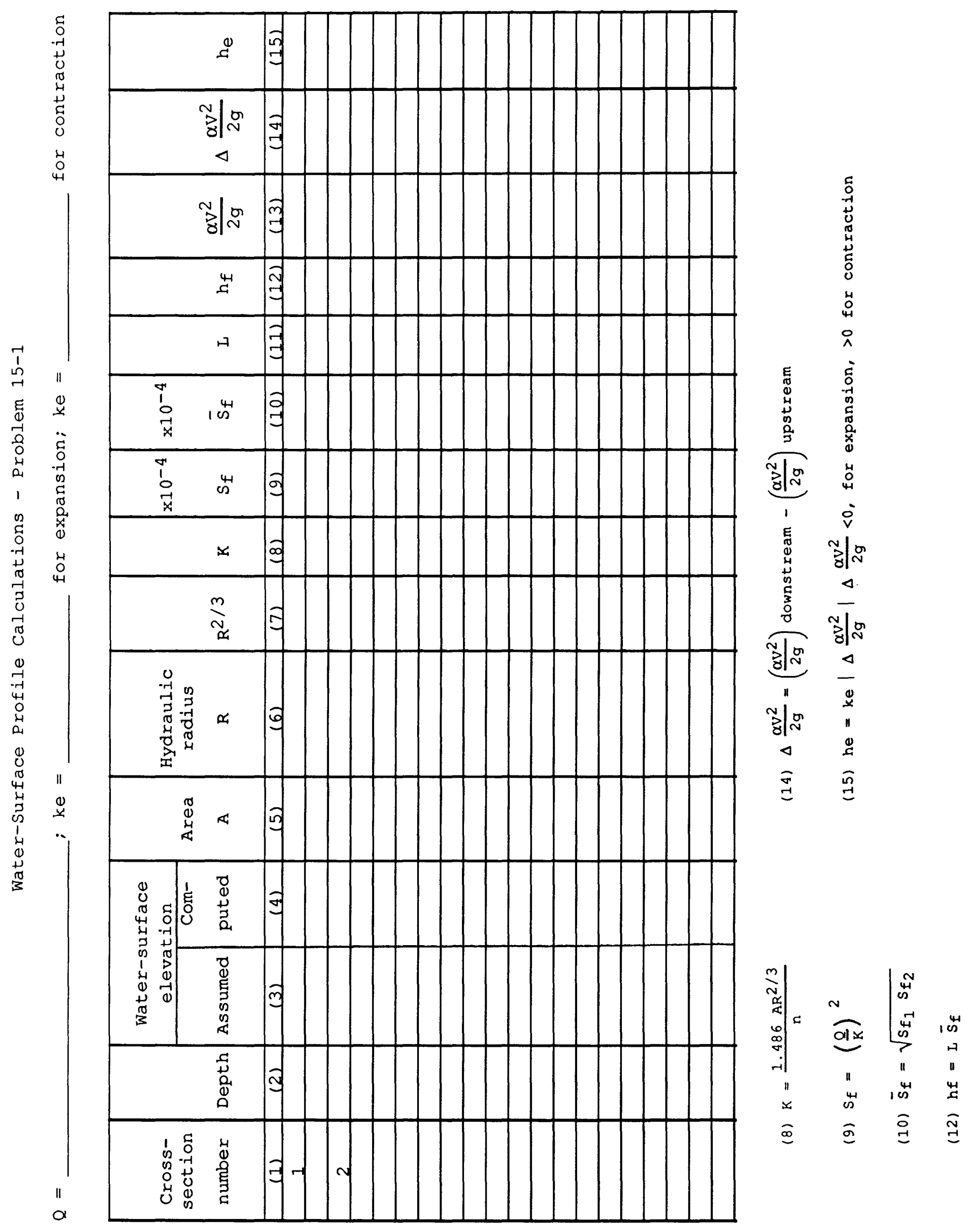




\section{PART V - DISCHARGE COMPUTATIONS FOR RAPIDLY VARIED FLOW}

\section{Lesson 16 - Rapidly Varied Flow at Constrictions}

The contraction of a stream channel by a roadway crossing creates an abrupt drop in water-surface elevation between an approach section and the contracted section under the bridge provided the upstream flow is subcritical $\left(F_{r}<1\right)$. The contracted section framed by the bridge abutments and the channel bed is, in a sense, a discharge meter that can be used to compute floodflows. The piezometric (hydraulic) heads are defined by high-water marks and the geometries of the channel and opening are defined by field surveys. The energy equation is used to relate the change in piezometric heads to the discharge. This lesson describes the theory behind using contracted sections as flow meters. Details of the procedure are presented by Matthai (1968) and Schneider and others (1977).

Consider the theoretical water-surface profile that occurs for steady flow through a contracted section of a rectangular channel which is 500 feet wide with a Manning's $n$ of 0.03 and a slope of 0.0002 while the discharge is $5,075 \mathrm{ft}^{3} / \mathrm{s}$. Figure $16-1$ is a plot of the theoretical water-surface and total-energy profiles that would occur if the constricted channel was a $100-$ foot wide rectangle with the same roughness and bottom slope as the natural channel. The opening is assumed to be 48 feet long (parallel to the flow) and have contraction (entrance) and expansion (exit) loss coefficients of 0.5 and 1.0, respectively.
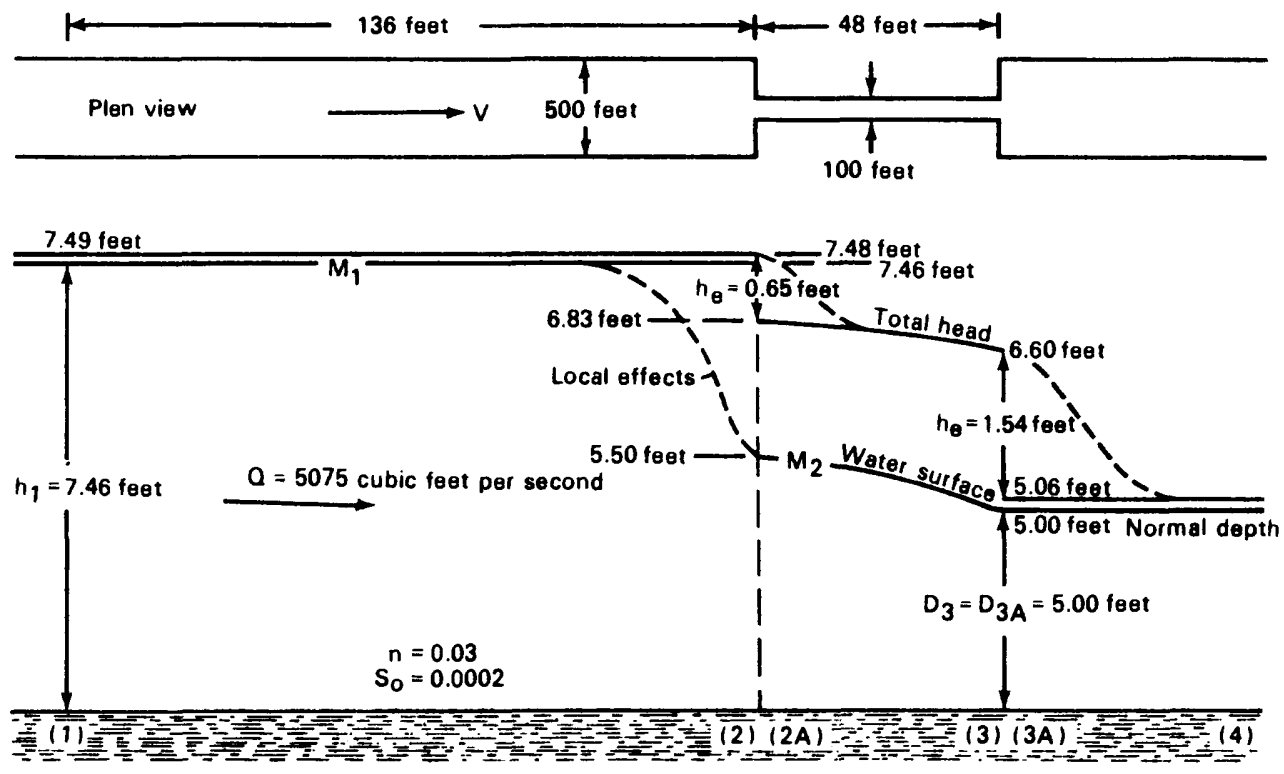

Figure 16-1.--Theoretical water-surface and energy profiles through a contracted opening. 
Within the contracted section, the normal depth, $D_{0}$, is 14.43 feet, as can be seen by use of the Manning equation, and the critical depth is

$$
D_{C}=\sqrt[3]{\frac{g^{2}}{g}}=\sqrt[3]{\frac{50.75^{2}}{32.2}}=4.31 \mathrm{ft}
$$

while the wide channel has a normal depth of 5.0 feet and a critical depth of 1.47 feet. For normal depth in the wide section the velocity is $2.03 \mathrm{ft} / \mathrm{s}$ and the Froude number is 0.16 .

The flow is subcritical throughout because $D_{O}>D_{C}$ throughout and there is no sudden drop in bed elevation. For subcritical flow, the control is always downstream. As can be seen by applying the water- surface profile shapes discussed in lesson 13, normal depth must exist all the way up to the opening on the downstream side. For the present discussion we ignore the local effects and assume the velocity is capable of suddenly changing from one value to another as the water leaves the constriction and enters the expanded section. Therefore, just downstream of the outlet (section 3A) the depth is 5.0 feet, the velocity is $2.03 \mathrm{ft} / \mathrm{s}$, the velocity head is 0.06 foot (assuming $\alpha=1.0$ ), so the total head is 5.06 feet (assuming the bed is at zero elevation at the outlet).

The depth just upstream of the outlet, section 3 , can be computed from the energy equation as

$$
\frac{V_{3}{ }^{2}}{2 g}+D_{3}+0=\frac{V_{3 A^{2}}}{2 g}+D_{3 A}+0+1.0\left(\frac{V_{3}^{2}}{2 g}-\frac{V_{3 A^{2}}}{2 g}\right) .
$$

where the values of $\alpha$ are assumed to be 1.0 and the expansion loss coefficient is assumed to be 1.0. Because the expansion loss coefficient is 1.0 , the velocity heads exactly cancel so the value of $D_{3}$ is equal to the value of $D_{3 A}$, and the theoretical water surface is continuous at the expansion. Had the expansion loss coefficient been assumed to be 0.8 , however, the theoretical value of $D_{3}$ would have been 4.64 feet for example. This would have indicated that the water surface suddenly increased by 0.36 foot as the flow expanded. In other words, 0.36 foot of the kinetic energy at section 3 would be converted instantaneously to pressure energy raising the water surface by 0.36 foot. With the loss coefficient of 1.0 , figure 16-1 indicates the instantaneous head loss at the expansion is 1.54 feet.

Within the contracted section, the depth is less than the normal depth of 14.43 but greater than the critical depth of 4.31 , so an M2 profile is indicated as plotted on figure 16-1. Projecting the water-surface profile back to the entrance (using the methods as outlined in lesson 15), the depth and total energies at section $2 \mathrm{~A}$ are as indicated on figure 16-1. Both the water-surface profile and energy line is concave downward as required by the M2 profile, but the curvature is probably too slight to detect on figure 16-1. equation

The next step is to compute the depth at section 2 by use of the energy

$$
\frac{\mathrm{V}_{2}{ }^{2}}{2 \mathrm{~g}}+\mathrm{D}_{2}+0.01=1.33+5.49+0.01+0.5\left(1.33-\frac{\mathrm{V}_{2}{ }^{2}}{2 \mathrm{~g}}\right) \text {. }
$$

from which the value of $D_{2}$ is seen to be 7.44 feet. 
The velocity and velocity heads are $1.36 \mathrm{ft} / \mathrm{s}$ and $0.03 \mathrm{foot}$, respectively, at section 2. The energy loss at the entrance is seen to be 0.65 foot compared to the exit loss of 1.54 feet. The theoretical water-surface profile is discontinuous at the entrance because it has been assumed that the velocity changes instantaneously as it passes the opening and that the energy is suddenly dissipated. Of course this discontinuity does not exist in nature and the actual water-surface profile and energy line will look somewhat as shown by the dashed curves. In general, these effects, which are due to streamline curvature, are very localized.

Upstream the depth is greater than both normal and critical, so an MI curve is indicated. The $\mathrm{M} 1$ curve is very slightly concave upward. For example, at 136 feet upstream of the entrance the theoretical depth is reduced to only 7.42 feet and it requires 36,300 feet for the depth to be reduced to 5.06 feet, which is still 0.06 foot above normal.

The Geological Survey is frequently faced with the problem of estimating the discharge based on high-water marks left after a flood. A bridge opening offers an ideal place to make this estimate. This is because there is generally a large difference in water-surface elevations that are directly related to the energy equation. For example, if the energy equation is written from sections 1 to 3

$$
\frac{\alpha_{1} V_{1}^{2}}{2 g}+D_{1}+z_{1}=\frac{\alpha_{3} V_{3}^{2}}{2 g}+D_{3}+z_{3}+h_{f} 1-2+h_{f}{ }^{2-3}+k_{e}\left(\frac{v_{2 A}{ }^{2}}{2 g}-\frac{v_{2}^{2}}{2 g}\right)
$$

in which there are several unknowns but the unknowns tend to be small. For example, if $D_{1}, z_{1}, D_{3}$, and $z_{3}$ are measured in the field, the values of $A_{1}$ and $A_{3}$ can be computed from the geometry of the cross section so that

$$
\frac{\alpha_{1} Q^{2}}{2 g A_{1}^{2}}+h_{1}=\frac{\alpha_{3 Q^{2}}}{2 g A_{3}^{2}}+h_{3}+h_{f}{ }^{1-2}+h_{f}{ }^{2-3}+k_{e}\left(\frac{v_{2 A^{2}}}{2 g}-\frac{v_{2}{ }^{2}}{2 g}\right) \text {. }
$$

In this equation, the unknowns are $\alpha_{1}, \alpha_{3}, h_{f}^{1-2}, h_{f} 2-3, k_{e}, v_{2 A}$, and $v_{2}$. Solving for $Q$

$$
\mathrm{Q}^{2}=\frac{2 \mathrm{~g}}{\left(\frac{\alpha_{3}}{\mathrm{~A}_{3}^{2}}-\frac{\alpha_{1}}{\mathrm{~A}_{1}^{2}}\right)}\left(\mathrm{h}_{1}-\mathrm{h}_{3}-\mathrm{h}_{\mathrm{f}} 1-2-\mathrm{h}_{\mathrm{f}}^{2-3}-\mathrm{h}_{\mathrm{e}}\right)
$$

in which the entrance loss term is represented by $h_{e}$. For the example given in figure $16-1, h_{1}-h_{3}=2.46$ feet, $h_{f} 1-2=0.01$ foot, $h_{f}{ }^{2-3}=0.23$ foot, and $h_{e}=0.65$ foot. The accuracy of the result would not be very much affected by substantial errors in $h_{f}{ }^{1-2}$ or $h_{f}{ }^{2-3}$ and even the entrance loss is not large, so that a significant error in this can be tolerated. The value of $\alpha_{3}$ will be nearly 1.0 because the section under the bridge is generally very regular in shape and the actual value of $\alpha_{1}$ is rather insignificant because $1 / \mathrm{A}_{3}{ }^{2}$ is 56 times larger than the value of $1 / \mathrm{A}_{1}{ }^{2}$.

The depth and total energy lines are strongly affected by local conditions at sections 2 and $2 \mathrm{~A}$. At sections $3 \mathrm{~A}$ and 4 additional unknowns are added, the expansion loss and the friction loss between $3 \mathrm{~A}$ and 4 . The exit loss term is also large, 1.54 feet in this example, so estimates of its value 
should be avoided if possible. For these reasons, sections 1 and 3 are almost always selected as application points for the energy equation.

Figure 16-2 shows typical streamlines for flow through a sharp-edged opening. The water following streamline A approaches the opening at a significant angle and is unable to change directions instantly upon passing the opening. The active jet, therefore, continues to contract in the downstream direction for a short distance after it passes the opening. The vena contracta is defined as the point where the active area is smallest (often as much as 20 percent less than the gross area). At the vena contracta the flow is nearly parallel so the energy equation can be applied with accuracy. The energy equation should not be applied upstream of the vena contracta because the curvature of the streamlines is large and the simple one-dimensional assumptions are not applicable.

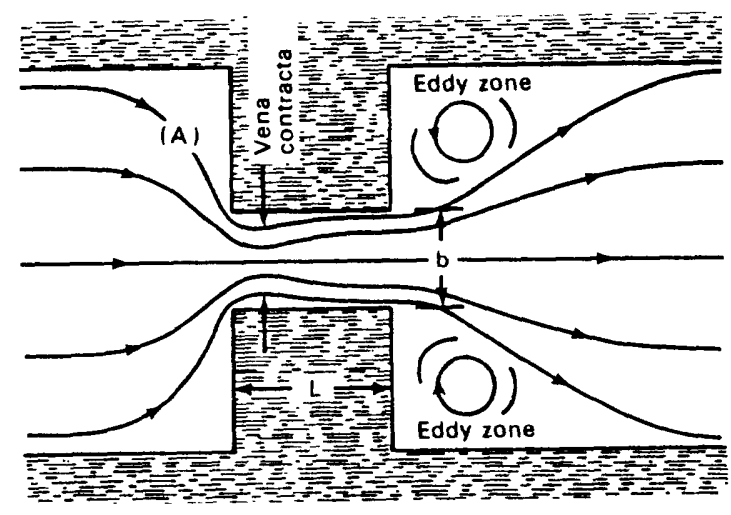

Figure 16-2.--Streamlines for flow through a sharp-edged opening.

The upstream section should be selected such that it is upstream of the local drawdown caused by the converging streamlines. Generally the drawdown effects extend upstream less than one opening width. Wide, heavily vegetated floodplains present unique problems that have been addressed by Schneider and others (1977).

Detailed procedures for computing discharges at contracted openings are presented by Matthai (1986). The basic equation used in this manual can be derived from equation $16-1$ by assuming the entrance loss can be estimated as

$$
h_{e}=k_{e} \frac{\alpha_{3} v_{3}^{2}}{2 g}
$$

instead of the expression given in equation 16-1. This assumption is desirable and reasonable because the velocities at section 2 are not generally known and $v_{3} \simeq V_{2 A}$ while $V_{2} \ll v_{2 A}$. Expressing the entrance loss as indicated above and replacing $V_{3}$ by $Q / A$, equation $16-1$ can be written

$$
\frac{\alpha_{1} v_{1}^{2}}{2 g}+h_{1}=h_{3}+h_{f} 1-3+\frac{\mathrm{e}^{2}}{A_{3}^{2}} \frac{\alpha_{3}}{2 g}\left(1+k_{e}\right)
$$

or solving for $Q$ yields

$$
Q=\frac{A_{3}}{\sqrt{\alpha_{3}\left(1+k_{e}\right)}} \sqrt{2 g\left(\Delta h+\frac{\alpha_{1} v_{1}^{2}}{2 g}-h_{f} 1-3\right)},
$$


which is identical to Matthai's equation 1

where

$$
c=\frac{1}{\sqrt{\alpha_{3}\left(1+k_{e}\right)}}
$$

and $\Delta h$ is the fall in water-surface elevation

$$
\Delta h=D_{1}+z_{1}-D_{3}-z_{3}=h_{1}-h_{3} .
$$

The entrance loss coefficient $k_{e}$ is dependent on the shape of the entrance, the angle of the approach flow, the length of the opening, etc. Values of $c$, which are mainly a function of $k_{e}$, have been measured for many shapes and hydraulic conditions using laboratory studies. The results of these studies are presented as tables and charts by Matthai (1968). It was found that the dominant factor in determining the value of $C$ is the channelcontraction ratio ( $m$ ) which describes the degree of contraction imposed by the constriction on the normal stream channel. The contraction ratio is a measure of the portion of the total flow that enters the contraction from the sides of the channel. It can be computed from the equation

$$
m=\left(Q-q^{\prime}\right) / Q
$$

in which $Q$ is the total discharge and $q^{\prime}$ is the discharge that would have passed through the area of the opening if the constriction was not there. For the example shown in figure $16-1, Q=5,075$ and $q^{\prime}=5,075 / 5$ because the channel is uniform so one-fifth of the flow would have passed through the center 100 feet had the constriction not existed. For very wide flood plains (width of flood plain greater than five times the width of the opening), or very rough approach conditions (Manning's $n$ greater than 0.05), special precautions are needed. For these conditions the special procedures developed by Schneider and others (1977) should be used.

The total value of $C$ is then computed as

$$
C=C^{\prime} k_{F} k_{\phi} \ldots
$$

in which $C^{\prime}$ is a function only of $\mathrm{m}$ and $\mathrm{L} / \mathrm{b}$ where $\mathrm{L}$ and $\mathrm{b}$ are defined in figure $16-3 C$ and $k_{F}, k_{\phi}$, etc., account for other factors such as shape.

Figure 16-3 contains a copy of some of the figures for a type 1 opening (Matthai, 1968). For this opening, the value of $\mathrm{C}^{\prime}$ is determined from figure 16-3A. The value of $C$ is equal to $C^{\prime}$ if the Froude number is 0.5 , the corners are not rounded, etc. If the Froude number is net 0.5 , the correction for $C^{\prime}$ can be determined from figure $16-3 \mathrm{~B}$ if the corners are rounded, the correction can be determined from figure $16-3 C$, etc. 

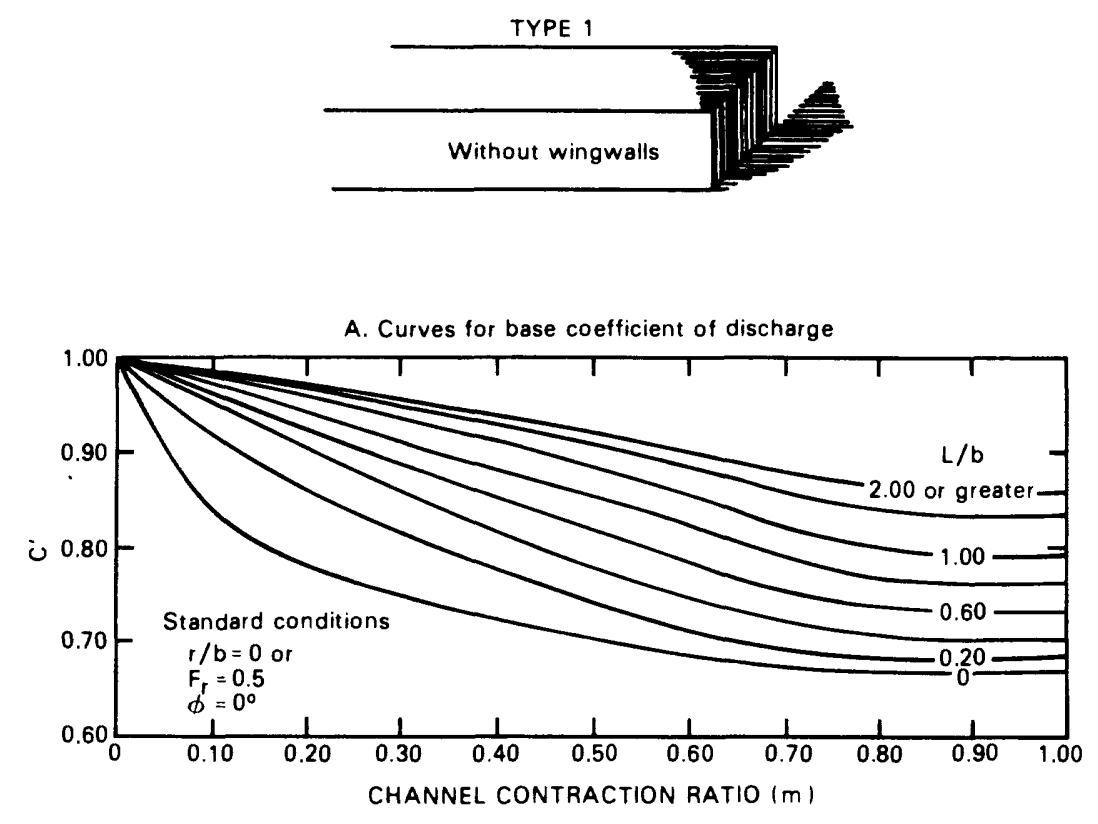

B. Adjustment factor variation with Froude number
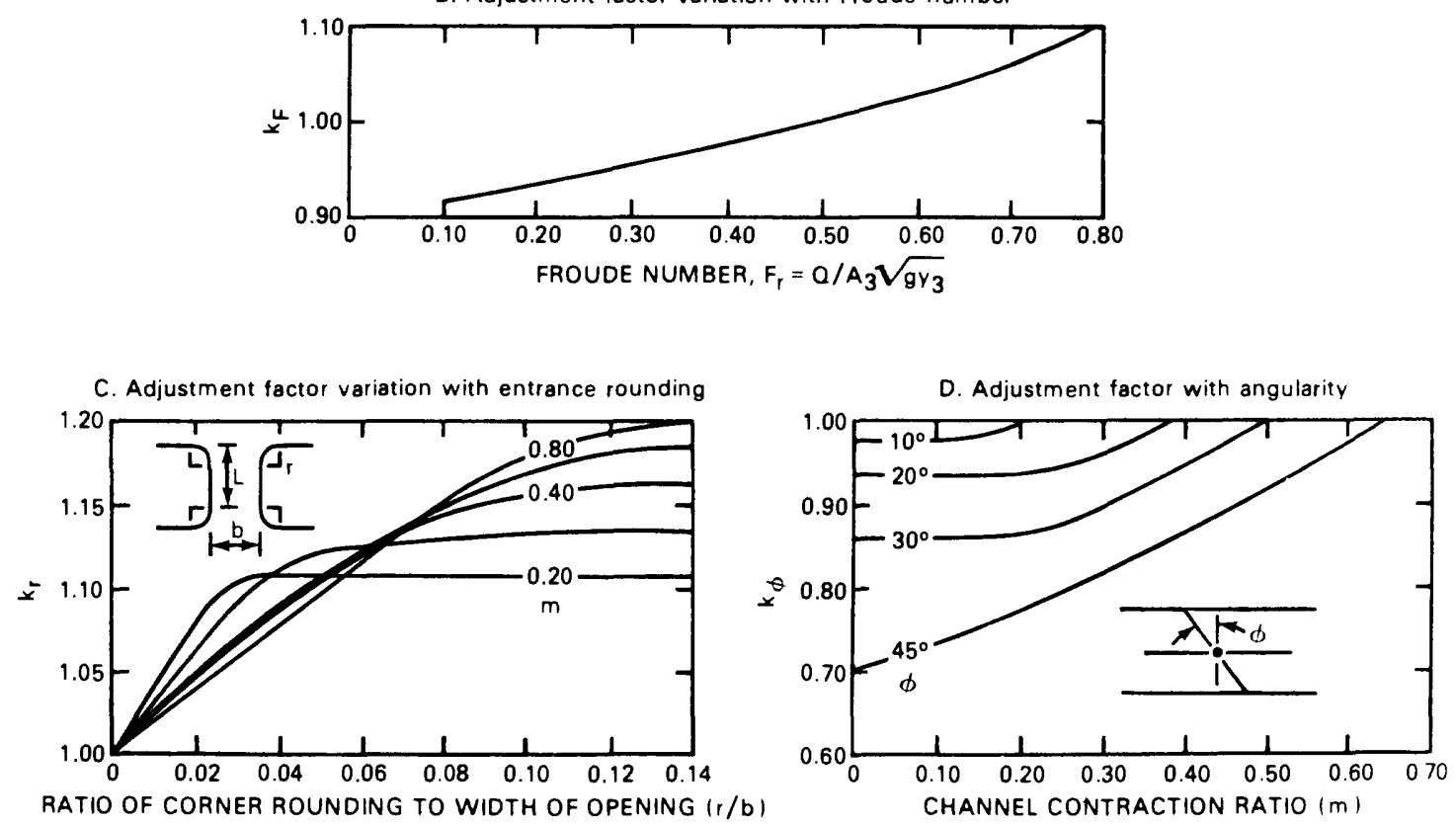

Figure 16-3.--Coefficients for type 1 opening, vertical embankments, and vertical abutments. 


\section{PROBLEM}

Compute the flood discharge through a highway bridge opening in a practically straight, uniform reach of a river. The bridge spans the main channel and completely blocks both overbanks. The bridge opening is 180 feet wide and 30 feet in length with vertical embankments and vertical abutments (Type I opening) and no piers as shown in the figure below. The average water surface at the contracted section was found to be 3.0 feet below that at the approach section. Data for the approach section and the contracted section are given below. The approach section is located 180 feet upstream from the obstruction.

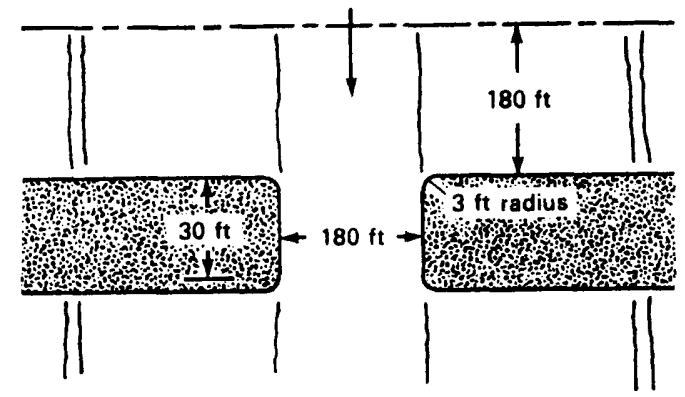

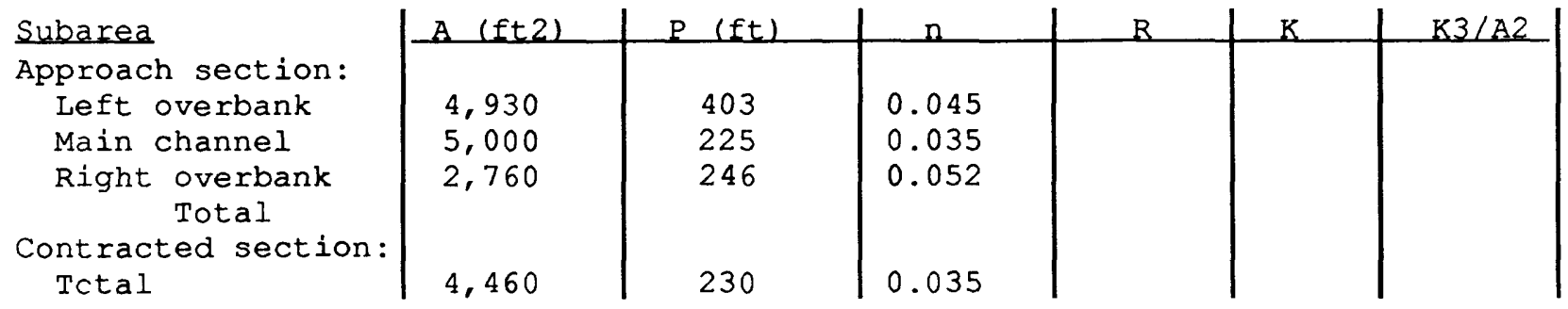


Solution Procedure:

(a) Compute conveyances at approach section.

(b) Compute velocity head correction factor at approach section ( $\alpha 1$ ).

(c) Compute conveyance at contracted section.

(d) Compute channel contraction ratio, $\mathrm{m}$, and length-to-width ratio, $\mathrm{L} / \mathrm{b}$.

(e) Determine C' for a Type I opening from figure 16-3A.

(f) Assuming a Froude number of 0.5, determine the discharge coefficient (C) from figures $16-3 \mathrm{~A}$ and $16-3 \mathrm{C}$.

(g) Compute the discharge through the contracted opening using equation 16-2 and the following table.

\begin{tabular}{|c|c|c|c|c|c|c|c|}
\hline $\begin{array}{c}\text { Assumed } \\
Q\end{array}$ & $\frac{\alpha_{1} V_{1} 2}{2 g}$ & $h_{f}^{1-2}=\frac{L^{12} Q^{2}}{K_{1} K_{3}}$ & $h_{f}{ }^{2-3}=\frac{L^{23} Q^{2}}{k_{3}{ }^{2}}$ & $v_{3}$ & $F_{r 3}$ & $\mathrm{k}_{\mathrm{F}}$ & $Q$ \\
\hline 25,000 & & & & & & & \\
\hline & & & & & & & \\
\hline & & & & & & & \\
\hline & & & & & & & \\
\hline & & & & & & & \\
\hline & & & & & & & \\
\hline & & & & & & & \\
\hline & & & & & & & \\
\hline & & & & & & & \\
\hline & & & & & & & \\
\hline & & & & & & & \\
\hline & & & & & & & \\
\hline
\end{tabular}


When a roadway crosses a small stream, the streamflow is usually carried under the roadway by use of a culvert. Like a bridge opening, the culvert invariably constricts the flow and the channel transition usually results in rapidly varied flow wherein acceleration rather than boundary friction dominates the flow pattern. Because acceleration is an efficient process, the energy losses are small and peak discharges through culverts can be determined from high-water marks that define the headwater and tail-water elevations. This indirect method is used extensively to estimate flood discharges from small drainage areas.

Culvert flow has been studied in laboratories by the Geological survey, the Bureau of Public Roads, and many universities. Detailed procedures for indirect discharge measurements are outlined by Bodhaine (1968). The purpose of this lesson is to review the theory upon which these procedures are based and to briefly outline the procedures that are used.

In all cases the flow rate is computed by writing the energy equation between a point upstream of the culvert and a second point within or downstream of the culvert, then solving for the discharge in terms of an estimate of the energy loss. The procedure has much in common with that used at bridge openings. Figure 17-1 represents a schematic of the flow through a culvert with the sections and terms defined. For culverts the best point to use as the downstream control (second point in energy equation) depends very much on the flow conditions. In general there are six types of flow possible. These are summarized in figure 17-2.

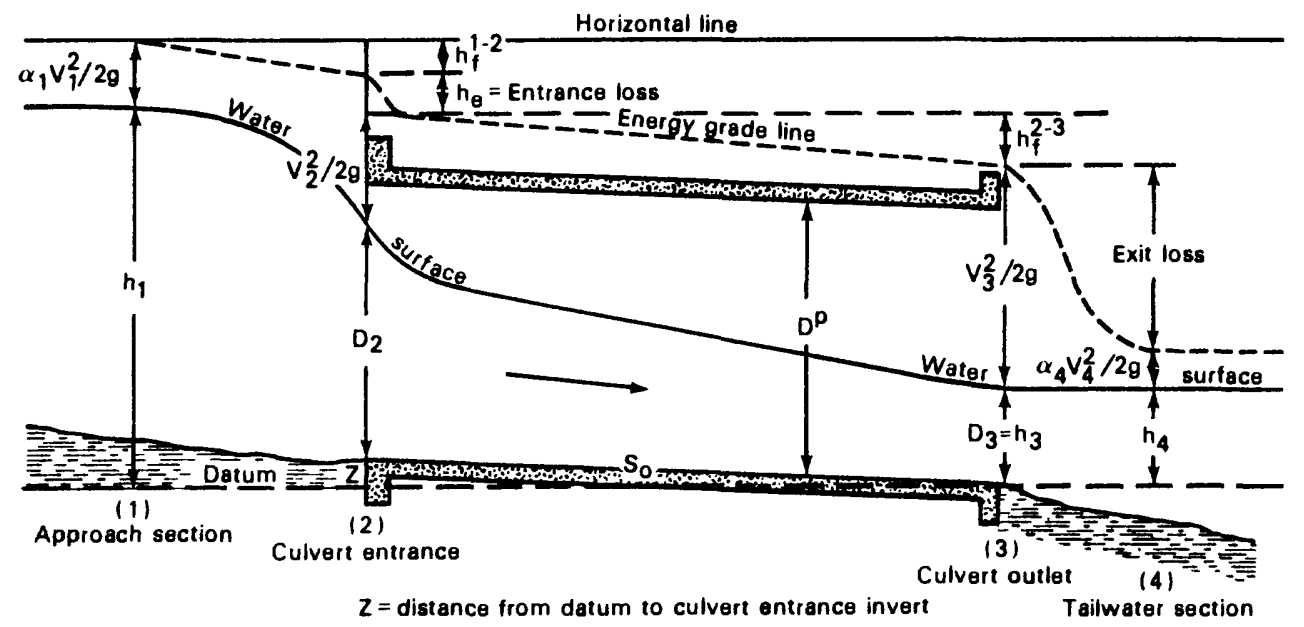

Figure 17-1.--Definition sketch of culvert flow.

Note: the loss of energy near the entrance is related to the sudden contraction and subsequent expansion of the live stream within the culvert barrel. 


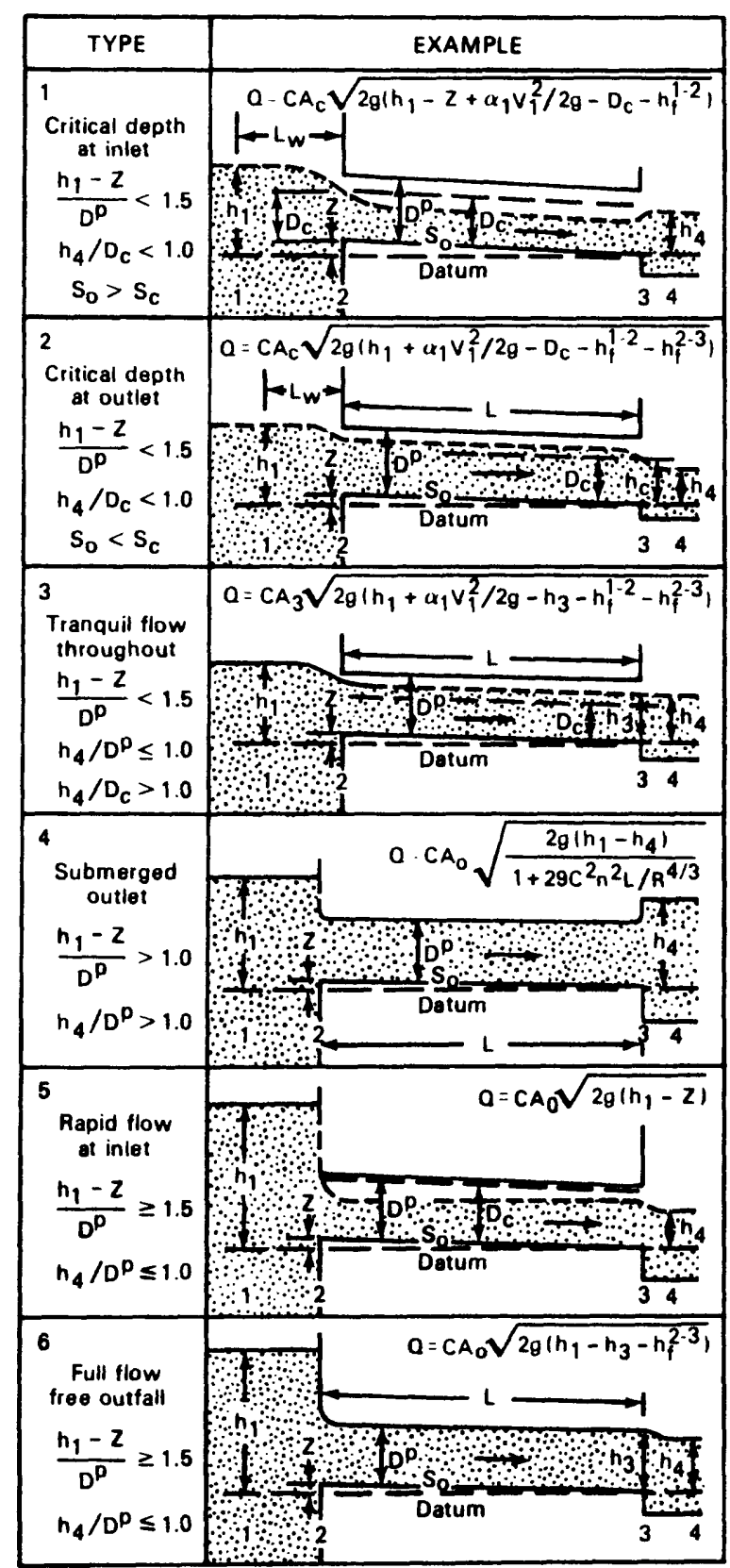

Figure 17-2.--Classification of culvert flow (after Bodhaine, 1968, p. 2). 
The discharge equation for type 1 flow will be derived to illustrate the procedure. Writing the energy equation from section 1 to section 2

$$
h_{1}+\frac{\alpha_{1} v_{1}^{2}}{2 g}=D_{2}+z+\frac{v_{2} 2}{2 g}+h_{e}+h_{f} 1-2,
$$

where $\alpha_{2}$ is assumed to be 1.0 because the flow velocity should be fairly uniform in the culvert. The entrance loss, he, for the contraction is approximated as

$$
h_{e}=k_{e} \frac{v_{2}{ }^{2}}{2 g}
$$

The value of $k_{e}$ has been found, by use of many experiments, to range from 0.1 to 0.6 depending on the shape of the entrance.

$$
\begin{aligned}
& \text { Solving for } \mathrm{v}_{2}{ }^{2} \\
& \qquad \frac{\mathrm{v}_{2}{ }^{2}}{2 \mathrm{~g}}+\mathrm{k}_{\mathrm{e}} \frac{\mathrm{v}_{2}{ }^{2}}{2 \mathrm{~g}}=\mathrm{h}_{1}-\mathrm{z}+\frac{\alpha_{1} \mathrm{v}_{1}{ }^{2}}{2 \mathrm{~g}}-\mathrm{D}_{2}-\mathrm{h}_{\mathrm{f}} 1-2
\end{aligned}
$$

in which $\mathrm{z}$ is the distance from the datum to the culvert invert, but $\mathrm{V}_{2}=\mathrm{Q}_{\mathrm{A}} \mathrm{A}$ and $A_{2}=A_{C}, D_{2}=D_{C}$ since critical depth occurs at the inlet so

$$
\frac{Q^{2}}{A_{C}{ }^{2} 2 g}\left(1+k_{e}\right)=h_{1}-z+\frac{\alpha_{1} V_{1}^{2}}{2 g}-D_{C}-h_{f} 1-2 .
$$

Define the coefficient of discharge, C, as

$$
c=\frac{1}{\sqrt{1+k_{e}}}
$$

then solve for $Q$ as

$$
Q=A_{C} C \sqrt{2 g\left(h_{1}-z+\frac{\alpha_{1} V_{1}{ }^{2}}{2 g}-D_{C}-h_{f} 1-2\right)}
$$

and the formula in figure $17-2$ is obtained. Notice as $k_{e}$ varies from 0.1 to 0.5 the value of $C$ ranges from 0.95 to 0.82 in excellent agreement with the values given in figure 17-3, which is a reproduction of Bodhaine's figure 23 (1968). The values in figure 17-3, as for most other figures in Bodhaine's report, were derived from laboratory experiments on scale models. The head loss term is computed as

$$
h_{f} 1-2=\frac{L Q^{2}}{K_{1} K_{2}}
$$

in which $L$ is the distance from section 1 to section 2 . 

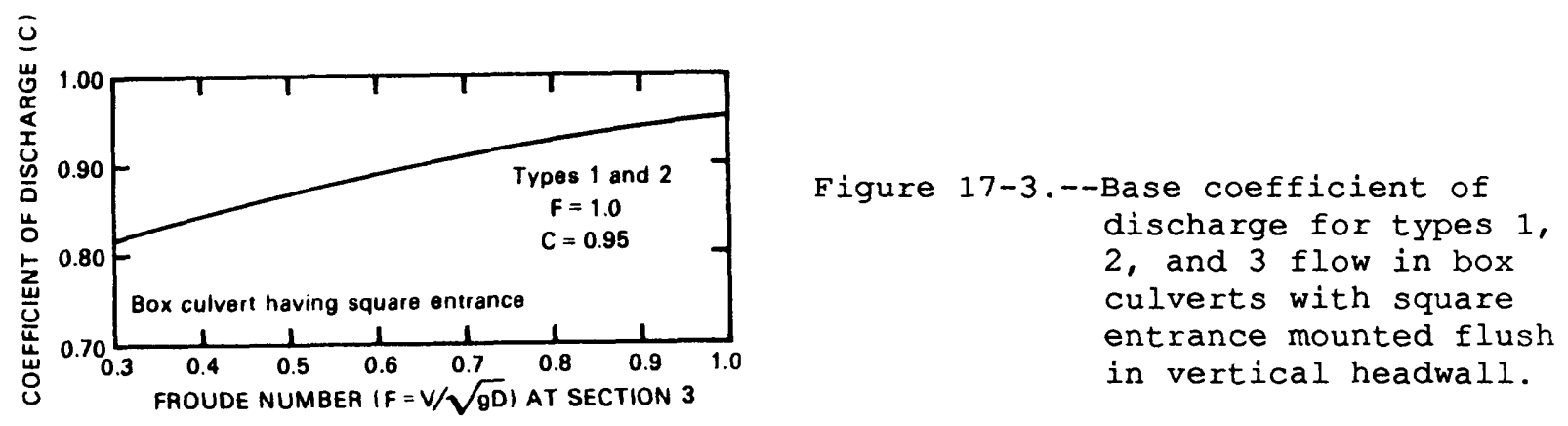

The critical depth at section 2 must be determined to apply equation 17-4. It will be recalled from lesson 11 (equations 11-4 and 11-8) that critical depth is uniquely related to specific energy and velocity head or

$$
D_{C}=2 / 3 E=2 \frac{V_{C}^{2}}{2 g} \text {. }
$$

The specific energy at section 2 can be easily computed by referring to equation $17-1$ or figure $17-1$ as

$$
\mathrm{E}_{2}=\mathrm{h}_{1}+\alpha_{1} \frac{\mathrm{V}_{1}^{2}}{2 \mathrm{~g}}-\mathrm{z}-\mathrm{h}_{\mathrm{f}} 1-2-\mathrm{k}_{\mathrm{e}} \frac{\mathrm{v}_{2}{ }^{2}}{2 \mathrm{~g}}
$$

letting $\mathrm{H}_{1}$ be defined as the specific energy at section 1 relative to the bottom of the culvert entrance

$$
\mathrm{H}_{1}=\mathrm{h}_{1}+\frac{\alpha_{1} \mathrm{~V}_{1}^{2}}{2 \mathrm{~g}}-\mathrm{z}
$$

and combining equations $17-6$ and $17-7$ it is seen that

$$
\mathrm{E}_{2}=1.5 \mathrm{D}_{\mathrm{C}}=\mathrm{H}_{1}-\mathrm{h}_{\mathrm{f}} 1-2-\mathrm{k}_{\mathrm{e}} \frac{\mathrm{D}_{\mathrm{C}}}{2}
$$

or that

$$
D_{C}=\frac{H_{1}-h_{f} 1-2}{\left(1.5+0.5 k_{e}\right)}
$$

If the entrance and friction losses were zero, $\mathrm{H}_{1}$ would equal $\mathrm{E}_{2}$ and $\mathrm{D}_{\mathrm{C}}$ would be $0.667 \mathrm{H}_{1}$. However, $k_{e}$ and $h_{f}{ }^{1-2}$ are never really zero so $D_{C}$ is always less than $0.667 \mathrm{H}_{1}$. The ratio of $\mathrm{D}_{\mathrm{C}}$ to $\mathrm{H}_{1}$ is called the $\mathrm{d}_{\mathrm{C}}$ factor and its value is computed from the coefficient of discharge (Bodhaine, 1968, p. 24). For example, assume $C=0.96$ and $h_{f}{ }^{1-2}=0$. From equation $17-3$ the entrance loss coefficient can be computed as

$$
(0.96)^{2}=\frac{1}{1+k_{e}}
$$

giving $k_{e}=0.085$ so 


$$
\mathrm{D}_{\mathrm{C}}=\frac{\mathrm{H}_{1}}{1.543}=0.648 \mathrm{H}_{1} \text {, }
$$

which agrees with the value given by Bodhaine (1968, p. 25).

As can be seen from figure 17-2, the six types of culvert flow can be divided into two groups $(1,2,3)$ and $(4,5,6)$ depending on whether or not the inlet is submerged. For subcritical upstream flow, critical depth is the smallest possible depth at the inlet to the culvert. So if critical depth at the inlet is larger than the pipe diameter, $D_{p}$, the inlet will be submerged. If you ignore the velocity head at section 1, the friction loss between sections 1 and 2 and the entrance loss, it can be seen from equation 17-9 that if $h_{1}-z$ is greater than $1.5 \mathrm{D}_{\mathrm{p}}$, the inlet will be submerged.

The flow equations for types 2 and 3 are obtained in the same way as the equation for type 1 except the downstream energy point is section 3 and the energy loss in the barrel must be accounted for.

Types 4, 5, and 6 occur when the inlet is submerged. In this case the velocity head at section one is ignored because it is assumed it would be negligible due to ponding upstream from the culvert.

The equation for type 4 is derived by writing the energy equation from section 1 to section 4 :

$$
h_{1}+\frac{\alpha_{1} v_{1}^{2}}{2 g}=h_{4}+\frac{\alpha_{4} v_{4}^{2}}{2 g}+h_{f} 1-2+h_{e}+h_{f} 2-3+h_{0}+h_{f} 3-4,
$$

in which $h_{e}$ and $h_{0}$ are the entrance and exit losses, respectively. Because of the large flow areas at sections 1 and 4 , these velocity head terms are assumed to be negligible as is the friction loss from 1 to 2 and 3 to 4 . The exit loss for a sudden expansion is computed in the usual way

$$
h_{0}=1.0 \frac{\left(V_{3}{ }^{2}-V_{4}{ }^{2}\right)}{2 g} \simeq \frac{V_{3}{ }^{2}}{2 g}=\frac{V_{p}{ }^{2}}{2 g}
$$

so rewriting with these assumptions

$$
h_{1}=h_{4}+k_{e} \frac{v_{p}^{2}}{2 g}+h_{f} 2-3+\frac{v_{p}^{2}}{2 g}
$$

computing the friction loss in the pipe from Manning's equation

$$
h_{f}{ }^{2-3}=\frac{L V_{p}^{2} n^{2}}{1.49^{2} R^{4 / 3}}
$$

solving for $V_{p}$

$$
\frac{v_{p}^{2}}{2 g}\left(1+k_{e}+\frac{2 g n^{2} L}{1.49^{2} R^{4 / 3}}\right)=h_{1}-h_{4}
$$

but $2 g / 1.49^{2}=29.01$ so

$$
\frac{Q^{2}}{A_{p}^{2} 2 g}\left(1+k_{e}\right)\left[1+\frac{1}{1+k_{e}} \frac{29 n^{2} L}{R^{4 / 3}}\right]=h_{1}-h_{4}
$$


letting $\frac{1}{1+k_{e}}=c^{2}$ as before

$$
Q=A_{p} C \sqrt{\frac{\left(h_{1}-h_{4}\right) 2 g}{1+\frac{29 C^{2} n^{2} L}{R^{4 / 3}}}}
$$

where $\mathrm{C}$ accounts for the entrance loss just as it does in all other cases.

The entrance loss coefficient is mainly a function of the rounding of the entrance as shown by table 17-1, which has been reproduced from Bodhaine's report $(1968$, p. 42).

$$
\begin{aligned}
& \text { Table 17-1.--Discharge coefficients for } \\
& \text { box or pipe culverts set } \\
& \text { flush in a vertical head- } \\
& \text { wall: types } 4 \text { and } 6 \text { flow } \\
& r / D / p \text { or } r / D \quad C \\
& r \text { = radius of curvature of bell }
\end{aligned}
$$

\begin{tabular}{ll}
\hline 0 & 0.84 \\
0.04 & 0.88 \\
0.08 & 0.96 \\
0.12 & 0.98 \\
\hline
\end{tabular}

Type 5 acts as an orifice where the velocity at 2 is $\sqrt{2 g\left(h_{1}-z\right)}$ and the $\mathrm{C}$ accounts for the vena contracta (contraction) at the orifice. Type 6 is treated as an orifice at section 3 (no contraction), but the head losses at the entrance and through the pipe must be accounted for. 


\section{PROBLEMS}

1. A 5-foot diameter concrete culvert is 180 feet long and has a Manning's $n$ of 0.015 . It has a bell entrance for which the radius of curvature of the bell is 0.4 foot, the pipe is set flush in a vertical headwall, and the pipe slope is 0.002 . High-water marks observed after a flood indicate that the headwater elevation was 7.36 feet and the tailwater elevation was 5.50 feet. The pipe is set flush in a headwall.
a. Was the outlet submerged? (See figure 17-2)
b. Was the inlet submerged? (See figure 17-2)
c. What type flow occurred? (See figure 17-2)
d. What was the flow rate? (See table 17-1)

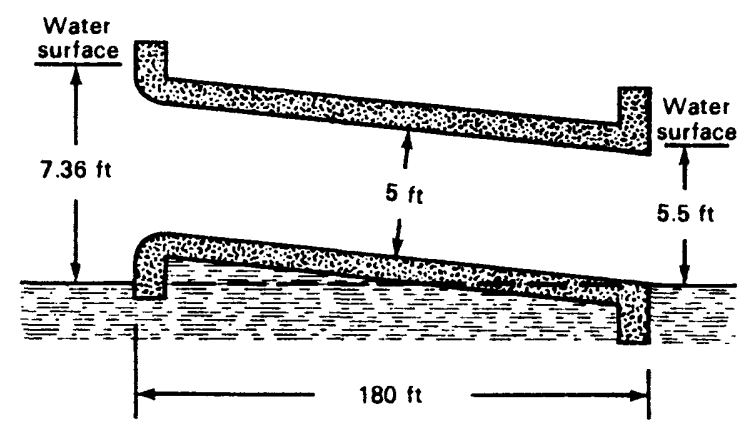


2. A box culvert 8-feet square is set on a steep slope and has a free getaway so there is no backwater. It has a square entrance mounted flush with a vertical headwall. The headwater elevation for a flood was observed to be 10 feet, which is 8 feet above the entrance invert. The approach section, which is 20 feet upstream of the culvert entrance, had an area of $330 \mathrm{ft}^{2}$ and a conveyance of $38,900 \mathrm{ft}^{3} / \mathrm{s}$. The Manning's coefficient in the pipe is 0.015 .

a. How do you know it was not type 4 flow?

b. How do you know it was not type 5 or 6 flow?

c. How do you know it was not type 2 or 3 flow?

d. Make a rough estimate of the flow assuming $\frac{\mathrm{V}_{1}^{2}}{2 \mathrm{~g}}=0$ and $\mathrm{D}_{\mathrm{C}}=2 / 3 \mathrm{H}_{1}$.

e. Compute the actual critical depth at the entrance by accounting for the entrance loss by use of equation 17-9. Ignore the friction loss.

f. Using the approximate discharge computed in step d as a first guess, compute the flow through the culvert by use of equation 17-4. Compare your results with those given in example 2 of Bodhaine (1968, p. 53).

g. Draw the energy and hydraulic grade lines between sections 1 and 2 on a figure like that shown in figure 17-1 and compute the values of all components of the curve. 


\section{Lesson 18 - Flow Over Weirs}

\section{Definitions}

A weir is an obstruction in a channel that causes water to back up behind it and flow over it, usually through an opening, er notch, of regular form. The term is also applied to the structure containing such a notch. Thus a weir may be a depression in the side of a tank, reservoir, or channel, or it may be an overflow spillway of a dam. In addition, weirs are the simplest, least expensive, and probably the most common type of devices used to measure flow in open channels. Detailed procedures for measuring peak discharges using dams, weirs, and embankments are described by Hulsing (1967). This lesson will only give the background theory and briefly introduce the methods.

The edge or surface over which the water passes is called the crest of the weir. If the edge of the weir is thin or beveled with a sharp upstream corner so that the water springs clear of the crest on the downstream side, the weir is referred to as a sharp-crested weir (fig. 18-1). If the weir notch is mounted in a wall or some other structure that is too thick for the water to spring clear, the weir is called a broad-crested weir (fig. 18-2).
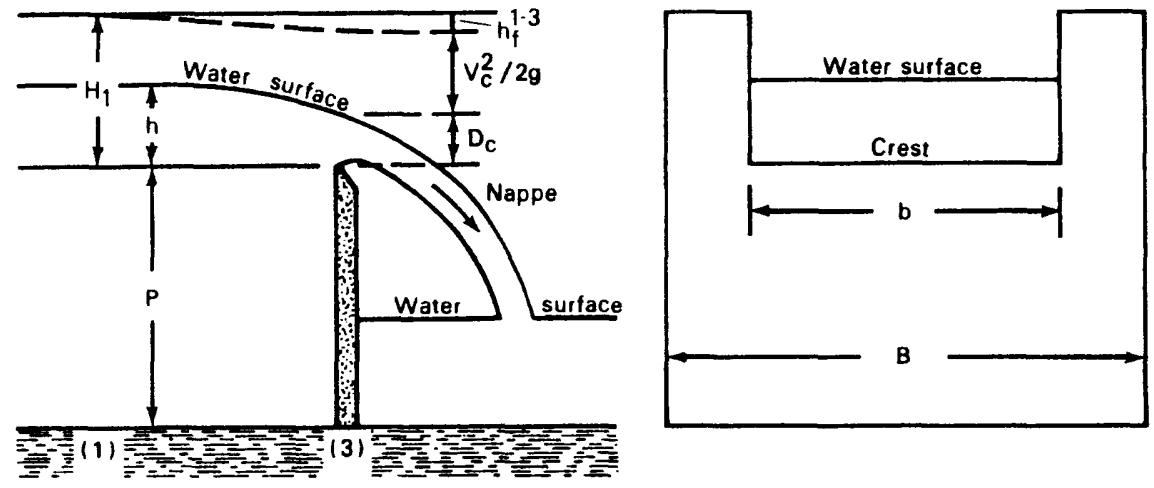

Figure 18-1.--Definition sketch for a contracted, sharp-crested weir.

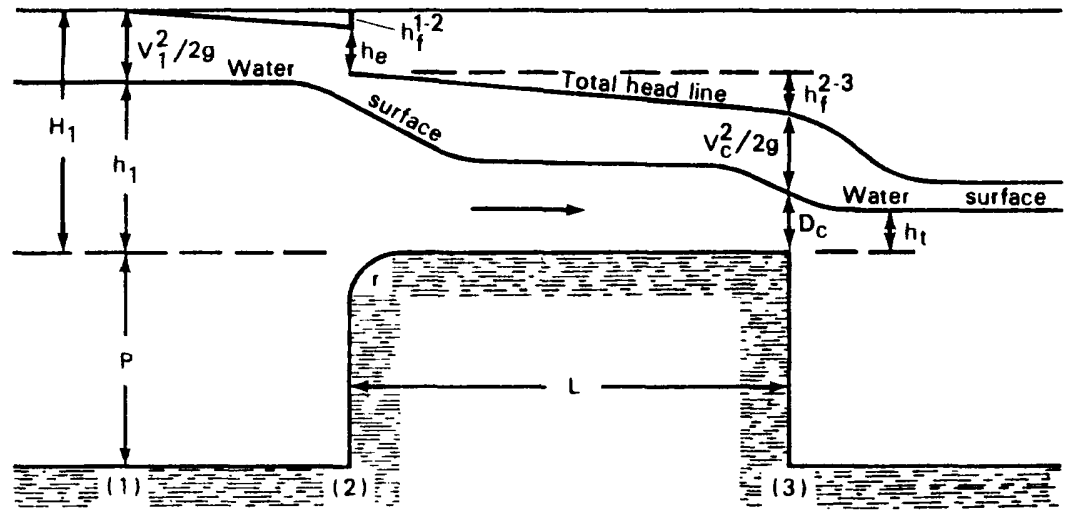

Figure 18-2.--Definition sketch for a broad-crested weir. 
The sheet of water flowing over the weir crest is called the nappe. When the water surface downstream from the weir is far enough below the crest so that air moves freely beneath the nappe (aeration), the discharge is said to be free or critical. When the water level under the nappe rises to the point where free aeration is not possible, the nappe is not ventilated. When the downstream water surface rises to a level above the crest, the flow is said to be submerged or drowned. When the downstream water surface is above the weir crest a distance equal to about two-thirds or more of the distance between the crest and the upstream water surface, the flow rate will be appreciably affected.

\section{Broad-Crested Weirs}

Consider the flow over a broad-crested weir as shown in figure 18-2. A flow constriction occurs so potential energy upstream of the weir is being converted to kinetic energy as the water accelerates over the weir and there is a drop in water-surface elevation. If the tailwater elevation, $h_{t}$, is less than the elevation of critical depth over the weir $\left(\simeq 2 / 3 \mathrm{H}_{1}\right)$, the flow rate will be independent of the tailwater elevation.

To develop the flow equations for a broad-crested weir, write the energy equation from section 1 to 3 on figure 18-2. Let section 3 be located at the critical depth point that will be near the downstream side of the weir if the crest slope is less than critical. If the slope of the crest is greater than the critical slope, the critical depth will occur near the upstream side of the weir. In either case, applying the energy equation between section 1 and the critical depth (section 3) yields

$$
\frac{\alpha_{1} V_{1}^{2}}{2 g}+h_{1}=H_{1}=\frac{V_{c}^{2}}{2 g}+D c+h_{f}^{1-2}+h_{e}+h_{f}^{2-3}
$$

Because the velocity upstream of the weir is usually small, it is common to assume $h_{f}{ }^{1-2}=0$. Likewise the length of the weir, L, is usually small so the value of $h_{f} 2-3$ is also ignored. The value of $h_{e}$ is approximated as usual by

$$
h_{e}=k_{e}\left(\frac{V_{c}^{2}}{2 g}-\frac{\alpha_{1} V_{1}^{2}}{2 g}\right)
$$

where $v_{1}$ is approximately zero, so simplifying equation 18-1 gives

$$
\mathrm{H}_{1}=\mathrm{D}_{\mathrm{C}}+\frac{\mathrm{VC}^{2}}{2 \mathrm{~g}}\left(1+\mathrm{k}_{\mathrm{e}}\right) \text {. }
$$

Recall from equation 11-8 that critical depth in a rectangular channel is related to the total specific energy and velocity as

$$
D_{C}=2 \frac{V_{C}^{2}}{2 g}=2 / 3 E_{C} \simeq 2 / 3 \mathrm{H}_{1} \text {, }
$$

so

$$
\mathrm{H}_{1}-\frac{2}{3} \mathrm{H}_{1}=\frac{\mathrm{H}_{1}}{3}=\frac{\mathrm{VC}^{2}}{2 \mathrm{~g}}\left(1+\mathrm{k}_{\mathrm{e}}\right)
$$




$$
v_{c}=\sqrt{\frac{2 g}{3\left(1+k_{e}\right)}} H_{1} 0.5 \text {. }
$$

The discharge can be directly computed as

$$
Q=b D_{C} V_{C}=b \frac{2}{3} \sqrt{\frac{2 g}{3\left(1+k_{e}\right)}} H_{1} 1.5 .
$$

This equation can be written simply as

$$
\mathrm{Q}=\mathrm{b} \mathrm{CH}^{1} \cdot 5 \text {, }
$$

where the theoretical discharge coefficient is

$$
C=\frac{2}{3} \sqrt{\frac{2 g}{3\left(1+k_{e}\right)}} .
$$

Figure 18-3 has been extracted from Hulsing (1967) to illustrate the variation of $C$ with weir height.

As stated before, the value of $k_{e}$ generally ranges from a low of 0 for very smooth openings or where the contraction ratio is small (h/L is small) to a maximum value of about 0.5 for sharp nonstreamlined openings and a large contraction ratio. As $\mathrm{k}_{\mathrm{e}}$ varies from 0.0 to 0.5 , the theoretical value of $\mathrm{C}$, based on equation 18-5 varies from 3.09 to 2.52 , which are within the range of values indicated on figure 18-3. For values of $\mathrm{h} / \mathrm{L}$ larger than 1.0, the length of the weir (L) is short and the weir begins behaving more like a sharp-crested weir, which as will be seen, has a larger coefficient of discharge. The efficiency of the weir increases (C increases) as the upstream face is sloped. This in effect streamlines the entrance and reduces the value of $\mathrm{ke}_{\mathrm{e}}$.

Figure 18-3.--Coefficients of discharge for full width, broad-crested weirs with downstream slope $=1: 1$, and various upstream slopes (Hulsing, 1967, p. 10).
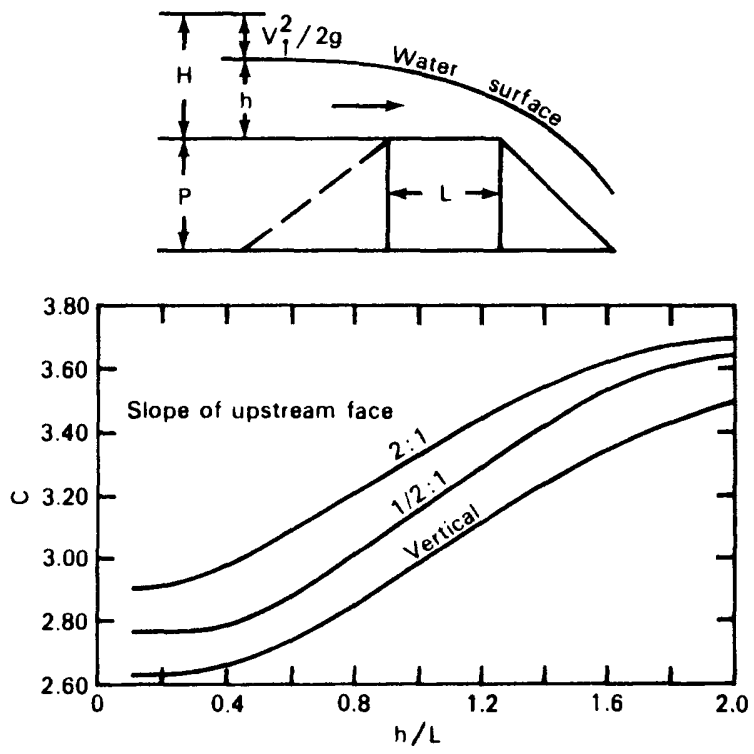
The coefficient of discharge in equation $18-4$ is actually a function of many variables besides $k_{e}$. In general, it is a function of the shape of the entrance and other variables as defined by

$$
C=f\left(\frac{h}{L}, \frac{r}{L}, H_{1} \text {, etc. }\right)
$$

in which $r$ is the radius of the rounding on the upstream corners. The effect of many of these variables has been quantified by laboratory experiments and the results are presented by Hulsing (1967). Corrections for other variables are accounted for by letting

$$
C=C^{\prime} k_{r} k_{s} \ldots
$$

in which $C^{\prime}$ is determined from figure $18-3$ and the $k^{\prime} s$ are determined from other figures or tables. For example, if the slope of the downstream face of the weir is flatter than 1:1, the values of C from figure 18-3 must be multiplied by the factor, $k_{s}$, given in the following table (Hulsing, 1967, p. 9).

\begin{tabular}{lllll}
\hline & \multicolumn{2}{c}{ Value of $\mathrm{k}_{\mathrm{S}}$ for a downstream slope of } \\
\cline { 2 - 5 } $\mathrm{h} / \mathrm{L}$ & $2: 1$ & $3: 1$ & $4: 1$ & $5: 1$ \\
\hline & & & & \\
\hline .1 & 1.00 & 1.00 & 1.00 & 1.00 \\
0.4 & 1.00 & 1.00 & 1.00 & 1.00 \\
1.0 & 0.98 & 0.96 & 0.95 & 0.94 \\
2.0 & 0.98 & 0.94 & 0.91 & 0.90 \\
\hline
\end{tabular}

If the upstream weir face is vertical and the entrance corner is rounded, the value of C from figure 18-3 must be multiplied by a factor, $k_{r}$, given in the following table (Hulsing, 1967, p. 9).

\begin{tabular}{llllllllll}
\hline $\mathrm{r} / \mathrm{h}$ & 0 & .02 & .04 & .06 & .08 & .10 & .12 & $\leq .14$ \\
\hline $\mathrm{k}_{\mathrm{r}}$ & 1.00 & 1.01 & 1.03 & 1.04 & 1.05 & 1.06 & 1.08 & 1.09 \\
\hline
\end{tabular}

\section{Sharp-Crested Weirs}

If the corner of the upstream face of the weir is very sharp and the length of the weir, $L$, is small, the water jet (nappe) will spring clear of the weir as shown in figure 18-1. In writing the energy equation for a sharpcrested weir, consider section 3 to be immediately downstream of the weir plate. Actually, the streamlines will have strong curvature at the face of the weir so the one-dimensional assumptions will not be strictly valid but nevertheless useful approximations result. 
Because the jet at section 3 is not supported from below, the pressure at all points in the jet is zero and does not increase from zero at the surface to $\gamma_{C}$ at the bottom as it does for a broad-crested weir. The hydraulic head (potential plus pressure-potential energy) therefore is not $D_{C}$ at section 3 but simply the average potential energy of parcels passing section 3. The potential energy of a water parcel on the bottom of the jet is zero while that of one on the top of the jet is $D_{C} f t-l b / l b$. Assuming the average potential energy of parcels passing section 3 is equal to the potential energy of the parcel passing through the centroid of the cross section, the energy equation yields

$$
\mathrm{H}_{1}=\frac{\mathrm{V}_{\mathrm{C}}^{2}}{2 \mathrm{~g}}+\frac{\mathrm{D}_{\mathrm{C}}}{2}+\mathrm{h}_{\mathrm{f}}^{1-3}+\mathrm{k}_{\mathrm{e}}\left(\frac{\mathrm{V}_{\mathrm{C}}^{2}}{2 \mathrm{~g}}-\frac{\mathrm{V}_{1}^{2}}{2 \mathrm{~g}}\right)
$$

because the centroid of the cross section (a rectangle) will be $D_{C} / 2$ feet above the crest of the weir. Equation 18-8 is identical to equation 18-1 except that the hydraulic head is adjusted to account for the fact that the pressure in the free jet is zero and so the average potential energy of water parcels passing section 3 is $D_{C} / 2 \mathrm{ft}-\mathrm{lb} / \mathrm{lb}$ rather than $D_{C} f t-1 b / l b$, which would occur if the pressure were hydrostatic. Because the depth upstream of the weir is generally large compared to the depth at the weir, we will consider $v_{1}$ and $h_{f}{ }^{1-3}$ to be zero.

With this slight modification to the energy equation, the flow over a sharp-crested weir can be analyzed exactly like that for flow over a broadcrested weir. The depth should be at critical depth at the weir plate so $D_{C}=2 / 3 \mathrm{H}_{1}$, which can be substituted into equation 18-8 to determine the average velocity in the jet

$$
\mathrm{v}_{\mathrm{C}}=\sqrt{\frac{4 \mathrm{~g}}{3\left(1+\mathrm{k}_{\mathrm{e}}\right)}} \sqrt{\mathrm{H}_{1}}
$$

Comparing the velocity in a free jet as computed above to that on a broadcrested weir computed previously, it is seen that the average free jet. is two times faster. This is because there is no pressure in the jet holding the water parcels back.

\section{Rectangular Weirs}

Computing the discharge for a sharp-edged rectangular weir from the velocity and the area, one obtains

$$
\mathrm{Q}=\mathrm{VA}=\left(\frac{2}{3} \mathrm{~b}_{\mathrm{H}}\right) \quad \sqrt{\frac{4 \mathrm{~g}}{3\left(1+\mathrm{k}_{\mathrm{e}}\right)}} \sqrt{\mathrm{H}_{1}}=\frac{2}{3} \mathrm{~b} \sqrt{\frac{4 \mathrm{~g}}{3\left(1+\mathrm{k}_{e}\right)}} \mathrm{H}_{1}{ }^{1} .5 .
$$

Again this equation is usually written as

$$
Q=b C H^{1.5} \text { or } Q=b C h^{1.5} \text {. }
$$

The values of total head (H) or piezometric head are often used interchangeably because the velocity head upstream is usually negligible. The theoretical value of the coefficient of discharge is 


$$
c=\frac{2}{3} \sqrt{\frac{4 g}{3\left(1+k_{e}\right)}} .
$$

As the entrance coefficient varies from 0 to 0.5 , the theoretical discharge coefficient varies from 4.37 to 3.57 , which is close to the experimental values presented by Hulsing (1967, p. 6). The minimum discharge coefficient presented by Hulsing is 3.27 for a very small weir $(h / P \rightarrow 0)$ and the maximum value is 4.29 .

If the width of the weir is less than the width of the channel ( $b<B$ on fig. 18-1), then the flow tends to contract downstream of the weir plate (a vena contracta is formed). The discharge coefficient is reduced because of the smaller effective width of the jet. As can be seen from figure 3 in Hulsing (1967, p. 6), this contraction can reduce the flow area by almost 30 percent.

If the nappe is not fully ventilated, a partial vacuum is created under the jet that reduces the pressure in the jet below atmospheric and increases the discharge just as reducing the pressure in the jet increases the discharge relative to the flow over a broad-crested weir.

\section{Triangular Weirs}

Triangular (V-notch) weirs permit the accurate measurement of much lower discharges than do horizontal rectangular weirs.

A definition sketch for the V-notch weir is shown in figure 18-4. The theoretical discharge for a $V$-notch weir is derived in the same manner as that for the rectangular weir.

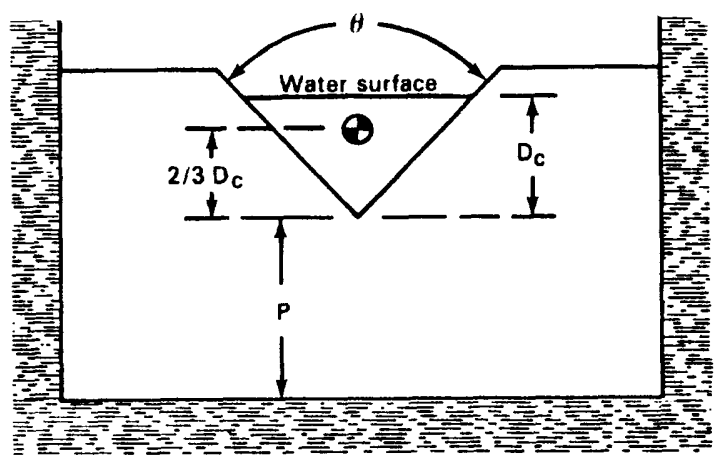

Figure 18-4.--Definition sketch of a V-notch (triangular) sharp-crested weir.

Section 3 is again just downstream of the opening and the pressure in the jet is zero so the average potential energy of water parcels must be used. For a triangular weir, the centroid of the cross-sectional area is at $2 / 3 \mathrm{D}_{C}$ (see fig. 18-4) so the energy equation becomes

$$
\mathrm{H}_{1}=\frac{\mathrm{V}_{\mathrm{C}}^{2}}{2 \mathrm{~g}}+\frac{2}{3} \mathrm{D}_{\mathrm{C}}+\mathrm{k}_{\mathrm{e}}\left(\frac{\mathrm{V}_{\mathrm{C}}^{2}}{2 \mathrm{~g}}-\frac{\mathrm{V}_{1}^{2}}{2 \mathrm{~g}}\right)+\mathrm{h}_{\mathrm{f}}^{1-3} \text {. }
$$

The critical depth in a triangular channel is not equal to two-thirds of the total specific energy as in a rectangular channel. It can be easily shown that critical depth in a triangular channel is 


$$
D_{C}=4 \frac{V_{C}^{2}}{2 g}=\frac{4}{5} E \simeq \frac{4}{5} H_{1}
$$

by use of equation $11-3$. So the velocity at the critical section can be determined by use of equations $18-11$ and $18-12$ as

$$
\mathrm{v}_{\mathrm{C}}=\sqrt{\frac{14 \mathrm{~g}}{15\left(1+\mathrm{k}_{\mathrm{e}}\right)}} \sqrt{\mathrm{H}_{1}}
$$

and the discharge is computed as

$$
Q=A_{C} V_{C}=\left(\frac{4}{5} H_{1}\right)^{2} \tan \frac{\theta}{2} \sqrt{\frac{14 g}{15\left(1+k_{e}\right)}} \sqrt{H_{1}}
$$

or

$$
Q=\tan \frac{\theta}{2} C_{H}^{5 / 2}
$$

in which the theoretical discharge coefficient

$$
C=\frac{16}{25} \sqrt{\frac{14 g}{15\left(1+k_{e}\right)}} .
$$

For a sharp, constricted entrance, the value of $k_{e}$ should be about 0.5 yielding a theoretical discharge coefficient for a V-notch weir of 2.86 . Experimental values of $C$ range from 2.46 for a $60^{\circ}$ weir to 2.48 for a $90^{\circ}$ weir (Daugherty, 1937, p. 148).

A correction factor, $k_{t}$, for submergence of sharp-crested $v$-notch weirs is given by villemonte (1947) as

$$
k_{t}=\left[1-\left(\frac{h_{t}}{H_{1}}\right)^{5 / 2}\right]^{0.385}
$$

in which $h_{t}=$ tailwater elevation above the weir crest. This equation was found to apply equally well to all types of sharp-crested weirs if the exponent of the term $\left(h_{t} / H_{1}\right)$ is equal to the exponent in the free-discharge equation of the particular weir.

\section{other Sharp-Crested Weirs}

The Cippoletti (trapezoidal) weir is similar to a rectangular weir with side contractions except that the sides are inclined outwardly with slopes of 4 vertical to 1 horizontal as shown in figure 18-5. The excess flow permitted by the flared sides of the Cippoletti weir corresponds to the decrement of flow induced by the lateral contraction. Therefore, the discharge can be computed using equation 18-9 with the coefficient selected as for the rectangular weir and no correction is needed for the side contractions.

Other types of sharp-crested weirs are used which have been developed to achieve certain head-discharge relations or to achieve some benefit peculiar to a particular type of site. The most common of these special types of weirs is the sutro, or proportional, weir (fig. 18-6a). Other special purpose weirs 
include the approximate linear weir (fig. 18-6b), the approximate exponential weir (fig. $18-6 \mathrm{c}$ ), and the poebing weir (fig. 18-6d).

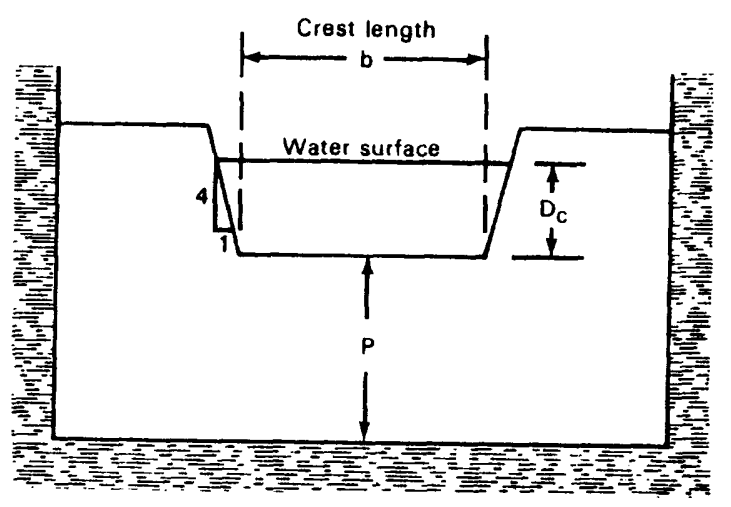
Figure 18-5.--Definition sketch of a Cippoletti (trapezoidal) sharp-crested weir.
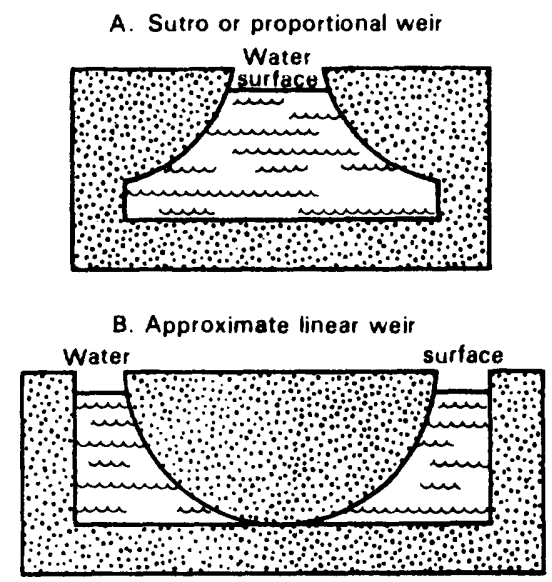

C. Approximate exponential weir

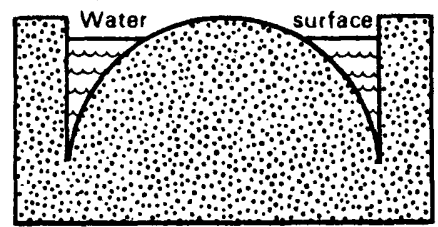

Figure 18-6.--Various other sharpcrested weir profiles.

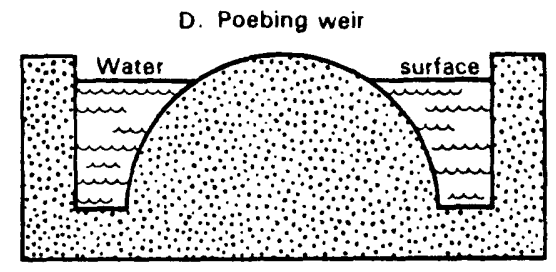




\section{PROBLEMS}

1. A broad-crested weir 5 feet high and 10 feet long has a rounded upstream corner with a radius of curvature 0.3 foot, a downstream slope of $1: 1$, a vertical upstream face, and spans the entire width of a 20 - foot wide rectangular channel. What is the discharge over the weir when the upstream water surface is 3 feet above the crest of the weir? 
2. Estimate the discharge over a vertical sharp-crested rectangular weir extending over the full width of a rectangular channel 5 feet wide if the weir is 3 feet high and the head is 0.84 foot. 
3. A rectangular sharp-crested weir having a horizontal crest length of 3 feet is located 2 feet above the bottom and is centered in a channel 5 feet wide. Determine the discharge when the head is 0.40 foot. 
4. A 10-foot wide rectangular irrigation canal carries a flow of $200 \mathrm{ft} 3 / \mathrm{s}$. At what height should a rectangular sharp-crested weir spanning the entire channel be installed in order to raise the water surface to a level 6 feet above the canal bottom? 
5. The head on a $60^{\circ} \mathrm{V}$-notch weir located 1 foot above the channel bottom is 0.5 foot. The approach channel is 4 feet wide. Compute the discharge and the velocity head in the approach channel. Is the velocity head in the approach channel significant? 


\section{REFERENCES}

Arcement, G.J., Jr., and Schneider, V.R., 1984, Guide for selecting Manning's roughness coefficient for natural channels and floodplains: U.S. Department of Transportation, Federal Highway Administration, FHWA-TS$84-204,62 \mathrm{p}$.

Barnes, H.H., 1967, Roughness characteristics of natural channels: U.S. Geological Survey Water-Supply Paper 1849, 213 p.

Bodhaine, G.L., 1968, Measurement of peak discharge at culverts by indirect methods: U.S. Geological Survey Techniques of Water-Resources Investigations, Book 3, Chapter A3, 60 p.

Bray, D.I., 1979, Estimating average velocity in gravel-bed rivers: Journal of the Hydraulics Division, American Society of Civil Engineering, $v$. 105, no. HY9, Proceeding Paper 14810, p. 1103-1122.

Chow, V.T., 1959, Open-channel hydraulics: New York, McGraw Hill, 680 p.

Cowan, W.L., 1956, Estimating hydraulic roughness coefficients: Agricultural Engineering, v. 37, no. 7, p. 473-475.

Daugherty, R.I., 1937, Hydraulics: New York, McGraw Hill, 148 p.

Davidian, Jacob, 1984, Computation of water-surface profiles in open channels: U.S. Geological Survey Techniques of Water-Resources Investigations, Book 3, Chapter A15, 48 p.

Griffiths, G.A., 1981, Flow resistance in coarse gravel bed rivers: Journal of Hydraulics Division, American Society of Civil Engineers, v. 107, no. 7, Proceeding Paper 16363, p. 899-918.

Guy, H.P., 1969, Laboratory theory and methods for sediment analysis: U.S. Geological Survey Techniques of Water-Resources Investigations, Book 5, Chapter C5, 58 p.

---- 1970, Fluvial sediment concepts: U.S. Geological Survey Techniques of Water-Resources Investigations, Book 3, Chapter C1, 51 p.

Henderson, F.M., 1966, Open channel flow: New York, Macmillan, p. 96.

Hulsing, H., 1967, Measurement of peak discharge at dams by indirect method: U.S. Geological Survey Techniques of Water-Resources Investigations, Book 3, Chapter A5, 29 p.

Jarrett, R.D., 1984, Hydraulics of high-gradient streams: Journal of Hydraulic Engineering, American Society of Civil Engineering, v. 110, no. HY11, Proceeding Paper 19272, p. 1519-1539.

Kilpatrick, F.A., and Schneider, V.R., 1983, Use of flumes in measuring discharge: U.S. Geological Survey Techniques of Water-Resources Investigations, Book 3, Chapter C14, $46 \mathrm{p}$.

Lane, E.W., and Carlson, E.J., 1953, Some factors affecting the stability of canals constructed in coarse granular materials: Proceedings of the Fifth Congress of the International Association for Hydraulic Research, Minneaopolis, Minnesota, p. 37-48. 
Limerinos, J.T., 1970, Determination of the Manning coefficient from measured bed roughness in natural channels: U.S. Geological Survey Water-Supply Paper 1898-B, 47 p.

Matthai, H.F., 1968, Measurement of peak discharge at width contractions by indirect methods: U.S. Geological Survey Techniques of Water-Resources Investigations, Book 3, Chapter A3, $44 \mathrm{p}$.

Meyer-Peter, E., and Muller, R., 1948, Formulas for bed load transport: Proceedings of Third Meeting of International Association of Hydraulic Research, Stockholm, p. 39-64.

Schneider, V.R., Board, J.W., Colson, B.E., Lee, F.N., and Druffel, Leroy, 1977, Computation of backwater and discharge at width constrictions of heavily vegetated flood plains: U.S. Geological Survey Water-Resources Investigations $76-129,64 \mathrm{p}$.

Simons, D.B., and Richardson, E.V., 1966, Resistance to flow in alluvial channels: U.S. Geological Survey Professional Paper 422-J, 61 p.

Simons, D.B., and Senturk, F., 1977, Sediment transport technology: Fort Collins, Colorado, Water Resources Publications, 807 p.

Strickler, A., 1923, Beitrage zur frage der geschwindigheits - formel und der rauhigkeitszahlen fur strome, kanale und geschlossene leitungen (Some contributions to the problems of the velocity formula and roughness factor for rivers, canals and closed conduits): Mitteilungen des Eidgenossischer Amtes fur Wasserwirtschaft, Bern Switzerland, no. $16 \mathrm{~g}$.

Vennard, J.K., 1962, Elementary fluid mechanics: New York, John Wiley.

Villemonte, J.R., 1947, Submerged-weir discharge studies: Engineering NewsRecord, December 29, p. 866. 


\section{ANSWERS TO PROBLEMS}

Lesson 1

2. specific weight $=49.27 \mathrm{lb} / \mathrm{ft}^{3}$

specific gravity $=0.79$

3. $187.2 \mathrm{lb} / \mathrm{ft}^{2}$

4. $0.014171 \mathrm{~b} s / \mathrm{ft}^{2}$

Lesson 2

1. $\mathrm{F}_{\mathrm{H}}=7,020 \mathrm{lb}$

$\mathrm{Y}=10 \mathrm{ft}$

2. $F=6,240 \mathrm{lb}$

$\mathrm{Yr}_{\mathrm{r}}=5.83 \mathrm{ft}$ below top of gate

3. $F_{\mathrm{H}}=4,0001 \mathrm{~b} \rightarrow$

$F_{V}=3,0001 \mathrm{lb} \downarrow$

4. $\mathrm{F}_{\mathrm{H}}=444 \mathrm{lb} \rightarrow$

5. $\quad F_{\mathrm{H}}=32,760 \mathrm{lb} \rightarrow$

$F_{\mathrm{V}}=28,308 \mathrm{lb} \uparrow$

Lesson 3

1. $V_{p}=0.89 \mathrm{ft} / \mathrm{s} \quad T_{p}=32.1 \mathrm{~min}$

2. $\mathrm{Q}_{\mathrm{m}}=0.838 \mathrm{ft}^{3} / \mathrm{s} \quad \Delta \mathrm{P}_{\mathrm{p}}=-1.34$ atmosphere (impossible cavitation will occur)

3. $F / \rho V^{2} L^{2}=f(\mu / \rho V L)$

4. $\frac{\mathrm{q}}{\mathrm{g} \mathrm{h}^{3 / 2}}=\mathrm{f}\left(\frac{\Delta \mathrm{h}}{\mathrm{h}_{1}}, \frac{\mathrm{P}}{\mathrm{h}_{1}}, \frac{\mathrm{r}}{\mathrm{h}_{1}}, \frac{\mathrm{w}}{\mathrm{h}_{1}}\right)$

Lesson 4

1. (a) $5.56 \mathrm{ft}$, (b) $0.15 \mathrm{ft}$ and $0.56 \mathrm{ft}$, (d) $2.03 \mathrm{ft}$

2. (a) $1.605 \mathrm{ft}^{3} / \mathrm{s}$, (c) $24.07 \mathrm{ft} / \mathrm{s}$

3. $1,716 \mathrm{ft}^{3} / \mathrm{s}$

4. $Q=1,200 \mathrm{ft}^{3} / \mathrm{s} \quad D_{2}=2.0$ or $3.5 \mathrm{ft}$ 
Lesson 5

1. $q=0.0071 \mathrm{ft}^{2} / \mathrm{s}, v_{\max }=0.529 \mathrm{ft} / \mathrm{s}, v=0.355 \mathrm{ft} / \mathrm{e}$, $R_{e}=584$ (barely Laminar)

2. $\tau_{0}=0.0312 \mathrm{lb} / \mathrm{ft}^{2}, u_{\star}=0.127 \mathrm{ft} / \mathrm{s}$

3. $\mathrm{v}_{0} .1=2.80, \mathrm{v}_{1}=3.53, \mathrm{v}_{3}=3.88, \mathrm{v}_{5}=4.04, \mathrm{v}=3.72$

Lesson 6

1. $\mathrm{h}_{l}^{\mathrm{A}-\mathrm{B}}=10.69 \mathrm{ft}, \mathrm{h}_{\mathrm{l}}^{\mathrm{B}-\mathrm{C}}=63.30 \mathrm{ft}, \Delta \mathrm{T}=0.1{ }^{\circ} \mathrm{F}$

2. (a) $21.49 \mathrm{ft}^{3} / \mathrm{s}$, (b) 1.125

3. $3.018 \mathrm{ft}$

4. $24.05 \mathrm{ft}$

Lesson 7

2. $0.784 \mathrm{ft} / \mathrm{mi}$

3. $1,980 \mathrm{ft}^{3} / \mathrm{s}$

4. $7.10 \mathrm{ft}$

5. $\mathrm{C}=145, \mathrm{f}=0.0123$

6. $\mathrm{Y} Q$

$1 \quad 121 \mathrm{ft}^{3} / \mathrm{s}$

$5 \quad 1,610$

5.1920

$6 \quad 1,815$

$10 \quad 8,100$

Lesson 8

1. (a) $\mathrm{K}=28,711 \mathrm{ft}^{3} / \mathrm{s}, Q=1,287 \mathrm{ft}^{3} / \mathrm{s}, V=10.72 \mathrm{ft} / \mathrm{s}$

(b) $\mathrm{K}=2,707 \mathrm{ft} / \mathrm{s}, Q=121 \mathrm{ft}^{3} / \mathrm{s}, V=5.82 \mathrm{ft} / \mathrm{s}$

(c) $K=48,855 \mathrm{ft}^{3} / \mathrm{s}, Q=2,185 \mathrm{ft}^{3} / \mathrm{s}, V=11.38 \mathrm{ft} / \mathrm{s}$

2. $3.95 \mathrm{ft}$ 
Lesson 9

1.

$\mathrm{ftt} / \mathrm{s}$

$Q f t^{3} / s$

$V f t / s$

Total section
Right
Center
Left
Subdivided

293,528
6,200
881,500
180,300
$1,068,000$

5,168

1.03

109

0.22

$15,520 \quad 7.76$

$3,175 \quad 1.27$

Subdivided

$1,068,000$

18,800

3.76

2. 3.53

Lesson 10
1. $1,065 \mathrm{Ib} \rightarrow$
2. $198.4 \mathrm{Ib} \rightarrow$, yes (the head loss is positive)
3. $D_{2}=6.12 \mathrm{ft}, \mathrm{hl}=1.43 \mathrm{ft}$

Lesson 11

1. (a) $3.676 \mathrm{ft}$, (b) $5.515 \mathrm{ft}$, (c) $7.51 \mathrm{ft}$, (d) $7.57 \mathrm{ft}, 2.04 \mathrm{ft}$,

(e) supercritical, (f) subcritical, 0.0263 steep, $0.0010 \mathrm{mild}$

(g) 0.00413

2. $D_{2}=6.12 \mathrm{ft}, \mathrm{hl}=1.43 \mathrm{ft}$

3. (a) $1.08 \mathrm{ft}$, (b) $w=7.21 \mathrm{ft}$

Lesson 12

1. $\mathrm{C}=122, \mathrm{n}=0.0251, \mathrm{f}=0.0174$

2. $\mathrm{n}=0.02+0.01+0.05=0.08$

3. Equation Channel A Channel B

$\begin{array}{lll}\text { Strickler } & 0.030 & 0.028 \\ \text { Limerinos } & 0.046 & 0.049 \\ \text { Bray 1979 } & 0.041 & 0.039 \\ \text { Bray 1979 } & 0.073 & 0.075 \\ \text { Bray 1979 } & 0.037 & 0.039 \\ \text { Griffiths } & 0.038 & 0.038 \\ \text { Griffiths } & 0.040 & 0.043 \\ \text { Froehlich } & 0.028 & 0.035\end{array}$

Lesson 13

1. $D_{C}=6.77 \mathrm{ft}, S_{C}=0.0017, D_{N}=7.97,9.82 \mathrm{ft}$ M1, Normal depth

2. $D_{N}=5.73, M 2$, Critical depth, s2

3. M2, Normal depth

4. NormaI depth, S2 
Lesson 14

1. $Q=551 \mathrm{ft}^{3} / \mathrm{s}, \mathrm{k}_{\mathrm{e}}=0.338$

Lesson 15

1. $D_{N}=3.362 \mathrm{ft}, M_{1}, D_{500}=4.39 \mathrm{ft}$

Lesson 16

1. (a) $\mathrm{K}_{\mathrm{L}}=8.67 \times 10^{5}, \mathrm{~K}_{\mathrm{M}}=1.68 \times 10^{6}, \mathrm{~K}_{\mathrm{R}}=3.96 \times 10^{5} \mathrm{ft} / \mathrm{s}$

(b) 1.42

(c) $1.37 \times 10^{6} \mathrm{ft}^{3} / \mathrm{s}$

(d) 0.429

(e) 0.75

(f) 0.78

(g) $49,080 \mathrm{ft}^{3} / \mathrm{s}$

Lesson 17

1. (a) $5.5>5.0>$ yes

(b) $(7.36-0.36) / 5.0>1$, yes

(c) Type 4

(d) $153.5 \mathrm{ft}^{3} / \mathrm{s}$

2. (a) Free getaway

(b) $(10-2) / 8<1.5$

(c) Steep slope, no backwater

(d) $559 \mathrm{ft}^{3} / \mathrm{s}$

(e) $5.15 \mathrm{ft}$

(f) $533.6 \mathrm{ft}^{3} / \mathrm{s}$

Lesson 18

1. $319 \mathrm{ft}^{3} / \mathrm{s}$

2. $13.73 \mathrm{ft}^{3} / \mathrm{s}$

3. $2.46 \mathrm{ft}^{3} / \mathrm{s}$

4. $3.1 \mathrm{ft}$

5. $0.292 \mathrm{ft}^{3} / \mathrm{s}, 0.00003 \mathrm{ft}$ 